\title{
Maximal oxygen consumption in healthy humans: theories and facts
}

\author{
Guido Ferretti
}

Received: 3 March 2014 / Accepted: 12 May 2014 / Published online: 2 July 2014

(C) Springer-Verlag Berlin Heidelberg 2014

\begin{abstract}
This article reviews the concept of maximal oxygen consumption $\left(\dot{V} \mathrm{O}_{2 \max }\right)$ from the perspective of multifactorial models of $\dot{V} \mathrm{O}_{2 \max }$ limitation. First, I discuss procedural aspects of $\dot{V} \mathrm{O}_{2 \max }$ measurement: the implications of ramp protocols are analysed within the theoretical work of Morton. Then I analyse the descriptive physiology of $\dot{V} \mathrm{O}_{2 \text { max }}$, evidencing the path that led to the view of monofactorial cardiovascular or muscular $\dot{V} \mathrm{O}_{2 \max }$ limitation. Multifactorial models, generated by the theoretical work of di Prampero and Wagner around the oxygen conductance equation, represented a radical change of perspective. These models are presented in detail and criticized with respect to the ensuing experimental work. A synthesis between them is proposed, demonstrating how much these models coincide and converge on the same conclusions. Finally, I discuss the cases of hypoxia and bed rest, the former as an example of the pervasive effects of the shape of the oxygen equilibrium curve, the latter as a neat example of adaptive changes concerning the entire respiratory system. The conclusion is that the concept of cardiovascular $\dot{V} \mathrm{O}_{2 \max }$ limitation is reinforced by multifactorial models, since cardiovascular oxygen transport provides most of the $\dot{V} \mathrm{O}_{2 \max }$ limitation, at least in normoxia. However, the same models show that the role of peripheral resistances is significant and cannot be neglected. The role of peripheral factors is greater the
\end{abstract}

Communicated by Nigel A.S. Taylor.

G. Ferretti $(\bowtie)$

Département des Neurosciences Fondamentales, Université de

Genève, 1 Rue Michel Servet, 1211 Geneva 4, Switzerland

e-mail: guido.ferretti@unige.ch

G. Ferretti

Dipartimento di Scienze Cliniche e Sperimentali, Università di

Brescia, Viale Europa 11, 25123 Brescia, Italy smaller is the active muscle mass. In hypoxia, the intervention of lung resistances as limiting factors restricts the role played by cardiovascular and peripheral factors.

Keywords Exercise - Cardiovascular system - Muscle · Oxygen flow $\cdot$ Models $\cdot$ Hypoxia $\cdot$ Bed rest

\section{List of symbols}

$a$

Angular coefficient of Whipp's model of a ramp test

$b \quad$ Y-intercept of Whipp's model of a ramp

$\mathrm{C}_{\mathrm{a}} \mathrm{O}_{2}$ test

$\mathrm{C}_{\overline{\mathrm{v}}} \mathrm{O}_{2}$

Arterial oxygen concentration

Dempsey effect

Mixed venous oxygen concentration

$D_{\mathrm{L}} \mathrm{O}_{2}$

Desaturation of arterial blood at maximal exercise in subjects with high $\dot{V} \mathrm{O}_{2 \text { max }}$

Lung diffusion capacity for oxygen

$D_{\mathrm{t}} \mathrm{O}_{2}$

F Tissue diffusion capacity for oxygen

$F_{\mathrm{I}} \mathrm{O}_{2}$ Fraction

$F_{\mathrm{L}}$ Inspired oxygen fraction Pulmonary fraction of oxygen flow limitation

$F_{\mathrm{m}} \quad$ Mitochondrial fraction of oxygen flow limitation

$F_{\mathrm{p}} \quad$ Peripheral fraction of oxygen flow limitation

Cardiovascular fraction of oxygen flow limitation

Tissue fraction of oxygen flow limitation Ventilatory fraction of oxygen flow limitation

Conductance

$G$
$G_{\mathrm{L}}$

$G_{\mathrm{m}}$ Mitochondrial conductance of oxygen flow 


\begin{tabular}{|c|c|}
\hline$G_{\mathrm{p}}$ & Peripheral conductance of oxygen flow \\
\hline$G_{\mathrm{Q}}$ & $\begin{array}{l}\text { Cardiovascular conductance of oxygen } \\
\text { flow }\end{array}$ \\
\hline$G_{\mathrm{T}}$ & Total conductance of oxygen flow \\
\hline$G_{\mathrm{t}}$ & Tissue conductance of oxygen flow \\
\hline$G_{\mathrm{V}}$ & Ventilatory conductance of oxygen flow \\
\hline$k$ & Velocity constant \\
\hline$K_{\mathrm{p}}$ & $\begin{array}{l}\text { Dimensionless constant relating } P_{\overline{\mathrm{V}}} \mathrm{O}_{2} \\
\text { and } P_{\overline{\mathrm{c}}} \mathrm{O}_{2}\end{array}$ \\
\hline$K_{\mathrm{W}}$ & $\begin{array}{l}\text { Wagner's constant (slope of diffusion } \\
\text { line) }\end{array}$ \\
\hline$P_{\mathrm{A}} \mathrm{O}_{2}$ & Mean alveolar oxygen partial pressure \\
\hline$P_{\mathrm{a}} \mathrm{O}_{2}$ & Arterial oxygen partial pressure \\
\hline$P_{\mathrm{b}}$ & Barometric pressure \\
\hline$P_{\overline{\mathrm{c}}} \mathrm{O}_{2}$ & Mean capillary oxygen partial pressure \\
\hline$P_{\mathrm{I}} \mathrm{O}_{2}$ & Inspired oxygen partial pressure \\
\hline$P_{\mathrm{m}} \mathrm{O}_{2}$ & Mitochondrial oxygen partial pressure \\
\hline$P_{\overline{\mathrm{v}}} \mathrm{O}_{2}$ & Mixed venous oxygen partial pressure \\
\hline$\dot{Q}$ & Cardiac output \\
\hline$\dot{Q}_{\max }$ & Maximal cardiac output \\
\hline$\dot{Q}_{\mathrm{a}} \mathrm{O}_{2}$ & $\begin{array}{l}\text { Oxygen flow in arterial blood (systemic } \\
\text { oxygen delivery) }\end{array}$ \\
\hline$R$ & Resistance \\
\hline$R_{\mathrm{L}}$ & Pulmonary resistance to oxygen flow \\
\hline$R_{\mathrm{m}}$ & Mitochondrial resistance to oxygen flow \\
\hline$R_{\mathrm{p}}$ & Peripheral resistance to oxygen flow \\
\hline$R_{\mathrm{Q}}$ & Cardiovascular resistance to oxygen flow \\
\hline$R_{\mathrm{T}}$ & Total resistance to oxygen flow \\
\hline$R_{\mathrm{t}}$ & Tissue resistance to oxygen flow \\
\hline$R_{\mathrm{V}}$ & Ventilatory resistance to oxygen flow \\
\hline$S$ & Ramp slope \\
\hline$S_{\mathrm{a}} \mathrm{O}_{2}$ & Arterial oxygen saturation \\
\hline STPD & Standard temperature and pressure dry \\
\hline$t$ & Time \\
\hline$T$ & Exhaustion time in a ramp test \\
\hline$T_{\mathrm{S}}$ & Step duration in a ramp test \\
\hline$\dot{V}$ & Gas flow \\
\hline$\dot{V}_{A}$ & Alveolar ventilation \\
\hline$\dot{V}_{\mathrm{A}} / \dot{Q}$ & Ventilation/perfusion ratio \\
\hline$V_{\mathrm{m}}$ & Mitochondrial volume \\
\hline$v$ & Speed \\
\hline$\dot{V} \mathrm{O}_{2}$ & Oxygen uptake \\
\hline$\dot{V} \mathrm{O}_{2 \max }$ & Maximal oxygen consumption \\
\hline$\dot{w}$ & Mechanical power \\
\hline$W^{\prime}$ & $\begin{array}{l}\text { Work carried out above the critical } \\
\text { power in a ramp test }\end{array}$ \\
\hline$\dot{w}_{\mathrm{cr}}$ & Critical power \\
\hline$\dot{w}_{\max }$ & Maximal mechanical aerobic power \\
\hline$\dot{w}_{\text {peak }}$ & Peak power of a ramp test \\
\hline$\beta_{\mathrm{b}}$ & Oxygen transfer coefficient for blood \\
\hline$\beta_{\mathrm{g}}$ & Oxygen transfer coefficient for air \\
\hline$\Delta$ & $\begin{array}{l}\text { Before a variable, designates a change in } \\
\text { the value of that variable }\end{array}$ \\
\hline
\end{tabular}

\section{Introduction}

Shortly after its discovery, it became clear that oxygen is used in animal metabolism and that the rate at which oxygen is consumed by an organism increases with the level of physical activity. Since the cells are the site of oxygen consumption, whereas oxygen is to be taken from ambient air, the concept of oxygen flow from air to cells along a pathway for oxygen (here defined as the respiratory system, taken in its broadest sense) started soon to gain momentum. The oxygen flow takes place across a number of intermediate steps, including flow into the lungs (ventilation), transfer from lungs to blood (essentially diffusion), convective transport by the blood (circulation) and transfer from blood to tissues (again diffusion). This concept can be traced back to Paul Bert and Claude Bernard in the second half of the nineteenth century and is included in the current definition of respiratory system. Yet the quantitative relationships describing the oxygen flow from air to cells were formulated only in more recent times (Otis 1987; Piiper et al. 1971, 1984; Piiper and Scheid 1981; Rahn and Fenn 1955; Shephard 1969). Each of these relationships can be expressed with equations that share an analogy with Ohm's law, in which oxygen flow is driven by pressure gradients against numerous resistances in series. The ensemble of these relationships sets the conceptual basis of the oxygen cascade theory of the respiratory system.

The concept of maximal oxygen consumption $\left(\dot{V} \mathrm{O}_{2 \max }\right)$ was actually created, when it was observed that the linear relationship between oxygen uptake $\left(\dot{V} \mathrm{O}_{2}\right)$ and mechanical power $(\dot{w})$ attains a plateau which cannot be overcome despite further increases of $\dot{w}$ (Herbst 1928; Hill and Lupton 1923). It immediately became clear that the $\dot{V} \mathrm{O}_{2 \max }$ must be limited at some levels along the respiratory system. The quest for the factors that limit $\dot{V} \mathrm{O}_{2 \max }$ has not ceased ever since. Yet for a long time, the oxygen cascade theory was not considered in addressing the subject of $\dot{V} \mathrm{O}_{2 \max }$ limitation, and the discussion focused on the identification of a single limiting step. The theoretical insufficiency of this concept, however, was driving research in the field towards a dead end.

A new vision, indicating a possible way out, took shape at the beginning of the 1980s, when Taylor and Weibel (1981) resumed the oxygen cascade theory as a tool for describing oxygen transfer from ambient air to the mitochondria on a whole-body level at maximal exercise, in an attempt at understanding the structural constraints of respiratory systems under maximal stress in animals encompassing a wide range of body size. That idea gave origin to a remarkable series of works on the structural support to $\dot{V} \mathrm{O}_{2 \max }$ in mammals, the results of which were summarized in a splendid book by Ewald Weibel (1984). Most important, that idea brought to maturity the process towards a 
revolutionary approach to $\dot{V} \mathrm{O}_{2 \max }$ limitation, whereby attention was moved from the identification of the single factor, to the ensemble of the multiple factors that contribute to $\dot{V} \mathrm{O}_{2 \max }$ limitation. The way to the conception of the first multifactorial model of $\dot{V} \mathrm{O}_{2 \max }$ limitation (di Prampero 1985; di Prampero and Ferretti 1990; Ferretti and di Prampero 1995, 2003) was open, and a second multifactorial model joined soon (Wagner 1992, 1993, 1996a, b).

The main aim of this review was to discuss $\dot{V} \mathrm{O}_{2 \max }$ from the perspective of the multifactorial models of $\dot{V} \mathrm{O}_{2 \max } \mathrm{lim}$ itation. Before doing this, however, I find useful to propose a discussion of some procedural aspects and consequences of $\dot{V} \mathrm{O}_{2 \max }$ measurement and a short analysis of the descriptive physiology of $\dot{V} \mathrm{O}_{2 \max }$, which focuses on the path that led to the classical view of monofactorial cardiovascular or muscular $\dot{V} \mathrm{O}_{2 \max }$ limitation. The multifactorial models are then presented in detail, criticized with respect to the experimental work that they generated, and a synthesis between them is attempted. Finally, I discuss the particular cases of $\dot{V} \mathrm{O}_{2 \max }$ in hypoxia and after bed rest, the former because of the effects of the shape of the oxygen equilibrium curve and the consequent progressively greater role of the lungs as limiting factor, the latter because it is a very neat example of adaptive changes concerning the entire respiratory system, studied under strictly controlled conditions.

\section{Methodological aspects of $\dot{V} \mathrm{O}_{2 \max }$ determination}

The classical protocol for $\dot{V} \mathrm{O}_{2 \max }$ measurement is the incremental discontinuous steady state protocol, by which $\dot{V} \mathrm{O}_{2 \max }$ is identified as the plateau attained by the relationship between "steady state" $\dot{V} \mathrm{O}_{2}$ and $\dot{w}$, in which $\dot{V} \mathrm{O}_{2}$ is given at standard temperature $\left(273^{\circ} \mathrm{K}\right)$ and pressure (760 $\mathrm{mmHg}$ ), dry (STPD). The $\dot{w}$ at which the plateau is attained was defined as the maximal mechanical aerobic power $\left(\dot{w}_{\text {max }}\right)$. In fact, $\dot{w}_{\max }$ corresponds to the minimal $\dot{w}$ requiring a rate of energy expenditure by the working muscles equal to $\dot{V} \mathrm{O}_{2 \max }$. The classical protocol was thought to allow a direct measurement of the actual $\dot{w}_{\text {max }}$, which is unequivocally identified as the $\dot{w}$ at the crossing between the $\dot{V} \mathrm{O}_{2 \max }$ plateau and the line describing the $\dot{V} \mathrm{O}_{2}$ versus $\dot{w}$ relationship (Åstrand et al. 2003; di Prampero 1981; Howley et al. 1995; Taylor et al. 1955). An example of a classical individual relationship between $\dot{V} \mathrm{O}_{2}$ and $\dot{w}$ is reported in Fig. 1, along with a graphical identification of $\dot{V} \mathrm{O}_{2 \max }$ and $\dot{w}_{\text {max }}$.

The $\dot{V} \mathrm{O}_{2 \max }$ plateau, however, is not observable in all tests. According to Gordon et al. (2012), the incidence of the $\dot{V} \mathrm{O}_{2 \max }$ plateau depends on the modality of exercise administration. In absence of a clear $\dot{V} \mathrm{O}_{2 \max }$ plateau, subsidiary criteria had to be defined, including: (1) a lack of

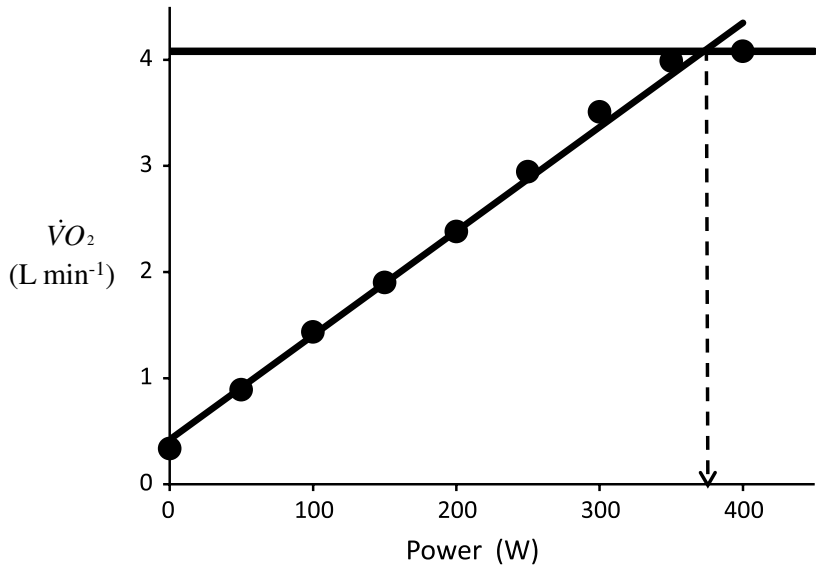

Fig. 1 An example of a relationship between oxygen uptake $\left(\dot{V} \mathrm{O}_{2}\right)$ and power during a classical discontinuous protocol for $\dot{V} \mathrm{O}_{2 \max }$ measurements. The reported data are unpublished and refer to a trained top-level cyclist tested in Geneva. The line through the points is the regression line calculated on the submaximal $\dot{V} \mathrm{O}_{2}$ values. The horizontal line indicates the $\dot{V} \mathrm{O}_{2 \max }$ plateau. The vertical dashed arrow indicates the maximal aerobic power

increase in heart rate between successive workloads; (2) a respiratory exchange ratio value $\geq 1.1$; (3) blood lactate concentration higher than $10 \mathrm{mM}$ at maximal exercise; and (4) a rate of perceived exertion on the Borg scale of at least 19/20 (Åstrand et al. 2003). When at least two of these subsidiary criteria for $\dot{V} \mathrm{O}_{2 \max }$ establishment are met at the end of the test, there is sufficiently high guarantee that the test was indeed terminated at $\dot{V} \mathrm{O}_{2 \max }$ (Howley et al. 1995). In absence of a plateau, if the subsidiary criteria hold, the $\dot{w}$ corresponding to the highest measured $\dot{V} \mathrm{O}_{2}$ can be retained as the $\dot{w}_{\max }$ of the test. In holding with these concepts, it is important to note that, when a $\dot{V} \mathrm{O}_{2 \max }$ test is coupled with a subsequent constant-power supramaximal exercise on the same subjects, no further increase in $\dot{V} \mathrm{O}_{2 \max }$ is observed (Hawkins et al. 2007).

The performance of the classical discontinuous $\dot{V} \mathrm{O}_{2 \max }$ test is associated also with the determination of the socalled lactate threshold. Under this respect, the classical protocol has the undoubtful advantage of foreseeing resting recovery pauses between successive loads, allowing for the measurement of peak blood lactate concentration after each sequential work load. Thus, a lactate versus $\dot{w}$ curve can be constructed where the lactate threshold can be clearly identified (Brooks 1985). Although it has little physiological significance (see di Prampero and Ferretti 1999 for a discussion of this issue), the lactate threshold has nonetheless remarkable practical importance for the prediction of performance, for it is related to the fraction of $\dot{V} \mathrm{O}_{2 \max }$ that can actually be sustained over a given performance time (di Prampero 1986; Ferretti et al. 2011; Helgerud 1994). 
Moritani et al. (1981) associated the lactate threshold with the concept of critical power $\left(\dot{w}_{\mathrm{cr}}\right)$. This variable was firstly defined by Monod and Scherrer (1965) as "the maximum power that can be kept up for a very long time without fatigue." This qualitative definition came nevertheless from the quantitative analysis of a graph in which they plotted the total work done, determined during several fatiguing exercise bouts of variable intensity, as a function of the exhaustion time. They gave a parabolic solution to this plot, where $\dot{w}_{\text {cr }}$ corresponds to the dependent variable's asymptote. This relationship can be linearized by replacing time with its reciprocal as independent variable, from which we can compute two parameters: the y-axis intercept, corresponding to $\dot{w}_{\text {cr }}$, and the line's slope, which was interpreted as yielding the energy store component allowing sustaining an exercise at higher powers than $\dot{w}_{\text {cr }}$ (see Jones et al. 2010 for details on treatment). Subsequent studies have related the energy store component to overall anaerobic capacity and $\dot{w}_{\text {cr }}$ to fully aerobic power, with all muscle fibres acting as normoaerobic fibres (di Prampero and Ferretti 1999). This made these two constants conceptually independent of each other (Hill 1993; Miura et al. 2000; Poole et al. 1990; Vanhatalo and Jones 2009).

This is not the place where to discuss the algebraic derivations of the $\dot{w}_{\text {cr }}$ concept, for which the interested reader may focus elsewhere (Jones et al. 2010; Morton 1996). More important is to remark the connections that exist between $\dot{w}_{\text {cr }}$ and steady state: during exercise below $\dot{w}_{\text {cr }}$, a steady state in $\dot{V} \mathrm{O}_{2}$ (and in blood lactate concentration) is always attained if exercise lasts longer than $3 \mathrm{~min}$; this is not so at $\dot{w}$ above $\dot{w}_{\text {cr }}$ (Poole et al. 1988; Pringle and Jones 2002). Some consequences of this have to do with the concept of $\dot{w}_{\max }$ and are discussed below.

Apart from the classical discontinuous protocol, a variety of procedures, either continuous or discontinuous, were proposed in the last decades to measure $\dot{V} \mathrm{O}_{2 \max }$. After the introduction of commercial breath-by-breath metabolic carts and the development of electromagnetically braked cycle ergometers, the continuous ramp protocols (Buchfuhrer et al. 1983) have achieved worldwide diffusion, so that they have been progressively replacing the classical discontinuous protocol. The main reason for the success of these protocols is that they have a much shorter duration than the classical steady state protocols, being normally completed within $12 \mathrm{~min}$. Ramp protocols and the classical discontinuous protocol yield the same values of $\dot{V} \mathrm{O}_{2 \max }$; moreover, the $\dot{V} \mathrm{O}_{2 \max }$ attained at the end of ramp protocols is independent of the ramp characteristics (Adami et al. 2013; Amann et al. 2004; Chidnok et al. 2013; Duncan et al. 1997; Fairshter et al. 1983; Maksud and Coutts 1971; McArdle et al. 1973; Morton et al. 1997; Zhang et al. 1991). In spite of this, ramp protocols generate higher peak mechanical powers $\left(\dot{w}_{\text {peak }}\right)$ at the end of the tests, the greater is the mean slope of the ramp (Adami et al. 2013; Morton et al. 1997). This means that the $\dot{w}_{\text {peak }}$ attained in a ramp test (1) varies with the protocol characteristics, (2) is unrelated to $\dot{V} \mathrm{O}_{2 \max }$ and (3) is not the $\dot{w}_{\text {peak }}$. The concept of a strict relation between $\dot{V} \mathrm{O}_{2 \max }$ and $\dot{w}_{\max }$ was undermined.

To sum up, if one is to measure $\dot{V} \mathrm{O}_{2 \max }$, he can rely on any type of ramp protocol. Conversely, if one is to measure also $\dot{w}_{\text {max }}$, ramp protocols are inadequate, and the classical discontinuous protocols are questioned.

\section{The relationship between $\dot{V} \mathrm{O}_{2 \max }$, critical power and maximal aerobic power}

The analysis of ramp protocols of $\dot{V} \mathrm{O}_{2 \max }$ testing led to the construction of two mechanical models: one proposed by Whipp (1994) and the other by Morton (1994, 2011). The former model, concerning discrete ramps with steps of varying duration, implies an inverse relationship between $\dot{w}_{\text {peak }}$ and step duration, described by a translated equilateral hyperbola of this form:

$T_{\mathrm{S}} \cdot\left(\dot{w}_{\text {peak }}-b\right)=a$

where $T_{\mathrm{S}}$ is the step duration, constant $b$ is equivalent to $\dot{w}_{\max }$ and constant $a$ to the anaerobic work, i.e. the amount of mechanical work carried out relying on anaerobic energy sources. Equation (1) can be rewritten as:

$\dot{w}_{\text {peak }}=\frac{a}{T_{\mathrm{S}}}+b$

Equation (2) describes the linear relationship between $\dot{w}_{\text {peak }}$ and $\frac{1}{T_{\mathrm{S}}}$, with slope equal to $a$ and y-intercept equal to $b$. Adami et al. (2013) validated Eq. (2) experimentally, and they obtained $b=264$ watt, which corresponded well to the experimental $\dot{w}_{\text {max }}$ that they determined during a classical $\dot{V} \mathrm{O}_{2 \text { max }}$ protocol (267 watt), and $a=2.61 \mathrm{~kJ}$.

On the other side, Morton $(1994,2011)$ assumed that the $\dot{w}$ in a ramp test increases continuously with time $(t)$ at a constant rate and thus implied a linear relationship between $\dot{w}$ and $t$ whose angular coefficient is the ramp slope $(S)$. In this case, the total mechanical work performed during a ramp is equal to the area of the triangle under the $\dot{w}$ versus $t$ line. The subsequent analytical developments by Morton (1994) led to formulate the following equation:

$T=\dot{w}_{\mathrm{cr}} \cdot S^{-1}+\sqrt{\frac{2 \mathrm{~W}^{\prime}}{S}}$

where $T$ is the time to exhaustion and $W^{\prime}$ is the work carried out above $\dot{w}_{\text {cr }}$ in a ramp test. If we then multiply Eq. (3) by $S$, we get:

$S \cdot T=\dot{w}_{\text {peak }}=\dot{w}_{\mathrm{cr}}+\sqrt{2 \mathrm{~W}^{\prime} S}$ 


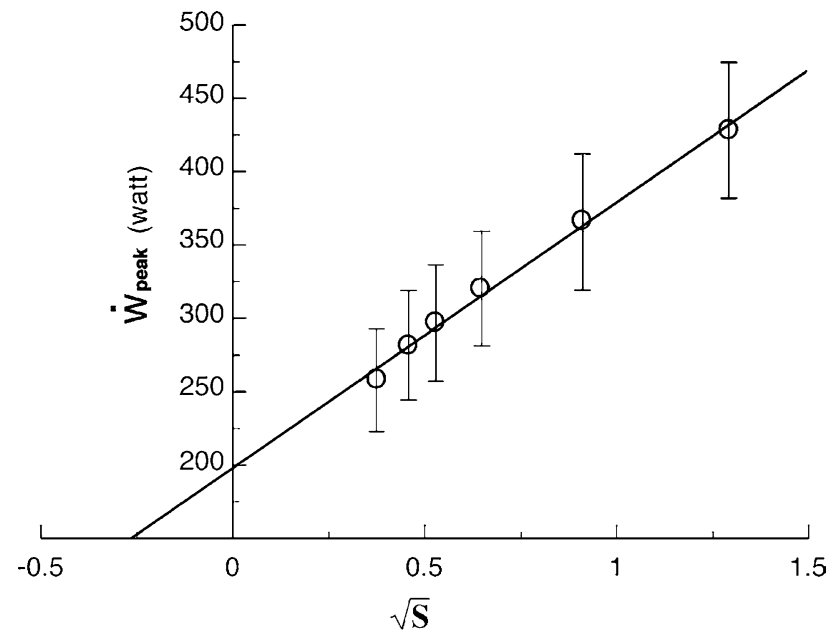

Fig. 2 An experimental analysis of Morton's model of ramp tests, whereby peak power $\left(\dot{w}_{\text {peak }}\right)$ is plotted as a function of the square root of the mean ramp slope $(S)$. Data are presented as mean $\pm \mathrm{SD}$. The regression line was calculated on the ensemble of the individual data. From Adami et al. (2013)

Equation (4) predicts that, if we plot $\dot{w}_{\text {peak }}$ as a function of $\sqrt{S}$ we obtain linear relationships with slope equal to $\sqrt{2 \mathrm{~W}^{\prime}}$ and y-intercept equal to $\dot{w}_{\text {cr. }}$ Adami et al. (2013) constructed such a plot (Fig. 2) and obtained $\dot{w}_{\mathrm{cr}}=198$ watt, i.e. $74.2 \%$ of the $\dot{w}_{\max }$ determined on the same subjects, and $W^{\prime}=16.8 \mathrm{~kJ}$. Similar values for $W^{\prime}$ were obtained also by Morton et al. (1997). Note that, according to Adami et al. (2013), $W^{\prime}$ was seven times greater than constant $a$ of Whipp's model, despite being calculated from the same experimental results. This discrepancy follows the fact that $a$ and $W^{\prime}$ have different meanings, for $a$ refers to the energy from anaerobic sources sustaining supramaximal powers, whereas $W^{\prime}$, which includes $a$, is the energy (aerobic and anaerobic) sustaining all the work carried out above $\dot{w}_{\text {cr }}$.

In both models, $\dot{w}_{\text {peak }}$ varies only with the mean ramp's slope, whereas $\dot{w}_{\text {cr }}$ (in Morton's model) and $\dot{w}_{\max }$ (in Whipp's model) are constants. Thus, for any given ramp, the two models must yield the same $\dot{w}_{\text {peak }}$ value. This allows combination of Eqs. (2) and (4), to obtain, after rearrangement (Adami et al. 2013):

$\sqrt{2 \cdot W^{\prime} \cdot S}=\frac{a}{T_{\mathrm{S}}}+\left(\dot{w}_{\max }-\dot{w}_{\mathrm{cr}}\right)$

Equation (5) tells that, if $\sqrt{2 \cdot W^{\prime} \cdot S}$ is plotted as a function of $\frac{1}{T_{\mathrm{S}}}$, we obtain a linear relationship with y-intercept equal to $\left(\dot{w}_{\max }-\dot{w}_{\text {cr }}\right)$ and slope equal to $a$. This implies that (1) the difference between $\dot{w}_{\text {max }}$ and $\dot{w}_{\text {cr }}$ is a constant, that is independent of anaerobic capacity, step duration and ramp slope; (2) $\dot{w}_{\max }$ and $\dot{w}_{\text {cr }}$ are coupled, since they can vary only by the same absolute amount; and (3) their ratio becomes higher the higher is $\dot{w}_{\max }$. Although they represent different concepts, there is an evident quantitative link between $\dot{w}_{\max }$ and $\dot{w}_{\mathrm{cr}}$.

Equation (5) provides the theoretical basis for explaining several observations about $\dot{w}_{c r}$, namely that the $\dot{w}_{\mathrm{cr}} / \dot{w}_{\max }$ ratio (1) is higher in athletes with elevated $\dot{V} \mathrm{O}_{2 \max }$ (Heubert et al. 2005) than in subjects with low $\dot{V} \mathrm{O}_{2 \max }$ (Adami et al. 2013); (2) increases with aerobic training (Heubert et al. 2003; Jenkins and Quigley 1992) and high-intensity interval training (Gaesser and Wilson 1988); (3) decreases in hypoxia (Dekerle et al. 2012; Valli et al. 2011). Since $\dot{w}_{\mathrm{cr}}$ is related to the so-called anaerobic threshold and thus to the sustainable fraction of $\dot{V} \mathrm{O}_{2 \max }$, Eq. (5) also explains why all these three variables are higher in endurance athletes and are increased by intense aerobic training (di Prampero 1986; Tam et al. 2012). Finally, Eq. (5) implies that $\dot{w}_{\text {max }}$ has a radically different meaning from $\dot{w}_{\text {peak }}$. It defines the maximal $\dot{w}$ that can be attained by the contracting muscle mass in which the chemical energy is converted into mechanical work. A theoretical corollary of this definition is the linearity of the $\dot{V} \mathrm{O}_{2}$ versus $\dot{w}$ relationship along the entire $\dot{w}$ range.

Experimentally, however, when $\dot{V} \mathrm{O}_{2}$ is measured at the mouth, this is not necessarily so. At high $\dot{w}$, above the $\dot{w}_{\text {cr }}$, when the step duration is shorter than $3 \mathrm{~min}$, the $\dot{V} \mathrm{O}_{2}$ versus $\dot{w}$ relationship bends downwards, because of the increase of the time constant of the primary component (phase II) of the $\dot{V} \mathrm{O}_{2}$-on kinetics and the ensuing "early" lactate accumulation (Cerretelli et al. 1979). On the other hand, when the step duration exceeds $5 \mathrm{~min}$, the appearance of the slow component (phase III) of the $\dot{V} \mathrm{O}_{2}$ on kinetics prevents the experimental attainment of a clear $\dot{V} \mathrm{O}_{2}$ steady state (Camus et al. 1988; Gaesser and Poole 1996; Henson et al. 1989; Poole et al. 1988, 1991, 1994). In this case, since the slope of the slow component is greater the higher is $\dot{w}$, the apparent relationship between $\dot{V} \mathrm{O}_{2}$ and $\dot{w}$ above $\dot{w}_{\text {cr }}$ bends upwards, becoming nonlinear (Zoladz et al. 1995). These phenomena may hinder the experimental observation of $\dot{w}_{\text {max }}$, making its identification impossible in a $\dot{V} \mathrm{O}_{2}$ versus $\dot{w}$ relationship. The further demonstration that at least some of the determinants of phase III are intrinsic to the contracting muscle mass (Bailey et al. 2010; Krustrup et al. 2009; Poole et al. 1991; Rossiter et al. 2001) not only undermined the meaning of the classical protocol for $\dot{V} \mathrm{O}_{2 \max }$ determination, but also led some authors to deny the physiological value of the $\dot{w}_{\max }$ concept. However, if Eq. (5) is correct, $\dot{w}_{\text {max }}$ is to fall on the $\dot{V} \mathrm{O}_{2}$ versus $\dot{w}$ relationship established at $\dot{w}$ values below the $\dot{w}_{\mathrm{cr}}$, as long as Eq. (5) predicts that it is independent of the characteristics of phase II and phase III. Thus, $\dot{w}_{\max }$ can still be identified after a classical discontinuous $\dot{V} \mathrm{O}_{2 \max }$ test by simply extrapolating the $\dot{V} \mathrm{O}_{2}$ versus $\dot{w}$ line up to a $\dot{w}$ for which a $\dot{V} \mathrm{O}_{2}$ equal to $\dot{V} \mathrm{O}_{2 \max }$ is attained, on the assumption that the extra oxygen consumed 
for phase III is not a need for sustaining the energy conversion in the actually contracting muscle fibres.

In any case, Eq. (5) is a nice tool for determining $\dot{w}_{\max }$ and $\dot{w}_{\text {cr }}$ from ramp tests. Although it requires the performance of multiple tests (at least three), it does not need the measurement of $\dot{V} \mathrm{O}_{2 \max }$ and thus the utilization of a metabolic cart. In fact, application of Eq. (5) to this aim requires only an assumption concerning $W^{\prime}$ and the knowledge of $S$ and $T_{\mathrm{s}}$. An alternative protocol for the computation of $\dot{w}_{\text {max }}$ may consist of a few $\dot{w}$ below $\dot{w}_{\text {cr }}$, carried out until steady state and followed by a steep ramp: the ramp would provide the $\dot{V} \mathrm{O}_{2 \max }$ value of the subject, the steady state light steps would allow construction of the submaximal $\dot{V} \mathrm{O}_{2}$ versus $\dot{w}$ line, and the extrapolation of this line up to $\dot{V} \mathrm{O}_{2 \max }$ would provide an estimate of the $\dot{w}_{\max }$ value.

In terms of mechanical work performed, a ramp test does not differ from a discontinuous test, provided the duration of each step is the same. In fact, an incremental stepwise ramp test corresponds to an intermittent test with recovery time between successive work loads equal to $0 \mathrm{~s}$ (Morton and Billat 2004). However, a comparison of continuous and intermittent protocols allowing determination of $\dot{w}_{\text {cr }}$ and $W^{\prime}$, characterized by similar amounts of work performed, showed that $\dot{w}_{\text {cr }}$ tends to be lower and $W^{\prime}$ to be higher with intermittent than with continuous exercise administration, in contrast with the predictions made (Morton and Billat 2004). In fact, theory predicts $\dot{w}_{\mathrm{cr}}$, and thus $\dot{w}_{\text {max }}$, to be independent of the applied protocol, and thus, in discontinuous protocols, of step duration and rest duration, and in ramp protocols, of the ramp's mean slope. Further studies may be needed to better clarify this issue.

\section{Descriptive physiology of $\dot{V} \mathrm{O}_{2 \max }$}

After its discovery, it soon became evident that the $\dot{V} \mathrm{O}_{2 \max }$ was subject to remarkable variability within the general population and as a consequence of genetic interindividual differences and of several adaptive phenomena. Moreover, several acute manoeuvres could alter the $\dot{V} \mathrm{O}_{2 \max }$ of a given subject. Eighty years of descriptive physiology of $\dot{V} \mathrm{O}_{2 \max }$ have demonstrated that, on a systemic level, $\dot{V} \mathrm{O}_{2 \max }$ is up to twice higher in endurance athletes than in sedentary individuals (Åstrand 1955; di Prampero et al. 1970; Losnegard et al. 2013; Lucia et al. 2006; Robinson et al. 1937; Saltin and Åstrand 1967; Strømme et al. 1977; Veicsteinas et al. 1984; Ventura et al. 2003). Differences, however, exist, depending on whether the athlete is expected to do antigravitational work, like in long-distance running or in uphill cycling (Billat et al. 2003; di Prampero 1986; di Prampero et al. 1970; Hagberg and Coyle 1984; Lucia et al. 2000; Padilla et al. 1999; Saltin and Åstrand 1967; Tam et al. 2012), or not, like in cycling or skiing on flat tracks
(Capelli et al. 1998; Gaskill et al. 1999; Losnegard et al. 2013; Lucia et al. 2000; Padilla et al. 1999; Rusko 1992; Strømme et al. 1977; Veicsteinas et al. 1984): in the former case, very high $\dot{V} \mathrm{O}_{2 \max }$ values normalized per unit body mass were reported; conversely, the latter athletes are characterized by high absolute $\dot{V} \mathrm{O}_{2 \max }$ values (expressed in $\mathrm{L}$ $\min ^{-1}$ ). The highest normalized $\dot{V} \mathrm{O}_{2 \max }$ value ever reported $\left(90.6 \mathrm{ml} \mathrm{min}{ }^{-1} \mathrm{~kg}^{-1}\right.$ ) was observed on an extremely trained top-level cross-country skier (Burtscher et al. 2011).

$\dot{V} \mathrm{O}_{2 \max }$ is also higher in men than in women (Aspenes et al. 2011; Åstrand 1956, 1960; Buskirk and Hodgson 1987; Plowman et al. 1979; Sanada et al. 2007), the difference being minimized when it is expressed relative to the lean body mass (Padilla et al. 1992; Vanderburgh and Katch 1996) or when gender differences in muscle mass are accounted for (Sanada et al. 2007). The gender differences for $\dot{V} \mathrm{O}_{2 \max }$ are maintained also as age progresses (Talbot et al. 2000). With the only exceptions of African Pygmies (Ferretti et al. 1991) and Nepalese Sherpas (Kayser et al. 1991; Faoro et al. 2014), no differences among ethnic groups were ever shown (Aghemo et al. 1971; Andersen et al. 1960; Billat et al. 2003; Ceaser et al. 2013; Chan et al. 1976; Chatterjee et al. 1991; Davies et al. 1972; di Prampero and Cerretelli 1969; Duncan and Horvath 1988; Duncan et al. 2005; Glick and Schwartz 1974; Greksa et al. 1984; Hunter et al. 2001; Rode and Shephard 1971, 1984; Sanada et al. 2007; Weston et al. 2000; Wyndham et al. 1963), also as far as top athletes are concerned (Billat et al. 2003; Bosch et al. 1990; Saltin and Åstrand 1967; Saltin et al. 1995; Tam et al. 2012). Genetic components were demonstrated as major determinants of $\dot{V} \mathrm{O}_{2 \max }$ variability in the population (Bouchard 2012; Bouchard et al. 1999, 2011b; Hildebrandt et al. 2003; Prior et al. 2003, 2006; Rice et al. 2012).

$\dot{V} \mathrm{O}_{2 \max }$ decreases with age (Aspenes et al. 2011; Åstrand 1956, 1960; Buskirk and Hodgson 1987; Heath et al. 1981; McGuire et al. 2001; Robinson 1938; Robinson et al. 1975, 1976; Sanada et al. 2007; Talbot et al. 2000), with athletes maintaining higher $\dot{V} \mathrm{O}_{2 \max }$ values along the entire life span (Grimsmo et al. 2010; Heath et al. 1981; Robinson et al. 1976; Rogers et al. 1990; Rusko 1992). The $\dot{V} \mathrm{O}_{2 \max }$ fall with age is largely a consequence of the development of muscle hypotrophy (Fleg and Lakatta 1989; Proctor and Joyner 1997) and is accelerated in oldest ages (Fleg et al. 2005).

Endurance training, whether with continuous or interval-training protocols, increases $\dot{V} \mathrm{O}_{2 \max }$, depending on the overall training intensity (Blomqvist and Saltin 1983; Clausen et al. 1973; Ekblom et al. 1968; Gormley et al. 2008; Helgerud et al. 2007; Henriksson and Reitmann 1977; Hickson et al. 1981, 1985, 1997; Hoppeler et al. 1985; Ogawa et al. 1992; Saltin et al. 1968), as does highintensity interval training (Astorino et al. 2012; Breil 
et al. 2010; Dunham and Harms 2012; Gibala et al. 2012; Perry et al. 2008; Sloth et al. 2013). It also slows down the $\dot{V} \mathrm{O}_{2 \max }$ decline with age (Grimsmo et al. 2010; Hagberg 1987; Hawkins et al. 2001; Ogawa et al. 1992). The opposite occurs in case of prolonged inactivity (Capelli et al. 2006; Convertino et al. 1982, 1986; Ferretti et al. 1997a; Greenleaf et al. 1989; Kashihara et al. 1994; Saltin et al. 1968; Stremel et al. 1976), a condition that will be discussed more in detail at a later stage using bed rest as the experimental paradigm (see "Of maximal oxygen consumption at the end of bed rest" section).

These effects on $\dot{V} \mathrm{O}_{2 \max }$ are associated with consensual changes in maximal cardiac output $\left(\dot{Q}_{\max }\right)$ (Blomqvist and Saltin 1983; Clausen et al. 1973; Daussin et al. 2007; Ekblom et al. 1968; McGuire et al. 2001; Ogawa et al. 1992; Wilmore et al. 2001), as well as in muscle capillarity, mitochondrial volume density and muscle oxidative enzyme activities (see below).

$\dot{V} \mathrm{O}_{2 \max }$ decreases in hypoxia, both acute and chronic (see for review Cerretelli 1980; Ferretti 1990; Cerretelli and Hoppeler 1996, more details are given in section "Of maximal oxygen consumption in hypoxia"). Conversely, exposure to elevated inspired oxygen pressures leads only to slight, if any, increases in $\dot{V} \mathrm{O}_{2 \max }$ (Bannister and Cunningham 1954; Esposito and Ferretti 1997; Fagraeus et al. 1973; Margaria et al. 1961, 1972; Taunton et al. 1970; Welch and Pedersen 1981). The effect of hyperoxia on $\dot{V} \mathrm{O}_{2 \max }$ is particularly evident in endurance athletes (Ferretti et al. 1997b), who are subject to the Dempsey effect (Dempsey and Wagner 1999; Dempsey et al. 1984; Lawler et al. 1988; Powers et al. 1989). It is smaller, the smaller is the active muscle mass (Cardus et al. 1998).

More recently, the evolution of sport science has led to numerous studies investigating the combined effects of hypoxia and training. In particular, the combination defined "live high-train low" received great consideration in an attempt at improving the effects of training on $\dot{V} \mathrm{O}_{2 \max }$ and performance, with contradictory results (Geiser et al. 2001; Hahn et al. 2001; Levine and Stray-Gundersen 1997; Rodríguez et al. 2007; Roels et al. 2007; Stray-Gundersen et al. 2001; Wilhite et al. 2013). These variable effects were attributed to several factors, including differences in ventilatory response to hypoxia (Wilhite et al. 2013), living altitude (Favier et al. 1995; Masuda et al. 2001; Stray-Gundersen and Levine 2008) and modality of training administration (Robertson et al. 2010; Stray-Gundersen and Levine 2008; Ventura et al. 2003). In permanent residents at altitude, training in hypoxia did not provide larger effects on $\dot{V} \mathrm{O}_{2 \max }$ than training in normoxia (Favier et al. 1995).

Special attention was given to the effects of acute manipulations of the cardiovascular oxygen transport system on $\dot{V} \mathrm{O}_{2 \max }$. In fact $\dot{V} \mathrm{O}_{2 \max }$ is lower in acute anaemia than in normaemia (Burnley et al. 2006; Celsing et al. 1987; Gledhill et al. 1999; Gordon et al. 2014; Krip et al. 1997; Woodson et al. 1978) and is higher in acute polycythaemia than in normaemia (Berglund and Hemmingsson 1987; Buick et al. 1980; Celsing et al. 1987; Ekblom and Huot 1972; Ekblom et al. 1976; Gledhill et al. 1999; Sawka et al. 1987; Spriet et al. 1986; Thomson et al. 1982; Turner et al. 1993), also when polycythaemia has been induced by erythropoietin administration (Audran et al. 1999; Berglund and Ekblom 1991; Russell et al. 2002; Thomsen et al. 2007). $\dot{V} \mathrm{O}_{2 \max }$ is lower also during carbon monoxide breathing than during air breathing (Ekblom and Huot 1972; Ekblom et al. 1975; Horvath et al. 1988; Pirnay et al. 1971; Vogel and Gleser 1972) and during cold exposure than at thermoneutral temperature (Bergh and Ekblom 1979; Kruk et al. 1991; McArdle et al. 1976; Pirnay et al. 1977).

A strong link was typically observed between $\dot{V} \mathrm{O}_{2 \max }$ and $\dot{Q}_{\max }$ (see Blomqvist and Saltin 1983 and Cerretelli and di Prampero 1987, for a review of this relationship), heart work capacity (Levine et al. 1991), and more recently with leg blood flow (Calbet et al. 2004, 2007; Richardson et al. 1995b). Moreover, muscle blood flow and specific muscle $\dot{V} \mathrm{O}_{2}$ can increase well above the levels attained at maximal exercise (Andersen and Saltin 1985; Richardson et al. 1995a; Rowell et al. 1986), suggesting the existence of a peripheral (muscular) reserve which cannot be fully exploited during exercise involving a big muscle mass. Finally, both selective and non-selective beta-adrenergic blockade were shown to decrease $\dot{V} \mathrm{O}_{2 \max }$ (Kaiser et al. 1986).

This impressive body of knowledge led a majority of scientists in the field to the conclusion that, at least during exercise with large muscle groups, the single factor that limits $\dot{V} \mathrm{O}_{2 \max }$ is cardiovascular oxygen transport capacity (Blomqvist and Saltin 1983; Clausen 1977; Ekblom 1969, 1986; Mitchell and Blomqvist 1971; Rowell 1974; Saltin and Rowell 1980; Saltin and Strange 1992; Scheuer and Tipton 1977).

However, several data seemed to contradict this view, namely that (1) the smaller is the active muscle mass, the lower is the measured $\dot{V} \mathrm{O}_{2 \max }$ (Åstrand and Saltin 1961; Bergh et al. 1976; Davies and Sargeant 1974; Hermansen and Saltin 1969; Ogita et al. 1996; Rådegran et al. 1999; Richardson et al. 1995b, 1999; Secher et al. 1974); (2) endurance training of one leg increases $\dot{V} \mathrm{O}_{2 \max }$ during exercise with that leg only (Saltin et al. 1976); (3) endurance athletes have not only a higher $\dot{Q}_{\max }$ (Ekblom and Hermansen 1968) but also a greater fraction of oxidative type I muscle fibres, a greater capillary density and a higher activity of oxidative enzymes than sedentary individuals (Brodal et al. 1977; Costill et al. 1976; Gollnick et al. 1972; 
Hermansen and Wachtlova 1971; Hoppeler and Weibel 2000; Howald 1982; Tesch and Karlsson 1985; Zumstein et al. 1983) and (4) muscle capillary supply, muscle mitochondrial volume and muscle oxidative enzyme activities are increased by physical training (Andersen and Henriksson 1977; Geiser et al. 2001; Gollnick et al. 1973; Henriksson 1977; Henriksson and Reitmann 1977; Holloszy and Coyle 1984; Hoppeler 1986; Hoppeler and Flück 2003; Hoppeler et al. 1985; Howald et al. 1985; Ingjer 1979; Perry et al. 2007) and decreased by prolonged inactivity (Berg et al. 1993; Booth 1982; Ferretti et al. 1997a; Hikida et al. 1989; Hoppeler and Flück 2003). Furthermore, it was shown that the $\dot{V} \mathrm{O}_{2 \max }$ of altitude-acclimatized subjects in chronic hypoxia, suddenly exposed to normoxic gas mixtures, does not return to the preacclimatization levels (Cerretelli 1976). The latter finding was attributed to a possible decrease in muscle mass and oxidative capacity induced by altitude acclimatization and prompted numerous studies on this subject (see Cerretelli and Hoppeler 1996 for a review and Ferretti 2003 for a critical revisitation of that study).

On these other grounds, some authors concluded that muscle oxidative capacity, rather than cardiovascular oxygen transport, limits $\dot{V} \mathrm{O}_{2 \max }$ (Cerretelli 1980; Lindstedt et al. 1988; Taylor 1987; Weibel 1987), especially during exercise with small muscle groups (Davies and Sargeant 1974; Kaijser 1970; Saltin 1977), and highly significant relationships between $\dot{V} \mathrm{O}_{2 \max }$ and either mitochondrial mass or capillary density were established (Hoppeler et al. 1985; Hoppeler 1990; Zumstein et al. 1983). More recently, experiments carried out with single-leg exercise protocols demonstrated clear peripheral limitation to oxygen flow (Rådegran et al. 1999; Richardson et al. 1995b; Roach et al. 1999). The same experimental model allowed demonstration of a different $\dot{V} \mathrm{O}_{2 \max }$ decrease in hypoxia when exercise was performed with small rather than big muscle masses (Calbet et al. 2009). Under some circumstances, the lungs were also considered as the limiting step, for instance in extreme hypoxia (West 1983) and in well-trained endurance athletes (Dempsey et al. 1984, 2008; Dempsey and Wagner 1999).

The search for the factor that limits $\dot{V} \mathrm{O}_{2 \max }$ in humans led to a diversity of viewpoints, and a long-lasting, stirring and essentially unresolved debate developed for some decades, to the point that still in Saltin and Strange (1992) could remark that no consensus exists on what limits the $\dot{V} \mathrm{O}_{2 \max }$. All this debate occurred within a well-defined context that of a monofactorial $\dot{V} \mathrm{O}_{2 \max }$ limitation. This concept is so deeply rooted in the mind of so many physiologists that still recently an important review on $\dot{V} \mathrm{O}_{2 \max }$ maintained a monofactorial focus (Levine 2008). Yet the perspective has radically changed, and this debate has become outdated, with the introduction of multifactorial models of $\dot{V} \mathrm{O}_{2 \max }$ limitation.
Obviously enough, what precedes is not an exhaustive report of the descriptive physiology of $\dot{V} \mathrm{O}_{2 \max }$. It is only a short summary of those data that pertain to whole-body level, most of which were taken to support the monofactorial theories of $\dot{V} \mathrm{O}_{2 \max }$ limitation. In recent times, remarkable developments concerned the molecular determinants of $\dot{V} \mathrm{O}_{2 \max }$. Genomic influences, control pathways, molecular regulatory mechanisms were widely studied as soon as the technological evolution made such studies possible. The molecular mechanisms affecting $\dot{V} \mathrm{O}_{2 \max }$ are not the object of this review. The interested reader can refer to other, more specific, articles (Bouchard et al. 2011a; Eliakim and Nemet 2010; Flück 2010; Hoppeler et al. 2008; Mooren et al. 2014; Seene et al. 2011). Going beyond the physiological context, the clinical aspects of $\dot{V} \mathrm{O}_{2 \max }$ and physical exercise capacity have also gained remarkable consideration in recent years, as long as low $\dot{V} \mathrm{O}_{2 \max }$ and sedentary lifestyles are universally recognized as major risk factors for systemic chronic diseases (Booth et al. 2012).

\section{Introducing the multifactorial models of $\dot{V} \mathrm{O}_{2 \max }$ limitation}

The oxygen cascade theory, applied to maximal exercise, is, I dare say, the axiom upon which the multifactorial models of $\dot{V} \mathrm{O}_{2 \text { max }}$ limitation were constructed. The oxygen cascade theory states that, in analogy with water flow in pipes or current in high-resistance electric lines, oxygen flow in the respiratory system (at maximal exercise, $\dot{V} \mathrm{O}_{2 \max }$ ) is driven by oxygen pressure gradients against several in series resistances. In principle, each of these resistances may provide a given measurable fraction of the overall $\dot{V} \mathrm{O}_{2 \text { max }}$ limitation. In the respiratory system, however, two different interpretations of the oxygen cascade theory can be proposed, depending on whether the cardiovascular oxygen transport step is considered merely convective or not. In the former case, the driving force of oxygen flow along the cardiovascular system from lung to muscle capillaries would be the gradient set by the mean capillary oxygen partial pressure $\left(P_{\overline{\mathrm{c}}} \mathrm{O}_{2}\right)$, respectively, in the lungs and in muscle, which should be obtained by Bohr's integration at the respective level. In this case, oxygen would be transferred from lungs to muscles by the convective movement of blood. In the latter case, the driving force would be the difference between arterial and mixed venous oxygen partial pressures $\left(P_{\mathrm{a}} \mathrm{O}_{2}\right.$ and $P_{\overline{\mathrm{v}}} \mathrm{O}_{2}$ respectively), thus making blood circulation tantamount to any resistance step of a hydraulic system.

Both approaches have advantages and inconveniences, which define their limits. In fact, there is an unresolved quantitative step related to the effects of heterogeneity of ventilation/perfusion $\left(\dot{V}_{\mathrm{A}} / \dot{Q}\right)$ distribution in the lungs, 
which generates the difference between mean alveolar oxygen partial pressure $\left(P_{\mathrm{A}} \mathrm{O}_{2}\right)$ and $P_{\mathrm{a}} \mathrm{O}_{2}$. The best analytical tool produced so far for describing the oxygen transfer between alveoli and arterial blood is the diffusion-perfusion interaction equation for the lung (Piiper and Scheid 1981), which nevertheless fails from including the effect of $\dot{V}_{A} / \dot{Q}$ heterogeneity on $P_{\mathrm{a}} \mathrm{O}_{2}$. This unresolved passage was treated differently in the two main multifactorial models, and this generated some apparent conceptual and analytical differences in the respective formulations. Also the experimental testing of the two models was as a consequence different, so that knowledge developed along two parallel pathways. The analysis that I propose (see section "A critical comparison of the two models") is aimed at demonstrating that in fact the two main multifactorial models, which for simplicity I will call di Prampero's model and Wagner's model, in honour of the two minds that conceived them, produce equivalent results as far as the analysis is restricted to the trait of the respiratory system distal to arterial blood. This restriction is acceptable in normoxia, as long as it is admitted that there is no limitation of $\dot{V} \mathrm{O}_{2 \max }$ imposed by pulmonary ventilation and lung diffusion.

\section{An analysis of di Prampero's model}

The first version of this model was proposed by di Prampero (1985) and subsequently refined in several other publications (di Prampero 2003; di Prampero and Ferretti 1990; Ferretti and di Prampero 1995). The analysis assumes (1) a full in series resistance model of the respiratory system from ambient air to the mitochondria and (2) steady state condition. If this is the case, assuming a system characterized by $n$ resistances in series, we have:

$\dot{V}=\frac{\Delta P_{1}}{R_{1}}=\frac{\Delta P_{2}}{R_{2}}=\cdots=\frac{\Delta P_{n}}{R_{n}}=\frac{\Delta P_{\mathrm{T}}}{R_{\mathrm{T}}}$

where $\dot{V}$ is the gas flow, $\Delta P$ is the pressure gradient sustaining $\dot{V}$ across the $i$ th resistance $R$ and $\Delta P_{\mathrm{T}}$ is the overall pressure gradient. In the respiratory system of a human at maximal exercise, $\dot{V}$ is $\dot{V} \mathrm{O}_{2 \max }$ and $\Delta P_{\mathrm{T}}$ is the difference between the inspired and the mitochondrial partial pressure of oxygen, $P_{\mathrm{I}} \mathrm{O}_{2}-P_{\mathrm{m}} \mathrm{O}_{2}$. Since $P_{\mathrm{m}} \mathrm{O}_{2}$ tends to $0 \mathrm{mmHg}$ (Gayeski and Honig 1986; Honig and Gayeski 1993; Richardson et al. 1995c, 2001; Wagner 2012), $\Delta P_{\mathrm{T}}$ can be set equal to $P_{\mathrm{I}} \mathrm{O}_{2}$ with negligible error. Of course, $\Delta P_{\mathrm{T}}$ is the sum of the pressure gradients across each resistance:

$\Delta P_{\mathrm{T}}=\Delta P_{1}+\Delta P_{2}+\cdots+\Delta P_{n}$

In analogy with Dalton's law on pressure in gas mixtures, we can define the fraction of the overall limitation imposed by the $i$ th resistance to oxygen flow as:

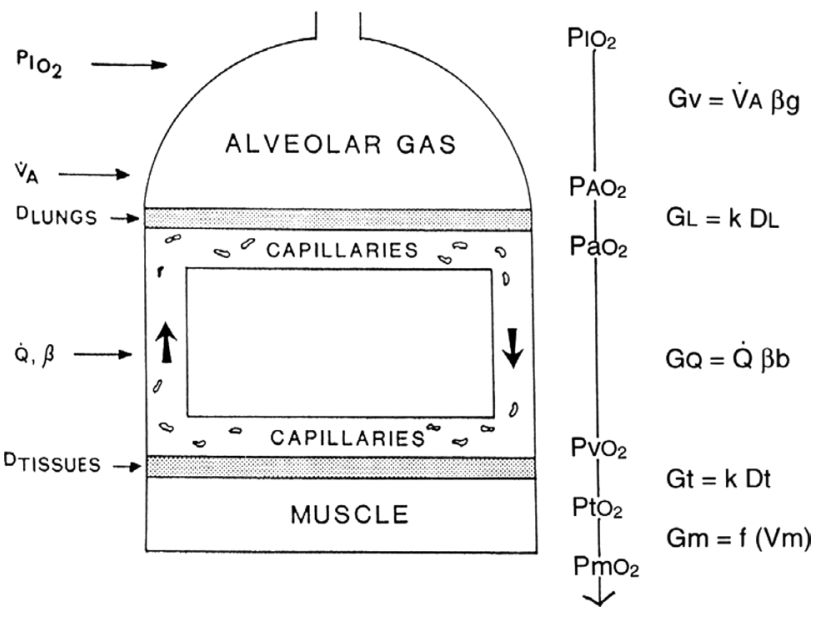

Fig. 3 Schematic representation of the oxygen cascade from ambient air to the mitochondria. Five steps are identified, namely oxygen flow (1) from ambient to alveolar air, (2) from alveolar air to arterial blood, (3) from arterial to mixed venous blood; (4) from mixed venous blood to the cells, (5) from cells to mitochondria. As long as oxygen proceeds in the respiratory system, its partial pressure drops, for energy is lost to overcome the in series resistances opposing oxygen flow. At each step, the resistances are indicated as conductances. Five conductance terms are identified. Symbols are as in the abbreviations' list. Modified after Taylor and Weibel (1981)

$F_{\mathrm{i}}=\frac{R_{\mathrm{i}}}{R_{\mathrm{T}}}$

whence

$\frac{R_{1}}{R_{\mathrm{T}}}+\frac{R_{2}}{R_{\mathrm{T}}}+\cdots+\frac{R_{n}}{R_{\mathrm{T}}}=F_{1}+F_{2}+\cdots+F_{n}=1$

This means that the overall limitation to the flow of gas in a hydraulic model of in series resistances, set equal to $100 \%$, is equal to the sum of the fractional limitations imposed by each of the resistances in the system.

The identification of five resistances of clear physiological meaning led to the version of the oxygen cascade reported in Fig. 3. From proximal (ambient air) to distal (mitochondria), these are the ventilatory resistance $\left(R_{\mathrm{V}}\right)$, the lung resistance $\left(R_{\mathrm{L}}\right)$, which refers to the transfer of oxygen from the alveoli to the arterial blood, the cardiovascular resistance $\left(R_{\mathrm{Q}}\right)$, the tissue resistance $\left(R_{\mathrm{t}}\right)$, which refers to oxygen transfer from peripheral circulation to muscle fibres, and the mitochondrial resistance $\left(R_{\mathrm{m}}\right)$, related to mitochondrial oxygen flow and utilization. These last two resistances, although they concern general concepts that can easily be perceived, are difficult to separate experimentally, because they are strongly interrelated on a structural basis. Therefore, for subsequent analysis, they have been merged to form a lumped peripheral resistance $\left(R_{\mathrm{p}}\right)$. For the specific case of $\dot{V} \mathrm{O}_{2 \max }$, Eq. (6) can thus be rewritten as follows: 


$$
\begin{aligned}
\dot{V} \mathrm{O}_{2 \max } & =\frac{P_{\mathrm{I}} \mathrm{O}_{2}-P_{\mathrm{A}} \mathrm{O}_{2}}{R_{\mathrm{V}}}=\frac{P_{\mathrm{A}} \mathrm{O}_{2}-P_{\mathrm{a}} \mathrm{O}_{2}}{R_{\mathrm{L}}} \\
& =\frac{P_{\mathrm{a}} \mathrm{O}_{2}-P_{\overline{\mathrm{v}}} \mathrm{O}_{2}}{R_{\mathrm{Q}}}=\frac{P_{\overline{\mathrm{v}}} \mathrm{O}_{2}}{R_{\mathrm{p}}}=\frac{P_{\mathrm{I}} \mathrm{O}_{2}}{R_{\mathrm{T}}}
\end{aligned}
$$

Of these resistances, only two are characterized by precisely defined physiological variables, namely $R_{\mathrm{V}}$ and $R_{\mathrm{Q}}$, which are, respectively, equal to:

$R_{\mathrm{V}}=\frac{1}{\dot{V}_{\mathrm{A}} \cdot \beta_{\mathrm{g}}}$

$R_{Q}=\frac{1}{\dot{Q} \cdot \beta_{b}}$

where $\dot{V}_{\mathrm{A}}$ is alveolar ventilation and $\dot{Q}$ is cardiac output. The other two variables are the oxygen transfer coefficient for air $\left(\beta_{\mathrm{g}}\right)$ and for blood $\left(\beta_{\mathrm{b}}\right)$, i.e. the volume of oxygen that can be displaced across a gradient of a unit of pressure. The former, in STPD condition, is equal to $1.16 \mathrm{ml} \mathrm{mmHg}{ }^{-1}$ and is an invariant constant. Concerning $\beta_{\mathrm{b}}$, it is equal to:

$\beta_{\mathrm{b}}=\frac{\left(C_{\mathrm{a}} \mathrm{O}_{2}-C_{\overline{\mathrm{v}}} \mathrm{O}_{2}\right)}{\left(P_{\mathrm{a}} \mathrm{O}_{2}-P_{\overline{\mathrm{v}}} \mathrm{O}_{2}\right)}$

This corresponds to the average slope of the oxygen equilibrium curve. Therefore, the value taken by $\beta_{\mathrm{b}}$ is not invariant, for it depends on the oxygen pressure range on which our blood operates. The other three resistances cannot be translated into equivalent physiological expressions. Somewhat arbitrarily, but not without logic, $R_{\mathrm{L}}, R_{\mathrm{t}}$ and $R_{\mathrm{m}}$ were set proportional, respectively, to a factor including lung diffusing capacity corrected for the effect of $\dot{V}_{\mathrm{A}} / \dot{Q}$ heterogeneity, to muscle capillary density and to muscle mitochondrial volume (di Prampero and Ferretti 1990).

Several manipulations, either chronic (e.g. training or prolonged bed rest) or acute, affect $\dot{V} \mathrm{O}_{2 \max }$ without affecting $P_{\mathrm{I}} \mathrm{O}_{2}$ and thus $\Delta P_{\mathrm{T}}$. As a consequence, the observed increase in $\dot{V} \mathrm{O}_{2 \max }$ is the result of changes in one or more of the resistances in series. The aim of the algebraic development of the model was to devise a manner of determining a value for the fraction of the overall $\dot{V} \mathrm{O}_{2 \text { max }}$ limitation that can be attributed to a given in series resistance. Assume that somebody trains an individual and obtains a given $\dot{V} \mathrm{O}_{2 \max }$ increase, $\Delta \dot{V} \mathrm{O}_{2 \max }$. This increase occurs because, according to the formulation of the oxygen cascade reported in Fig. 3, at least three resistances have decreased, namely $R_{\mathrm{Q}}$, $R_{\mathrm{t}}$ and $R_{\mathrm{m}}$, and so has $R_{\mathrm{T}}$. Thus, after training has induced a measurable increase in $\dot{V} \mathrm{O}_{2 \max }$ with respect to the value before training, Eq. (10) can be rewritten as follows:

$\dot{V} \mathrm{O}_{2 \max }+\Delta \dot{V} \mathrm{O}_{2 \max }=\frac{P_{\mathrm{I}} \mathrm{O}_{2}}{R_{\mathrm{T}}+\Delta R_{\mathrm{T}}}$
If we divide Eq. (10) by Eq. (13), we obtain:

$\frac{\dot{V} \mathrm{O}_{2 \max }}{\left(\dot{V} \mathrm{O}_{2 \max }+\Delta \dot{V} \mathrm{O}_{2 \max }\right)}=1+\frac{\Delta R_{\mathrm{T}}}{R_{\mathrm{T}}}$

which, since $\Delta R_{\mathrm{T}}$ is the sum of the changes in the ith resistances in series, can also be written as follows:

$$
\begin{aligned}
& \frac{\dot{V} \mathrm{O}_{2 \max }}{\left(\dot{V} \mathrm{O}_{2 \max }+\Delta \dot{V} \mathrm{O}_{2 \max }\right)} \\
& =1+\frac{\left(\Delta R_{\mathrm{V}}+\Delta R_{\mathrm{L}}+\Delta R_{\mathrm{Q}}+\Delta R_{\mathrm{p}}\right)}{R_{\mathrm{T}}}
\end{aligned}
$$

As a consequence of the definition of $F$ (see Eqs. 8 and 9), when a change in any resistance is induced by any specific manoeuvre acting on it, we have:

$\frac{R_{\mathrm{i}}}{R_{\mathrm{T}}}=F_{\mathrm{i}} \cdot \frac{\Delta R_{\mathrm{i}}}{R_{\mathrm{i}}}$

So, Eq. (15) can be reformulated as follows:

$$
\begin{aligned}
\frac{\dot{V} \mathrm{O}_{2 \max }}{\left(\dot{V} \mathrm{O}_{2 \max }+\Delta \dot{V} \mathrm{O}_{2 \max }\right)}= & 1+F_{\mathrm{V}} \frac{\Delta R_{\mathrm{V}}}{R_{\mathrm{V}}}+F_{\mathrm{L}} \frac{\Delta R_{\mathrm{L}}}{R_{\mathrm{L}}} \\
& +F_{\mathrm{Q}} \frac{\Delta R_{\mathrm{Q}}}{R_{\mathrm{Q}}}+F_{\mathrm{p}} \frac{\Delta R_{\mathrm{p}}}{R_{\mathrm{p}}}
\end{aligned}
$$

Equation (17) has four unknowns, and as such cannot be solved. However, if we deal with a condition in which only one resistance is varied by an acute manipulation, as is the case, according to di Prampero and Ferretti (1990), for $R_{\mathrm{Q}}$ after acute blood reinfusion or withdrawal, three terms of Eq. (17) annihilate, and we remain with a simplified version of it, with only one unknown, which, for the specific case of changes in $R_{\mathrm{Q}}$ only, takes the following form:

$\frac{\dot{V} \mathrm{O}_{2 \max }}{\left(\dot{V} \mathrm{O}_{2 \max }+\Delta \dot{V} \mathrm{O}_{2 \max }\right)}=1+F_{\mathrm{Q}} \frac{\Delta R_{\mathrm{Q}}}{R_{\mathrm{Q}}}$

Equation (18) allows computation of $F_{\mathrm{Q}}$, provided we know the $\dot{V} \mathrm{O}_{2 \max }$ before and after the manoeuvre, the $R_{\mathrm{Q}}$ before the manoeuvre and the absolute change in $R_{\mathrm{Q}}$ induced by the manoeuvre. An analytical solution of Equation (18), using data from different sources in the literature, is reported in Fig. 4, where the ratio between the $\dot{V} \mathrm{O}_{2 \max }$ values before and after the manoeuvre (left-hand branch of Eq. 18) is plotted as a function of the ratio between $\Delta R_{Q}$ and $R_{\mathrm{Q}}$ : this relationship ought to be linear, with y-intercept equal to 1 and slope equal to $F_{\mathrm{Q}}$. From linear regression analysis of the data reported in Fig. 4, di Prampero and Ferretti (1990) obtained $F_{\mathrm{Q}}=0.70$, indicating that cardiovascular oxygen transport provides $70 \%$ of the fractional limitation of $\dot{V} \mathrm{O}_{2 \max }$. 


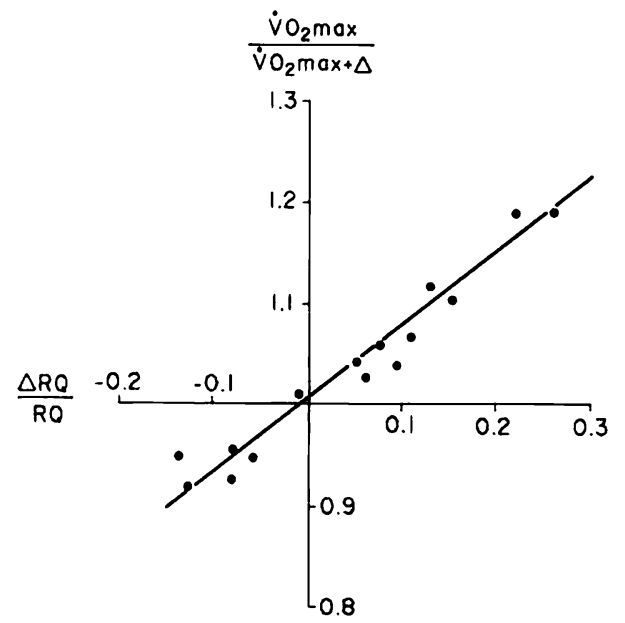

Fig. 4 Graphical representation of Eq. (22). The changes in $\dot{V} \mathrm{O}_{2 \max }$ consequent to an acute manoeuvre acting on the cardiovascular resistance to oxygen flow $\left(R_{\mathrm{Q}}\right)$ are expressed as the $\dot{V} \mathrm{O}_{2 \max }$ before the manoeuvre over the $\dot{V} \mathrm{O}_{2 \max }$ after the manoeuvre $\left(\dot{V} \mathrm{O}_{2 \max }+\Delta\right)$ and plotted as a function of the ratio between the induced change in $R_{\mathrm{Q}}\left(\Delta R_{\mathrm{Q}}\right)$ and the $R_{\mathrm{Q}}$ before the manoeuvre. Points are mean values from different sources in the literature. The continuous straight line is the corresponding regression equation $(y=1.006+0.7 x, r=0.97$, $n=15$ ). The slope of the line, equal to 0.7 , indicates that $70 \%$ of the overall limitation to $\dot{V} \mathrm{O}_{2 \max }$ is imposed by cardiovascular oxygen transport. Modified after di Prampero and Ferretti (1990)

\section{Of a nonlinear respiratory system}

The finding that $F_{\mathrm{Q}}=0.70$ implies that the respiratory system does not have linear behaviour. In fact, if the respiratory system provided linear responses, the ratio of any given $R_{\mathrm{i}}$ to $R_{\mathrm{T}}$ would be equal to the ratio of the pressure gradient over that $\mathrm{Ri}$ to the overall pressure gradient, so that we would have:

$F_{\mathrm{Q}}=\frac{\left(P_{\mathrm{a}} \mathrm{O}_{2}-P_{\overline{\mathrm{V}}} \mathrm{O}_{2}\right)}{P_{\mathrm{I}} \mathrm{O}_{2}}$

from which we would have obtained $F_{\mathrm{Q}}=0.50$ instead of 0.70 (di Prampero and Ferretti 1990).

The source of nonlinearity, and thus the source of this discrepancy, can be identified in the effects of the oxygen equilibrium curve on $\beta_{\mathrm{b}}$, as shown in Fig. 5. These effects have remarkable consequences, which I would summarize as follows. Assume that an acute manoeuvre is able to act directly on $R_{\mathrm{V}}$ only, e.g. reducing it. This would tend to increase $P_{\mathrm{A}} \mathrm{O}_{2}$, and thus $P_{\mathrm{a}} \mathrm{O}_{2}$, but would not change the associated $C_{\mathrm{a}} \mathrm{O}_{2}$, because in normoxia our blood operates on the flat portion of the oxygen equilibrium curve. Therefore, since $P_{\overline{\mathrm{V}}} \mathrm{O}_{2}$ undergoes only small changes, we would have a reduction of $\beta_{\mathrm{b}}$ and thus, according to Eq. (11b), an increase in $R_{\mathrm{Q}}$. This means that, just because of the shape of the oxygen equilibrium curve, as long as we are in normoxia, a specific manoeuvre acting only on $R_{\mathrm{V}}$ cannot have effects on $\dot{V} \mathrm{O}_{2 \max }$, because any change in $R_{\mathrm{V}}$ would inevitably entail an opposite effect on $R_{\mathrm{Q}}$. Thus, (1) we would have a solution of Eq. (10) with at least two unknowns instead of one, and (2) we would have a $\dot{V} \mathrm{O}_{2 \max }$ ratio of 1: in normoxia, $R_{\mathrm{V}}$ and $R_{\mathrm{L}}$ do not limit $\dot{V} \mathrm{O}_{2 \max }$.

In normoxia, we thus remain with a kind of two-site system in which the effective limitation appears distally to $P_{\mathrm{a}} \mathrm{O}_{2}$. This is sufficient to explain why $F_{\mathrm{Q}}=0.7$ instead of 0.5 , so that we necessarily have $F_{\mathrm{p}}=0.3$, partly attributable to $F_{\mathrm{t}}$, partly to $F_{\mathrm{m}}$. An analysis of the possible repartition of $F_{\mathrm{p}}$ between $F_{\mathrm{t}}$ and $F_{\mathrm{m}}$ was carried out by Ferretti et al.

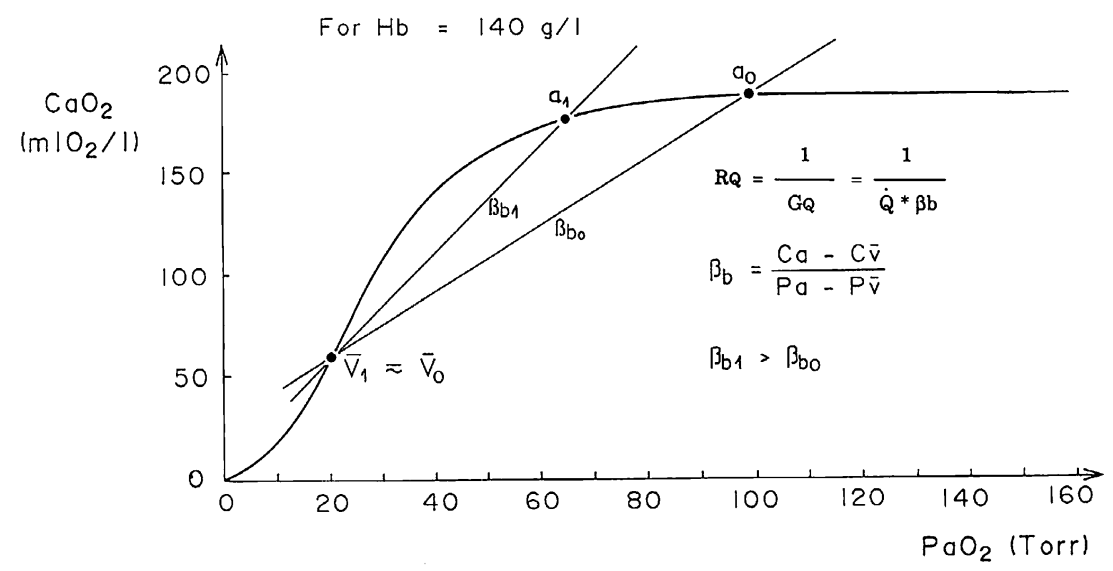

Fig. 5 Average oxygen equilibrium curve for blood. Two arterial and mixed venous points are reported, applying to normoxaemia $\left(a_{0}, v_{0}\right)$ and hypoxaemia $\left(a_{1}, v_{1}\right)$. The two straight lines connecting the two couples of points have a slope that is equal to the respective oxygen transport coefficients for blood $\left(\beta_{\mathrm{b}}\right)$, which turns out higher in the latter than in the former case. As a consequence, when an increase in the ventilatory resistance $R_{\mathrm{V}}$ entails a decrease in arterial oxygen partial pressure, $\beta_{\mathrm{b}}$ becomes higher and the cardiovascular resistance $R_{\mathrm{Q}}$ lower. These two phenomena compensate each other, so that no changes in $\dot{V} \mathrm{O}_{2 \max }$ are induced by an acute change in $R_{\mathrm{V}}$ : the lungs do not limit $\dot{V} \mathrm{O}_{2 \max }$ in normoxia. Symbols are as in the abbreviation list. Modified after di Prampero (1985) 
(1997a). Their analysis suggests that the differences in $\dot{V} \mathrm{O}_{2 \max }$ would be minimal, if we assume, on one extreme, $R_{\mathrm{t}}=R_{\mathrm{p}}$, and on the other extreme, $R_{\mathrm{m}}=R_{\mathrm{p}}$, and that it makes no difference to assume $R_{\mathrm{t}}$ and $R_{\mathrm{m}}$ in series or in parallel. Direct experimental assessment of the parameters of Eq. (18) confirmed that $F_{\mathrm{Q}}$ in normoxia is between 0.65 and 0.76 (Bringard et al. 2010; Turner et al. 1993).

\section{Experimental testing of di Prampero's model}

Beside the notion that $R_{\mathrm{V}}$ and $R_{\mathrm{L}}$ do not limit $\dot{V} \mathrm{O}_{2 \max }$ in normoxia, the nonlinearity of the model implies that (1) $R_{\mathrm{V}}$ and $R_{\mathrm{L}}$ do limit $\dot{V} \mathrm{O}_{2 \text { max }}$ in hypoxia; (2) $R_{\mathrm{Q}}$ in hypoxia is less than 0.7 ; (3) the decrease of $\dot{V} \mathrm{O}_{2 \max }$ in hypoxia is larger in subjects undergoing the Dempsey effect; (4) subjects with high $\dot{V} \mathrm{O}_{2 \max }$ in normoxia undergo an increase in $\dot{V} \mathrm{O}_{2 \max }$ in hyperoxia, contrary to subjects with low $\dot{V} \mathrm{O}_{2 \max }$ in normoxia; (5) there ought to be a linear relationship between $\dot{V} \mathrm{O}_{2 \max }$ and $S_{\mathrm{a}} \mathrm{O}_{2}$; (6) $F_{\mathrm{Q}}$ is lower and $F_{\mathrm{p}}$ is higher when exercise is carried out with small than with big muscle masses; (7) the fall of $\dot{V} \mathrm{O}_{2 \max }$ in hypoxia is smaller the smaller is the contracting muscle mass.

The roles played by $R_{\mathrm{V}}$ and $R_{\mathrm{L}}$ in normoxia and hypoxia were investigated by Esposito and Ferretti (1997), who acted acutely on $R_{\mathrm{V}}$ by changing air density through the replacement of nitrogen with helium in the inspired gas mixture. They found no change in $\dot{V} \mathrm{O}_{2 \max }$ while breathing the $\mathrm{He}-\mathrm{O}_{2}$ mixture in normoxia, despite the increase in $\dot{V}_{\mathrm{A}}$ at maximal exercise, whereas in hypoxia, the increase in $\dot{V} A$ under $\mathrm{He}-\mathrm{O}_{2}$ breathing was accompanied by a significant increase in $\dot{V} \mathrm{O}_{2 \max }$, coherently with the predictions. Similar results were recently obtained also by Ogawa et al. (2010). Consistently, several studies showed no effects of respiratory muscle training on $\dot{V} \mathrm{O}_{2 \max }$ in normoxia (Downey et al. 2007; Edwards and Cooke 2004; Esposito et al. 2010; Markov et al. 2001; Sonetti et al. 2001), but a positive effect was observed in hypoxia (Downey et al. 2007; Esposito et al. 2010).

Points (2), (4) and (5) of the above list were studied in acute hypoxia and hyperoxia by Ferretti et al. (1997b), who investigated two groups of subjects, one with high, the other with low $\dot{V} \mathrm{O}_{2 \max }$ in normoxia. They demonstrated that (1) the decrease in $\dot{V} \mathrm{O}_{2 \max }$ was larger in the former than in the latter group at all investigated $F_{\mathrm{I}} \mathrm{O}_{2}$; (2) the former group, contrary to the latter, underwent a $\dot{V} \mathrm{O}_{2 \max }$ increase in hyperoxia; (3) there was a highly significant linear relationship between $\dot{V} \mathrm{O}_{2 \max }$, expressed relative to the value in hyperoxia set equal to $100 \%$, and $S_{\mathrm{a}} \mathrm{O}_{2}$; (4) this relationship was the same in both groups, in agreement with the above predictions. Wehrlin and Hallén (2006) even reported a linear decrease of $\dot{V} \mathrm{O}_{2 \max }$ in hypoxia in endurance athletes. Coherent with this picture is also the finding that can be reckoned from several publications (Benoit et al. 1995; Gavin et al. 1998; Kayser et al. 1994; Marconi et al. 2004; Wilhite et al. 2013; Woorons et al. 2005) that the $\dot{V} \mathrm{O}_{2 \max }$ decrease in hypoxia is smaller the stronger is the ventilatory response to hypoxia.

\section{An analysis of Wagner's model}

Wagner (1993) constructed a three-equation system with three unknowns $\left(P_{\mathrm{A}} \mathrm{O}_{2}, P_{\mathrm{a}} \mathrm{O}_{2}\right.$ and $\left.P_{\overline{\mathrm{V}}} \mathrm{O}_{2}\right)$ by combining the mass conservation equation for blood (Fick principle) and the two diffusion-perfusion interaction equations (Piiper and Scheid 1981; Piiper et al. 1984), which, at steady state, must have equal solutions. The algebraic development of the system led to three equations allowing a solution for $P_{\mathrm{A}} \mathrm{O}_{2}, P_{\mathrm{a}} \mathrm{O}_{2}$ and $P_{\overline{\mathrm{V}}} \mathrm{O}_{2}$. These equations would lead to a unique, necessary $\dot{V} \mathrm{O}_{2 \max }$ value for any combination of known values of $P_{\mathrm{I}} \mathrm{O}_{2}, \dot{V}_{\mathrm{A}}, D_{\mathrm{L}}, \dot{Q}, \beta_{\mathrm{b}}$ and $D_{\mathrm{t}}$ at maximal exercise (Wagner 1993). Wagner's system of equations carries along a different vision of the oxygen cascade from di Prampero's, with two mass balance equations responsible for convective oxygen transfer, associated with two conductive components, described by the diffusion-perfusion interaction equations. Proximally, the action of a convective component with a diffusive component sets the maximal flow of oxygen in arterial blood $\left(\dot{Q}_{\mathrm{a}} \mathrm{O}_{2 \text { max }}\right)$, and this is the first step in the system. Distally, the action of a convective component (Fick principle), combined with that of a diffusive component (the diffusion-perfusion interaction equation setting oxygen flow from peripheral capillaries to the muscle fibres), sets $\dot{V} \mathrm{O}_{2 \max }$. This is the key step of Wagner's model, on which he concentrated his attention, and which deserves more detailed analysis, especially for its quantitative consequences. The Fick equation can take either of the following solutions:

$\dot{V} \mathrm{O}_{2 \max }=\dot{Q} \cdot\left(C_{\mathrm{a}} \mathrm{O}_{2}-C_{\overline{\mathrm{v}}} \mathrm{O}_{2}\right)=\dot{Q} \cdot \beta_{\mathrm{b}} \cdot\left(P_{\mathrm{a}} \mathrm{O}_{2}-P_{\overline{\mathrm{v}}} \mathrm{O}_{2}\right)$

The presence of the term $\beta_{\mathrm{b}}$ in Eq. (20) implies a nonlinear negative relationship between $\dot{V} \mathrm{O}_{2 \max }$ and $P_{\overline{\mathrm{V}}} \mathrm{O}_{2}$ (convective curve), the algebraic expression of which depends on the solution that we may wish to give to the oxygen equilibrium curve. Concerning the diffusive component, it is described by the following equation:

$\dot{V} \mathrm{O}_{2 \max }=D_{\mathrm{t}} \mathrm{O}_{2} \cdot\left(P_{\overline{\mathrm{c}}} \mathrm{O}_{2}-P_{\mathrm{m}} \mathrm{O}_{2}\right)$

where $D_{\mathrm{t}} \mathrm{O}_{2}$ is tissue diffusing capacity for oxygen and $P_{\mathrm{m}} \mathrm{O}_{2}$ is again equal to $0 \mathrm{mmHg}$. At steady state, Eqs. (20) and (21) must have the same solution, but since their right branches do not share any term, they cannot as such be compared on the same plot. The solution figured out by Wagner was to assume direct proportionality between $P_{\overline{\mathrm{V}}} \mathrm{O}_{2}$ 
and $\mathrm{P} \overline{\mathrm{c}} \mathrm{O} 2$, because the segment of the oxygen equilibrium curve between these two pressures is essentially linear, and so within that segment $\beta_{\mathrm{b}}$ can be considered invariant. Thus, Eq. (21) can be rewritten as follows:

$\dot{V} \mathrm{O}_{2 \max }=D_{\mathrm{t}} \mathrm{O}_{2} \cdot K_{\mathrm{p}} \cdot P_{\overline{\mathrm{v}}} \mathrm{O}_{2}$

where $K_{\mathrm{p}}$ is the dimensionless constant relating $P_{\overline{\mathrm{v}}} \mathrm{O}_{2}$ and $P_{\overline{\mathrm{c}}} \mathrm{O}_{2}$. Equation (22) implies a positive linear relationship between $\dot{V} \mathrm{O}_{2 \max }$ and $P_{\mathrm{v}} \mathrm{O}_{2}$ (diffusion line), which Roca et al. (1989) determined experimentally. The slope of the line is equal to the product $D_{\mathrm{t}} \mathrm{O} 2 \cdot K p$, which from here on I will call Wagner's constant, $K_{\mathrm{W}}$. Equations (20) and (22) give origin to analytical relationships that, if we plot $\dot{V} \mathrm{O}_{2 \max }$ on the $\mathrm{y}$-axis and $P_{\overline{\mathrm{V}}} \mathrm{O}_{2}$ on the x-axis, can be represented on the same graph and directly compared (Fig. 6). In Fig. 6, the resulting $\dot{V} \mathrm{O}_{2 \max }$ for any combination of $\dot{Q}_{\mathrm{a}} \mathrm{O}_{2 \max }$ and $K_{\mathrm{W}}$ corresponds to the crossing of the two represented functions, which occurs at a precise value of $P_{\overline{\mathrm{V}}} \mathrm{O}_{2}$.

Concerning the diffusive component, a decrease in $D_{\mathrm{t}} \mathrm{O}_{2}$ implies a decrease in $K_{\mathrm{W}}$ : the result is a drop of $\dot{V} \mathrm{O}_{2 \max }$ and an increase in $P_{\overline{\mathrm{v}}} \mathrm{O}_{2}$. The reverse is caused by an increase in $D_{\mathrm{t}} \mathrm{O}_{2}$. On the convective curve, representative of Eq. (20) an increase in the product $\dot{Q} \cdot \beta_{\mathrm{b}}$ carries along an increase in both $\dot{V} \mathrm{O}_{2 \max }$ and $P_{\overline{\mathrm{v}}} \mathrm{O}_{2}$. The intercept on the x-axis of the convective curve corresponds to the $P_{\mathrm{a}} \mathrm{O}_{2}$ point, i.e. the point at which $P_{\overline{\mathrm{v}}} \mathrm{O}_{2}=P_{\mathrm{a}} \mathrm{O}_{2}$ : hyperoxia displaces this point to the right, implying a slightly higher $\dot{V} \mathrm{O}_{2 \max }$, whereas hypoxia displaces it to the left. The y-intercept of the convective curve corresponds to the $\dot{Q}_{\mathrm{a}} \mathrm{O}_{2 \text { max }}$ point, representing the condition in which $\dot{V} \mathrm{O}_{2 \max }=\dot{Q}_{\mathrm{a}} \mathrm{O}_{2 \max }$ (Wagner 1995, 1996a).

\section{Experimental testing of Wagner's model}

Wagner's model predicts that a drop of $K_{\mathrm{W}}$ carries along a decrease in $\dot{V} \mathrm{O}_{2 \max }$ with associated increase in $P_{\overline{\mathrm{V}}} \mathrm{O}_{2}$. This is virtually impossible to test in humans with acute manoeuvres acting on $D_{\mathrm{t}} \mathrm{O}_{2}$, the most important determinant of $K_{\mathrm{W}}$. Moreover, $D_{\mathrm{t}} \mathrm{O}_{2}$ is affected by haemoglobin concentration, as demonstrated in isolated-perfused dog muscle (Hogan et al. 1991a, b) and in humans (Schaffartzik et al. 1993). Looking at chronic alterations of $D_{\mathrm{t}} \mathrm{O}_{2}$ led to predict quite accurately the effects on $\dot{V} \mathrm{O}_{2 \max }$ and $P_{\overline{\mathrm{v}}} \mathrm{O}_{2}$ in patients affected by chronic obstructive pulmonary disease, once allowance was made for the simultaneous impairment of cardiovascular oxygen transport (Wagner 1996a). An analysis of literature data of muscle morphometry and $\dot{V} \mathrm{O}_{2 \text { max }}$ of altitude-acclimatized climbers (Hoppeler et al. 1990; Oelz et al. 1986) or endurance-trained subjects (Hoppeler et al. 1985), in which I assumed direct proportionality between $K_{\mathrm{W}}$ and muscle capillary density, led to $P_{\overline{\mathrm{V}}} \mathrm{O}_{2}$ values coherent with Wagner's predictions.

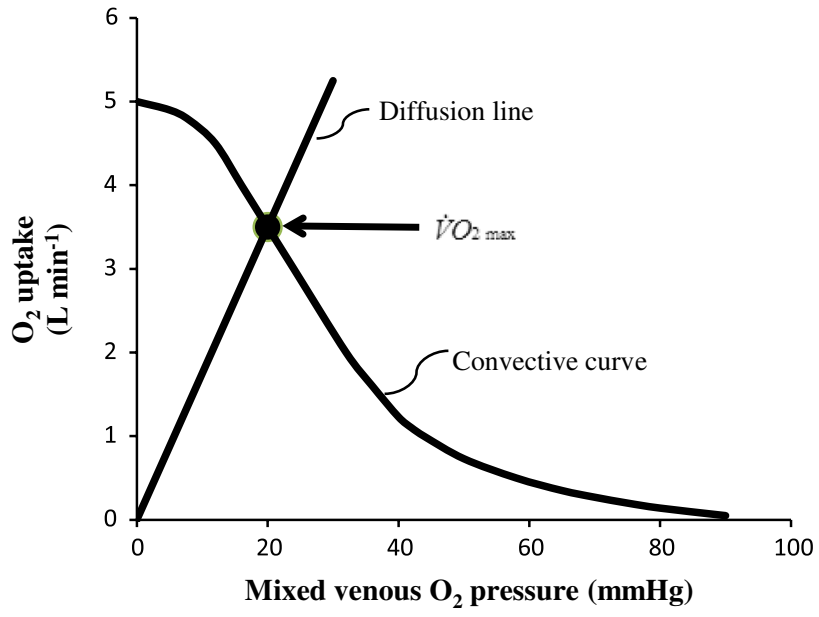

Fig. 6 Graphical representation of Wagner's model. Oxygen uptake $\left(\dot{V} \mathrm{O}_{2}\right)$ is plotted as a function of mixed venous oxygen pressure $\left(P_{\overline{\mathrm{V}}} \mathrm{O}_{2}\right)$. The curve with negative slope is Wagner's convective curve. The straight line with positive slope is Wagner's diffusion line, whose slope is Wagner's constant $K_{\mathrm{w}}$. The convective curve intercepts the y-axis at a $\dot{V} \mathrm{O}_{2}$ equal to arterial oxygen flow $\left(\dot{Q}_{\mathrm{a}} \mathrm{O}_{2}\right)$, which is the case when $K \mathrm{~W}=\infty$. It intercepts the $\mathrm{x}$-axis when $P_{\overline{\mathrm{V}}} \mathrm{O}_{2}$ is equal to arterial oxygen pressure, which is the case when $K_{\mathrm{w}}=0$. The $\dot{V} \mathrm{O}_{2 \max }$ value is found on the crossing of the convective curve with the diffusion line (full dot)

Controversial is the case of hyperoxia. The results of Fig. 6 would lead to predict an increase in $\dot{V} \mathrm{O}_{2 \max }$, because the rightwards displacement of the $P_{\mathrm{a}} \mathrm{O}_{2}$ point would change the slope of the convective curve in such a way that the diffusion line would be intercepted at a higher $\dot{V} \mathrm{O}_{2 \max }$ value. Such an increase was rarely observed in humans, the only clear effects having been observed in subjects with elevated $\dot{V} \mathrm{O}_{2 \max }$, who are subject to the Dempsey effect (see section "Descriptive Physiology of $\dot{V} \mathrm{O}_{2 \max }$ "). Richardson et al. (1999) had to use pure oxygen breathing to be able to observe a $\dot{V} \mathrm{O}_{2 \max }$ increase during single-leg exercise, as a consequence of increased free oxygen concentration. The thoroughbred horse, a highly athletic animal characterized by deep hypoxaemia at maximal exercise, was proposed as the nicest example supporting this prediction (Wagner 1996a; Wagner et al. 1989, 1996), which is not surprising at all, if one considers the size of the active muscle mass of a maximally exercising horse. Similar results were obtained with single-leg exercise studies, in which local $\dot{V} \mathrm{O}_{2}$ can be measured by catheterizing the femoral artery and vein (Knight et al. 1993; Roca et al. 1992). This apparent discrepancy between theoretical predictions and experimental data is hard to explain, and the hypotheses put forwards so far are scarcely convincing. On the opposite side of the spectrum, more convincing results were obtained in hypoxia, but these will be discussed more in detail in a specific paragraph (see "Of maximal oxygen consumption in hypoxia" section). 
Wagner's model provided several a posteriori interpretations. An increase in oxygen transport capacity, whether for an increase in $\dot{Q}$ or for an increase in haemoglobin concentration, generates a $\dot{V} \mathrm{O}_{2 \max }$ increase, because the convective curve is displaced upwards and becomes steeper. Athletes have elevated $\dot{V} \mathrm{O}_{2 \max }$ because they have high $K_{\mathrm{W}}$ and a simultaneously upwards displacement of the convective curve. The opposite should occur with muscle disuse. Changing haemoglobin oxygen affinity would act on the convective curve.

\section{A critical comparison of the two models}

The two models obviously share the vision that $\dot{V} \mathrm{O}_{2 \max }$ is set by multiple factors that di Prampero described as a number of resistances in series and Wagner as an interconnected relation between oxygen supply and oxygen diffusion. In other terms, di Prampero had a more holistic approach, while Wagner drew most of his attention to what happens into muscles. Whereas anatomical shunts were recently excluded as possible determinants of $P_{\mathrm{a}} \mathrm{O}_{2}$ at maximal exercise (Vogiatzis et al. 2008), both models have difficulties in dealing with that black box related to the effects of $\dot{V}_{\mathrm{A}} / \dot{Q}$ heterogeneity. Wagner skipped it by stating that it has minimal effects in normoxia, di Prampero artificially included it in $R_{\mathrm{L}}$, but without a specific quantitative analysis of its effects. These divergent approaches entailed some conceptual differences in the two models that I have summarized in Table 1. Most of them are direct consequences of the way cardiovascular oxygen transport is considered, either a purely convective step or one of many resistances in series. It is curious indeed that through different ways both models share the conclusion that in normoxia there is no $\dot{V} \mathrm{O}_{2 \max }$ limitation imposed by pulmonary ventilation and oxygen diffusion capacity in healthy non-athletic humans. Both models admit that these variables provide a limitation to $\dot{V} \mathrm{O}_{2 \max }$ only in case of arterial blood desaturation, in agreement with the conclusions arrived at by others from a different perspective (Johnson et al. 1992; Powers et al. 1989; Steinacker et al. 1996). So they both finally focused on what occurs distally to $P_{\mathrm{a}} \mathrm{O}_{2}$. This facilitates a comparison of the two models. The following lines are an attempt at demonstrating that, despite appearances, the two models provide the same information and that the term $F_{\mathrm{Q}}$ of di Prampero's model is included in the graphical representation shown in Fig. 6.

Equations (20) and (22) are in fact common to the two models. The former defines $R_{\mathrm{Q}}$, since, because of Eq. (11b):

$\dot{V} \mathrm{O}_{2 \max }=\dot{Q} \cdot \beta_{\mathrm{b}} \cdot\left(P_{\mathrm{a}} \mathrm{O}_{2}-P_{\overline{\mathrm{v}}} \mathrm{O}_{2}\right)=\frac{1}{R_{\mathrm{Q}}} \cdot\left(P_{\mathrm{a}} \mathrm{O}_{2}-P_{\overline{\mathrm{v}}} \mathrm{O}_{2}\right)$

On the other side, Eq. (22), once we assume $P_{\mathrm{m}} \mathrm{O}_{2}=0 \mathrm{mmHg}$, defines $R_{\mathrm{p}}$, since:
Table 1 Main apparent differences between the two multifactorial models of $\dot{V} \mathrm{O}_{2 \max }$ limitation

\begin{tabular}{ll}
\hline Wagner's model & Di Prampero's model \\
\hline $\begin{array}{l}\text { Blood oxygen transport } \\
\text { Purely convective element }\end{array}$ & $\begin{array}{c}\text { One of many resistances } \\
\text { in series }\end{array}$ \\
$\begin{array}{l}\text { Hydraulic model of in series resistances } \\
\text { Partially applicable }\end{array}$ & Fully applicable \\
Pressure gradient at alveolar level & \\
$P_{\mathrm{A}} \mathrm{O}_{2}-P_{\overline{\mathrm{c}}} \mathrm{O}_{2}$ & $P_{\mathrm{A}} \mathrm{O}_{2}-P_{\mathrm{a}} \mathrm{O}_{2}$ \\
Pressure gradient in blood circulation & \\
No oxygen pressure difference & $P_{\mathrm{a}} \mathrm{O}_{2}-P_{\overline{\mathrm{v}}} \mathrm{O}_{2}$ \\
Peripheral diffusion & \\
Imposed by mean capillary pressure & Imposed by $P_{\overline{\mathrm{v}}} \mathrm{O}_{2}$ \\
Role of $P_{\overline{\mathrm{V}}} \mathrm{O}_{2}$ & \\
End point of the diffusion process & Driving pressure for dif- \\
& fusion \\
\hline
\end{tabular}

Symbols as in abbreviations' list

$\dot{V} \mathrm{O}_{2 \max }=D_{\mathrm{t}} \mathrm{O}_{2} \cdot K_{\mathrm{p}} \cdot P_{\overline{\mathrm{v}}} \mathrm{O}_{2}=K_{\mathrm{W}} \cdot P_{\overline{\mathrm{v}}} \mathrm{O}_{2}=\frac{1}{R_{\mathrm{p}}} \cdot P_{\overline{\mathrm{v}}} \mathrm{O}_{2}$

which indicates that Wagner's constant $K_{\mathrm{W}}$ is the reciprocal of $R_{\mathrm{p}}$, i.e. $G_{\mathrm{p}}$.

Concerning Eq. (23), it is noteworthy that $\dot{Q}$ corresponds to the maximal cardiac output only when the systemic oxygen delivery of the whole organism is considered. However, in the context of Wagner's model, when single-leg exercise is accounted for, $\dot{Q}$ does not correspond to the maximal cardiac output, but to the blood flow through the active muscle mass, which is less.

As a consequence of Eqs. (23) and (24), Fig. 6, which is a plot of $\dot{V} \mathrm{O}_{2}$ as a function of $P_{\overline{\mathrm{V}}} \mathrm{O}_{2}$, can receive a different, novel interpretation. If we replace Eq. (22) by Eq. (24), then the slope of the diffusive line of Fig. 6 becomes equal to $G_{\mathrm{p}}$ or $1 / R_{\mathrm{p}}$. The y-intercept of the same line on the origin of the axes indicates that all oxygen delivered to the active muscle mass (or to the body cells) is extracted, so that $\dot{V} \mathrm{O}_{2 \max }=\dot{Q}_{\mathrm{a}} \mathrm{O}_{2 \max }$ and, according to di Prampero's model, $F_{\mathrm{Q}}=1$. Concerning the convective curve, Eq. (23) implies a nonlinear relationship in which the slope is equal to $-\dot{Q} \beta$, i.e. $-G_{\mathrm{Q}}$ or $-1 / R_{\mathrm{Q}}$, and the $\mathrm{y}$-axis intercept is equal to $\dot{Q}_{\mathrm{a}} \mathrm{O}_{2}$. This means that Wagner's model includes two terms that characterize di Prampero's model: $R_{\mathrm{Q}}$ and $R_{\mathrm{p}}$.

If we assume, as discussed above, that indeed the lungs do not limit $\dot{V} \mathrm{O}_{2 \max }$ in normoxia, the simplified version of di Prampero's model, describing the flow of oxygen downstream of the lungs, can be treated as linear, so that: 
$F_{\mathrm{Q}}=\frac{\left(P_{\mathrm{a}} \mathrm{O}_{2}-P_{\overline{\mathrm{v}}} \mathrm{O}_{2}\right)}{P_{\mathrm{a}} \mathrm{O}_{2}}=\frac{R_{\mathrm{Q}}}{\left(R_{\mathrm{Q}}+R_{\mathrm{p}}\right)}$

whence

$\frac{1}{F_{\mathrm{Q}}}=\frac{\left(R_{\mathrm{Q}}+R_{\mathrm{p}}\right)}{R_{\mathrm{Q}}}=1+\frac{R_{\mathrm{p}}}{R_{\mathrm{Q}}}=1+\frac{G_{\mathrm{Q}}}{G_{\mathrm{p}}}$

Equation (26) expresses $F_{\mathrm{Q}}$ in terms of ratio between the slopes of Eqs. (23) and (24). There is, however, more than this behind Fig. 6. We know in fact that:

$\dot{Q}_{\mathrm{a}} \mathrm{O}_{2 \max }=\dot{Q} \cdot C_{\mathrm{a}} \mathrm{O}_{2}=\dot{Q} \cdot \beta_{\mathrm{b}} \cdot P_{\mathrm{a}} \mathrm{O}_{2}$

Dividing Eq. (23) by Eq. (27), we obtain:

$$
\begin{aligned}
\frac{\dot{V} \mathrm{O}_{2 \max }}{\dot{Q}_{\mathrm{a}} \mathrm{O}_{2 \max }} & =\frac{\dot{Q} \cdot\left(C_{\mathrm{a}} \mathrm{O}_{2}-C_{\overline{\mathrm{v}}} \mathrm{O}_{2}\right)}{\dot{Q} \cdot C_{\mathrm{a}} \mathrm{O}_{2}} \\
& =\frac{\dot{Q} \cdot \beta_{\mathrm{b}} \cdot\left(P_{\mathrm{a}} \mathrm{O}_{2}-P_{\overline{\mathrm{v}}} \mathrm{O}_{2}\right)}{\dot{Q} \cdot \beta_{\mathrm{b}} \cdot P_{\mathrm{a}} \mathrm{O}_{2}} \\
& =\frac{\left(P_{\mathrm{a}} \mathrm{O}_{2}-P_{\overline{\mathrm{v}}} \mathrm{O}_{2}\right)}{P_{\mathrm{a}} \mathrm{O}_{2}}
\end{aligned}
$$

Equation (28) is just a different way of expressing Eq. (25), whence:

$$
\frac{\dot{V} \mathrm{O}_{2 \max }}{\dot{Q}_{\mathrm{a}} \mathrm{O}_{2 \max }}=F_{\mathrm{Q}}
$$

This implies that $F_{\mathrm{Q}}$ in normoxia is equal to the oxygen extraction coefficient! It also derives from Eq. (29) that, if $\dot{V} \mathrm{O}_{2}=\dot{Q}_{\mathrm{a}} \mathrm{O}_{2}, F_{\mathrm{Q}}=1$, and thus $F_{\mathrm{p}}=0$ : all oxygen delivered to peripheral capillaries is consumed by mitochondria. This condition is represented by the y-axis intercept of the convective curve in Fig. $6\left(\dot{Q}_{\mathrm{a}} \mathrm{O}_{2}\right.$ point $)$. On the contrary, when $\dot{V} \mathrm{O}_{2}=0, F_{\mathrm{Q}}=0$, and thus $F_{\mathrm{p}}=1$, and $R_{\mathrm{p}}=\infty$ or $K_{\mathrm{W}}=0$ : no oxygen flows from capillaries to mitochondria. This condition is represented by the $\mathrm{x}$-axis intercept of the convective curve in Fig. 6, i.e. the point where $P_{\overline{\mathrm{V}}} \mathrm{O}_{2}=P_{\mathrm{a}} \mathrm{O}_{2}$. All intermediate solutions of Eq. (29) lie somewhere between these two extremes on the convective curve, the closer to the $P_{\mathrm{a}} \mathrm{O}_{2}$ point, the lower is $K_{\mathrm{W}}$, and thus the higher is $R_{\mathrm{p}}$. The relationship between $F_{\mathrm{Q}}$ and $P_{\overline{\mathrm{v}}} \mathrm{O}_{2}$, shown in Fig. 7 , is a mere representation of the convective curve, on a plot where $\dot{V} \mathrm{O}_{2}$ is expressed relative to $\dot{Q}_{\mathrm{a}} \mathrm{O}_{2}$.

The diffusion-perfusion interaction equation for peripheral capillaries (Piiper et al. 1984) is as follows:

$P_{\overline{\mathrm{V}}} \mathrm{O}_{2}=P_{\mathrm{a}} \mathrm{O}_{2} \cdot e^{-D_{\mathrm{t}} / \dot{Q} \cdot \beta_{\mathrm{b}}}$

Combining Eqs. (20) and (30), we then obtain:

$$
\begin{aligned}
\dot{V} \mathrm{O}_{2 \max } & =\dot{Q} \cdot \beta_{\mathrm{b}} \cdot P_{\mathrm{a}} \mathrm{O}_{2}\left(1-e^{-D_{\mathrm{t}} / \dot{Q} \cdot \beta_{\mathrm{b}}}\right) \\
& =\dot{Q}_{\mathrm{a}} \mathrm{O}_{2 \max }\left(1-e^{-D_{\mathrm{t}} / \dot{Q} \cdot \beta_{\mathrm{b}}}\right)
\end{aligned}
$$

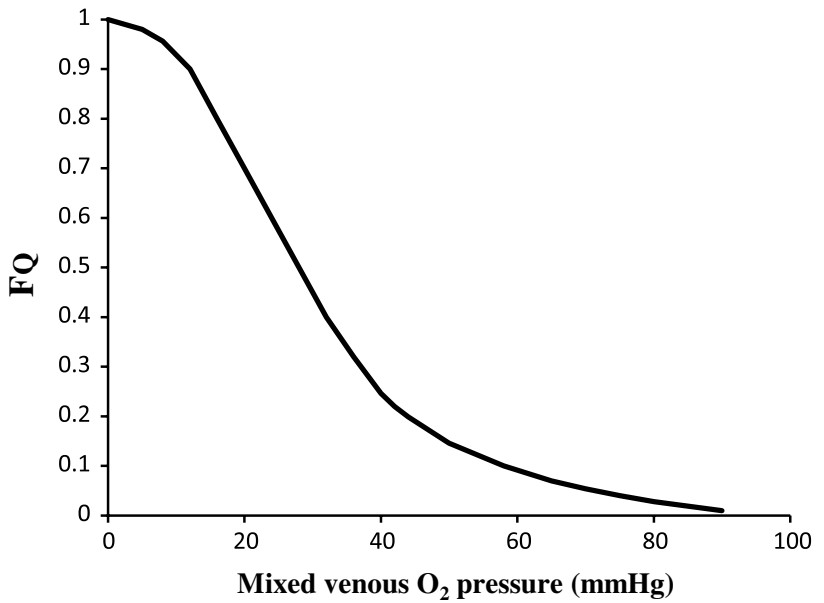

Fig. 7 Fractional limitation to $\dot{V} \mathrm{O}_{2 \max }$ imposed by the cardiovascular oxygen transport system $\left(F_{\mathrm{Q}}\right)$ in normoxia as a function of mixed venous oxygen pressure

whence:

$\frac{\dot{V} \mathrm{O}_{2 \max }}{\dot{Q}_{\mathrm{a}} \mathrm{O}_{2 \max }}=F_{\mathrm{Q}}=1-e^{-D_{\mathrm{t}} / \dot{Q} \cdot \beta_{\mathrm{b}}}$

and

$F_{\mathrm{p}}=1-F_{\mathrm{Q}}=e^{-D_{\mathrm{t}} / \dot{Q} \cdot \beta_{\mathrm{b}}}$

This implies that $F_{\mathrm{p}}$ is the natural logarithm of the exponent of Eq. (30), an equivalence allowing inclusion of the diffusion-perfusion interaction equation for peripheral capillaries in di Prampero's model, and representing a further step towards a more complete representation of the quantitative relations describing oxygen flow at maximal exercise. Incidentally, it is of note that, according to Fig. $4, F_{\mathrm{Q}}$ is a constant whose value is invariant in normoxia, and so is, according to Eq. (32), the $D_{\mathrm{t}} / \dot{Q} \cdot \beta_{\mathrm{b}}$ ratio. This provides further theoretical support to Wagner's assumption of a direct proportionality between $P_{\overline{\mathrm{V}}} \mathrm{O}_{2}$ and $P_{\overline{\mathrm{c}}} \mathrm{O}_{2}$. A similar analysis, which, however, was not pushed to include $F_{\mathrm{Q}}$ and $F_{\mathrm{p}}$, can be found also in Roca et al. (1992).

To sum up, the present analysis has demonstrated that indeed di Prampero's model and Wagner's model converge on the same conclusion, namely that both cardiovascular oxygen transport and muscle oxygen diffusion and utilization are necessary determinants of $\dot{V} \mathrm{O}_{2 \max }$, the former being responsible for the larger fraction of the overall $\dot{V} \mathrm{O}_{2 \max }$ limitation (some $70 \%$, according to di Prampero and Ferretti 1990). If a musical analogy is allowed, the two models at stake appear as variations around the theme of the oxygen conductance equation that eventually converge on the same final accords. 


\section{Of maximal oxygen consumption in hypoxia}

That $\dot{V} \mathrm{O}_{2 \max }$ decreases in hypoxia, whether acute or chronic, is a universally accepted notion (Cerretelli and Margaria 1961; Cymerman et al. 1989; Dill et al. 1966; Fagraeus et al. 1973; Ferretti 1990; Fulco et al. 1988; Koistinen et al. 1995; Lawler et al. 1988; Marconi et al. 2004; Mollard et al. 2007; Pugh et al. 1964; Roca et al. 1989; Steinacker et al. 1996; Vogel et al. 1967; Wehrlin and Hallén 2006; West et al. 1983; Woorons et al. 2005). The main cause of the $\dot{V} \mathrm{O}_{2 \max }$ decrease in hypoxia is the drop of $P_{\mathrm{I}} \mathrm{O}_{2}$. The point is why $\dot{V} \mathrm{O}_{2 \max }$ decreases so little in mild hypoxia, at altitudes below 3,000 $\mathrm{m}$ above sea level. I already underlined the linear relationship between $\dot{V} \mathrm{O}_{2 \max }$ and $S_{\mathrm{a}} \mathrm{O}_{2}$, implying that we have a $\dot{V} \mathrm{O}_{2 \max }$ decrease in hypoxia as soon as we have a drop of $S_{\mathrm{a}} \mathrm{O}_{2}$. This does not occur as long as blood operates on the flat portion of the oxygen equilibrium curve, so that we need a decrease in $P_{\mathrm{a}} \mathrm{O}_{2}$ as big as required to attain the steep part of the oxygen equilibrium curve in order to see significant falls of $\dot{V} \mathrm{O}_{2 \max }$.

In the context of di Prampero's model, this concept can be expressed by stating that, as $P_{\mathrm{a}} \mathrm{O}_{2}$ decreases, $\beta_{\mathrm{b}}$ increases, and thus $R_{\mathrm{Q}}$ falls, until, once the steep part of the oxygen equilibrium curve has been attained, $\beta_{\mathrm{b}}$ and $R_{\mathrm{Q}}$ do not change anymore and the drop of $\dot{V} \mathrm{O}_{2 \max }$ becomes linear (see Fig. 8). In conclusion, we can well state that the curve describing the $\dot{V} \mathrm{O}_{2 \max }$ decrease in hypoxia is a kind of mirror image of the oxygen equilibrium curve (Ferretti 1990, 2003; Ferretti et al. 1997b). A detailed analysis of the interrelations between $R_{\mathrm{Q}}$ and $R_{\mathrm{V}}$, and thus between $F_{\mathrm{Q}}$ and $F_{\mathrm{V}}$ in hypoxia was carried out elsewhere (Ferretti and di Prampero 1995). These authors calculated that in extreme hypoxia $F_{\mathrm{Q}}$ may decrease down to 0.20 with $F_{\mathrm{V}}$ going up to about 0.35 .

Several consequences of the conclusions arrived at by Ferretti and di Prampero (1995) underwent experimental testing. The effects of hypoxia on $\dot{V} \mathrm{O}_{2 \max }$ are greater the higher is the subject's $\dot{V} \mathrm{O}_{2 \max }$ in normoxia (Dempsey et al. 2008; Dill and Adams 1971; Ferretti et al. 1997b; Gavin et al. 1998; Koistinen et al. 1995; Lawler et al. 1988; Pugh 1967; Wehrlin and Hallén 2006; Woorons et al. 2005), because of the Dempsey effect. They are smaller the more intense is the ventilatory response to hypoxia (Giesbrecht et al. 1991; Marconi et al. 2004; Ogawa et al. 2007). Great surprise at the time was generated by the observation that the climbers who reached the highest summits on Earth without supplementary oxygen had relatively low $\dot{V} \mathrm{O}_{2 \max }$ in normoxia, much lower than that of endurance athletes (Oelz et al. 1986). In fact, since athletes undergo a bigger fall of $\dot{V} \mathrm{O}_{2 \max }$ in hypoxia, the differences in $\dot{V} \mathrm{O}_{2 \max }$ which we may observe at sea level disappear on the top of Mount Everest.
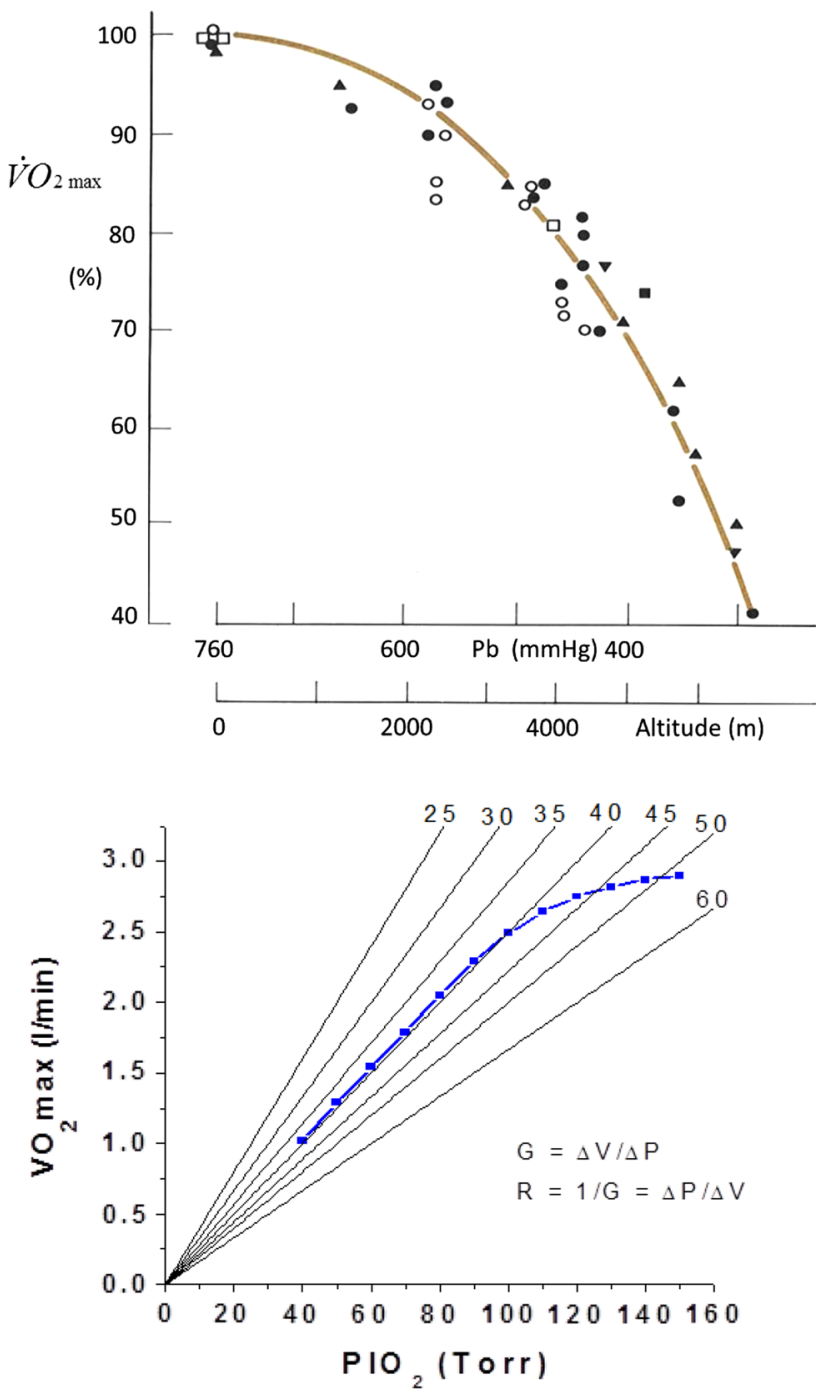

Fig. 8 Top panel Fall of maximal oxygen consumption $\left(\dot{V} \mathrm{O}_{2 \max }\right)$ at altitude. $\dot{V} \mathrm{O}_{2 \max }$ is expressed relative to the value observed at sea level, set equal to $100 \%$. Two $\mathrm{x}$-axis are reported, one indicating barometric pressure $\left(P_{\mathrm{b}}\right)$, the other, below, indicating altitude. Open dots refer to acute hypoxia, full dots refer to chronic hypoxia. Data from Cerretelli (1980). Bottom panel Same curve as on top, calculated for a sea level $\dot{V} \mathrm{O}_{2 \max }$ of $2.8 \mathrm{~L} / \mathrm{min}$ (Cerretelli and di Prampero 1987 ), where $P_{\mathrm{b}}$ has been replaced by the inspired oxygen pressure $\left(P_{\mathrm{I}} \mathrm{O}_{2}\right)$, which corresponds to the overall oxygen pressure gradient. The straight lines that converge on the origin of the axes have a slope $(\Delta \mathrm{V} / \Delta \mathrm{P})$ that is equal to the overall conductance to oxygen of the respiratory system $(G)$. The modest $\dot{V} \mathrm{O}_{2 \max }$ decrease at moderate altitude, less than the corresponding $P_{\mathrm{I}} \mathrm{O}_{2}$ fall, is a consequence of the simultaneous increase in $G$ (decrease in resistance $R$ ), due to the effects of the shape of the oxygen equilibrium curve

In aerobic sport activities, the fall of $\dot{V} \mathrm{O}_{2 \max }$ in hypoxia generally affects performance negatively. A nice example of this is provided by the decline of aerobic performance at altitude, which follows a similar pattern to that of $\dot{V} \mathrm{O}_{2 \max }$ (Roi et al. 1999). At the Olympic Games in Mexico City in 1968, counter performances occurred in all long-distance 


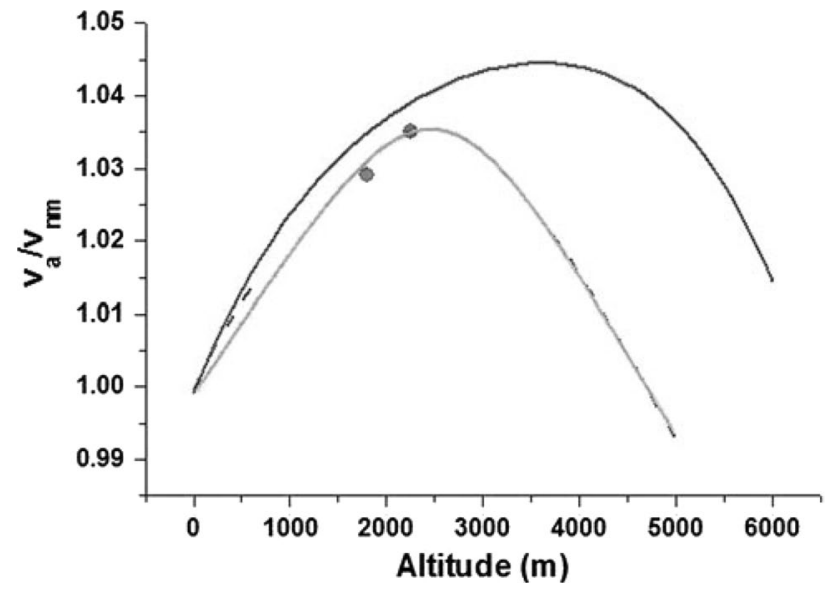

Fig. 9 Effects of altitude on the maximal cycling speed. Speed is expressed relative to the maximal speed at sea level, set equal to 1 $\left(v_{\mathrm{a}} / v_{\mathrm{nm}}\right.$, ordinate). The top curve represents the predictions made after di Prampero et al. (1979), based on the classical description of the $\dot{V} \mathrm{O}_{2 \max }$ decrease at altitude (Fig. 10). The lower curve modifies the previous prediction by accounting for the fact that athletes undergo greater $\dot{V} \mathrm{O}_{2 \max }$ decrease than non-athletes (Ferretti et al. 1997b), due to the Dempsey effect (Dempsey et al. 1984). The two points refer to the performances of the two athletes (Francesco Moser from Italy and Jeannie Longo from France) who in the eighties established world records of $1 \mathrm{~h}$ unaccompanied cycling on track at sea level and at altitude with equivalent bicycles. From Ferretti et al. (2011), who modified the figure after di Prampero (2000)

running races. Only exception is cycling, in which altitude affects performance in two opposite manners. On one side, we have a negative effect on performance related to the fall of $\dot{V} \mathrm{O}_{2 \max }$. On the other side, there is a positive effect on performance due to the reduction of air density, which reduces air resistance, and thus the energy cost of cycling. The latter effect is essentially linear, depending on barometric pressure and temperature; the former is nonlinear for the reasons explained above. The performance results from the balance of these two effects. Going up from sea level, because of the small decrease in $\dot{V} \mathrm{O}_{2 \text { max }}$ at relatively low altitude, the effect of air density prevails, and the maximal performance speed $\left(v_{\max }\right)$ increases. Going up further, as soon as the cyclist's blood operates on the steep part of the oxygen equilibrium curve, the decline of $\dot{V} \mathrm{O}_{2 \max }$ becomes more important than that of air density. As a consequence, the relationship between $v_{\max }$ and altitude, shown in Fig. 9, is such that, as altitude is increased, $v_{\max }$ firstly increases to reach a peak at a given altitude, above which it decreases (Capelli and di Prampero 1995; di Prampero 2000; di Prampero et al. 1979; Ferretti et al. 2011). Of the two curves reported in Fig. 9, one, established by di Prampero et al. (1979) after the $\dot{V} \mathrm{O}_{2 \max }$ versus altitude curve for ordinary people (see Fig. 8), identifies the optimal altitude for best performances in long-distance cycling on flat terrain at about 3,600 $\mathrm{m}$ above sea level. The other, constructed on

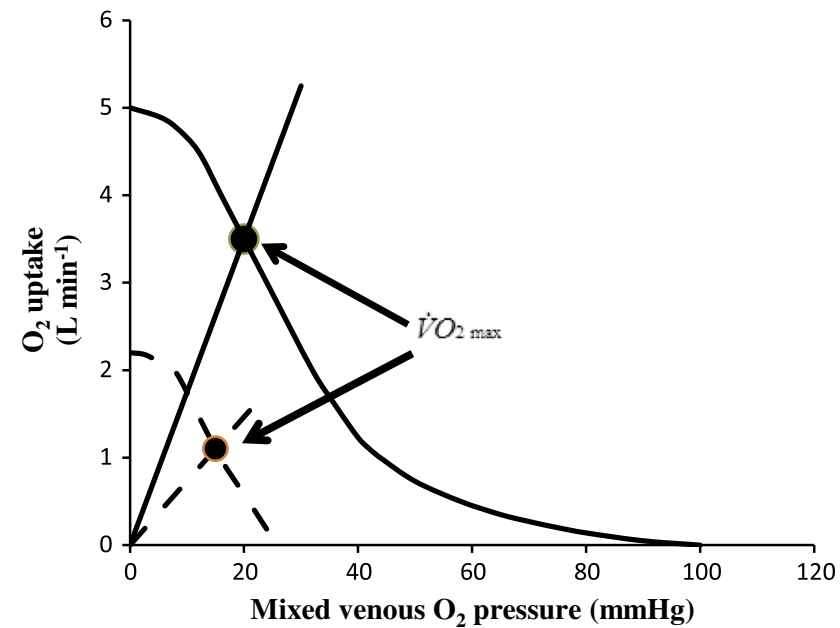

Fig. 10 Graphical representation of Wagner's model in hypoxia. Oxygen uptake $\left(\dot{V} \mathrm{O}_{2}\right)$ is plotted as a function of mixed venous oxygen pressure $\left(P_{\overline{\mathrm{V}}} \mathrm{O}_{2}\right)$. Continuous lines represent the convective curve and the diffusion line, as from Fig. 8. Dashed lines refer to the convective curve and the diffusion line in hypoxia. Concerning the convective curve in hypoxia, it lacks the flattening part on high $P_{\overline{\mathrm{v}}} \mathrm{O}_{2}$ values, because we operate exclusively of the steep part of the oxygen equilibrium curve. The diffusion line in hypoxia indicates the decrease in Wagner's constant $K_{\mathrm{w}}$. In normoxia, arterial oxygen partial pressure was assumed equal to $100 \mathrm{mmHg}$, and $P_{\overline{\mathrm{V}}} \mathrm{O}_{2}$ was assumed equal to $20 \mathrm{mmHg}$. The data of Operation Everest II were used for the changes in hypoxia (Wagner 2010)

the basis of the data reported by Ferretti et al. (1997b) for athletes who are subject to the Dempsey effect, predicts a peak for $v_{\max }$ at an altitude of about 2,200 m (di Prampero 2000). Actual performances of professional athletes, also reported in Fig. 9, fall on the latter curve.

The two multifactorial models of $\dot{V} \mathrm{O}_{2 \max }$ limitation appear to diverge in hypoxia, although this divergence depends only on the fact that Wagner keeps looking at the respiratory system distally to $P_{\mathrm{a}} \mathrm{O}_{2}$, whereas the holistic perspective of di Prampero's model led to integrate the effects of $R_{\mathrm{V}}$ and $R_{\mathrm{L}}$, which in hypoxia, contrary to normoxia, become limiting steps. In the graphical representation of Wagner's model, hypoxia implies a displacement downwards and leftwards of the convective curve, which lacks the flat part at high $P_{\overline{\mathrm{v}}} \mathrm{O}_{2}$, because it covers only the steep part of the oxygen equilibrium curve and intercepts the $\mathrm{x}$-axis at a lower value (Fig. 10). Using data from Operation Everest II, Wagner (1996b) demonstrated that in hypoxia it makes no difference in considering the oxygen equilibrium curve linear rather than nonlinear, providing a sound theoretical basis for a linear convective curve in deep hypoxia in the $P_{\mathrm{a}} \mathrm{O}_{2}-P_{\overline{\mathrm{v}}} \mathrm{O}_{2}$ pressure range. Similar results were obtained also in acute hypoxia (Roca et al. 1989). If we accept the concept of a linear oxygen equilibrium curve, and thus of an invariant $\beta_{\mathrm{b}}$, in di Prampero's model we would obtain: 
$F_{\mathrm{Q}}=\frac{\dot{V} \mathrm{O}_{2 \max }}{\dot{Q}_{\mathrm{a}} \mathrm{O}_{2 \max }} \cdot \frac{P_{\mathrm{a}} \mathrm{O}_{2}}{P_{\mathrm{I}} \mathrm{O}_{2}}$

If we solve Eq. (34) using the data of Operation Everest II reported by Wagner (1996b), we get $F_{\mathrm{Q}}=0.19$, a value very close to the theoretical value of 0.20 obtained by Ferretti and di Prampero (1995) in their simulation with di Prampero's model. On the other hand, we would have:

$F_{\mathrm{p}}=\left(1-\frac{\dot{V} \mathrm{O}_{2 \max }}{\dot{Q}_{\mathrm{a}} \mathrm{O}_{2 \max }}\right) \cdot \frac{P_{\mathrm{a}} \mathrm{O}_{2}}{P_{\mathrm{I}} \mathrm{O}_{2}}$

whence, using the same data, $F_{\mathrm{p}}=0.22$. Wagner (1996b) pointed out the predominance of the peripheral diffusing component in setting $\dot{V} \mathrm{O}_{2 \max }$ variations as a consequence of acute manoeuvres in extreme hypoxia. This viewpoint is substantiated by the present analysis in the context of di Prampero's model.

\section{Of maximal oxygen consumption at the end of bed rest}

Bed rest without countermeasures is an excellent, wellcontrolled adaptive condition in which the entire respiratory system undergoes functional adaptations entailing a change in $\dot{V} \mathrm{O}_{2 \max }$. It is generally recognized that $\dot{V} \mathrm{O}_{2 \max }$ decreases after bed rest (Bringard et al. 2010; Capelli et al. 2006; Convertino et al. 1982, 1986; Ferretti et al. 1997a; Friman 1979; Greenleaf et al. 1989; Kashihara et al. 1994; Lee et al. 2007, 2009; Mekjavic et al. 2005; Saltin et al. 1968; Stremel et al. 1976; Trappe et al. 2006). The decrease appears also after very short bed rest duration (Smorawinski et al. 2001). The size of the $\dot{V} \mathrm{O}_{2 \max }$ decrease is larger the longer is the bed rest duration (Capelli et al. 2006). It is generally implicit that these statements apply to $\dot{V} \mathrm{O}_{2 \max }$ measurements carried out in upright posture shortly after the end of the bed rest period. During bed rest (or space flight) or in supine posture after bed rest, things are remarkably different, as long as no changes, or very small changes, in $\dot{V} \mathrm{O}_{2 \max }$ were found (Bringard et al. 2010; Greenleaf et al. 1989; Levine et al. 1996; Trappe et al. 2006).

From an analysis of data obtained in upright posture after bed rests lasting 7-30 days, Convertino (1996) proposed a linear decrease of $\dot{V} \mathrm{O}_{2 \max }$ as a function of bed rest duration, at a rate of about $1 \%$ per day. At such a rate of decline, however, $\dot{V} \mathrm{O}_{2 \max }$ would reach zero (100\% loss) within 4 months in bed. Yet space missions inside the International Space Station last 6 months, and the exercise capacity of Astronauts in upright posture upon return, although greatly reduced, is not that much impaired. This suggests that the $\dot{V} \mathrm{O}_{2 \max }$ decrease after bed rest is rapid in the first days, and then it slows down as long as bed rest proceeds. In other terms, the change in $\dot{V} \mathrm{O}_{2 \max }$ in upright posture at the end of bed rest, as a function of bed rest duration, cannot be linear, but must tend to an asymptote.

In bed rest programmes, which Space Agencies often organize as a simulation tool to investigate microgravity effects on Astronauts, if no countermeasures are applied, only the duration of the bed rest period varies among studies, making transversal comparisons from different studies particularly efficient. Thus, for an evaluation of the time courses of alterations of physiological variables, bed rest is a better experimental tool than training, for which there is no standardization of protocols. The time course of $\dot{V} \mathrm{O}_{2 \max }$ changes in upright posture at the end of head-down tilt bed rest without countermeasures is shown in Fig. 11. The assumption behind the construction of Fig. 11 is that the decay of $\dot{V} \mathrm{O}_{2 \max }$ after bed rest, tending to an asymptote, follows exponential patterns. Thus, if the change in $\dot{V} \mathrm{O}_{2 \max }$ is expressed in logarithmic form, as done in the bottom panel of Fig. 11 (Ferretti and Capelli 2009), the relationship between $\dot{V} \mathrm{O}_{2 \max }$ change and time of bed rest would become linear, with slope corresponding to the velocity constant of the exponential decay. The bottom panel of Fig. 11 allows clear identification of two components in the $\dot{V} \mathrm{O}_{2 \max }$ decline with bed rest. The algebraic formulation of the $\dot{V} \mathrm{O}_{2 \max }$ decline with bed rest would then take the following form:

$\dot{V} \mathrm{O}_{2 \max }=\dot{V} \mathrm{O}_{2 \max } \cdot\left(e^{-k_{1} \cdot t}+e^{-k_{2} \cdot t}\right)$

where $k_{1}$ and $k_{2}$ are the velocity constants of the two components of the $\dot{V} \mathrm{O}_{2 \max }$ decrease. The lines reported in Fig. 11 are regression lines calculated for bed rests lasting less than 20 days and longer than 20 days, respectively. The calculated slopes of the two lines show that $k_{1}$ is equal to $0.083 \mathrm{day}^{-1}$, whereas $k_{2}$ corresponds to 0.0098 day $^{-1}$. The corresponding time constants were equal to 8.4 and 70.7 days, respectively.

Figure 11 suggests that the distal part of respiratory system, from arterial blood to the mitochondria, may consist of two capacitances of different size connected in series. When an adaptive change takes place on the overall system, the effects on the smaller capacitance would prevail first, imposing a rapid change in $\dot{V} \mathrm{O}_{2 \max }$ already in the first days, but it would reach its asymptote soon, within one month in this case. This does not imply a steady $\dot{V} \mathrm{O}_{2 \max }$ value, because the second, larger capacitance takes over imposing a further, though slower, $\dot{V} \mathrm{O}_{2 \max }$ decline. It was postulated that (Ferretti and Capelli 2009) the fast component of the $\dot{V} \mathrm{O}_{2 \max }$ max decrease in upright posture after bed rest is due to changes in $R_{\mathrm{Q}}$, and thus to the reduction of $\dot{Q}_{\mathrm{a}} \mathrm{O}_{2 \max }$, whereas the slow component is a consequence of changes in $R_{\mathrm{p}}$, and thus follows the development of muscle hypotrophy. Concerning $R_{\mathrm{Q}}$, it is noteworthy that the decrease of $\dot{Q}$ at maximal exercise after bed rest appears 

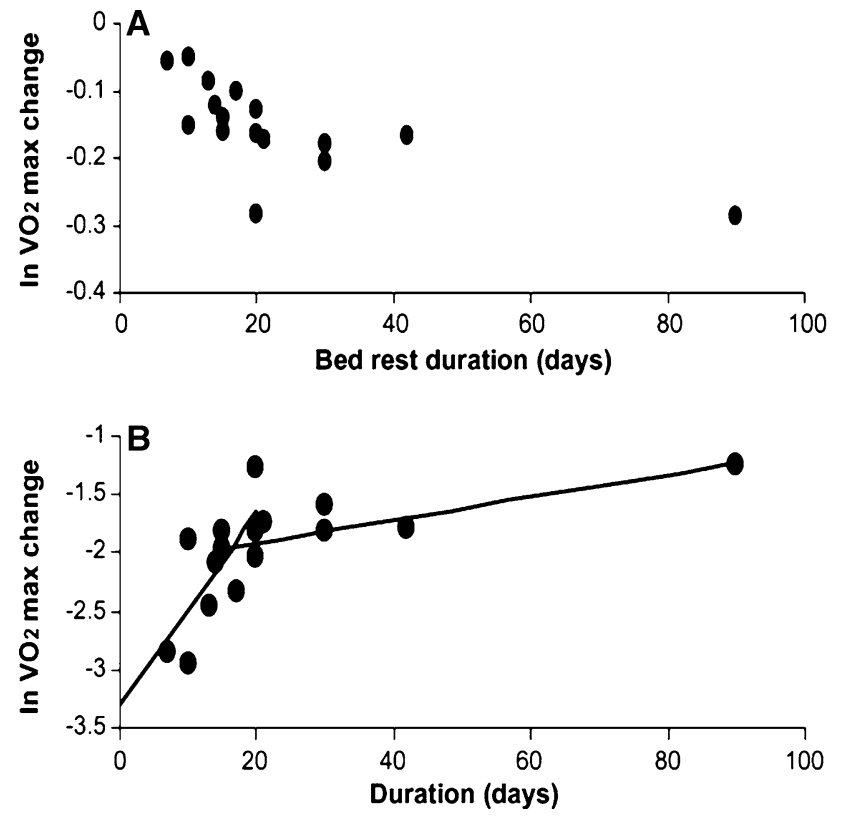

Fig. 11 Top panel The change in maximal oxygen consumption $\left(\dot{V} \mathrm{O}_{2 \max }\right)$ in upright posture, at the end of bed rest or space flight, is expressed as the absolute change in $\dot{V} \mathrm{O}_{2 \max }$ with respect to the corresponding prebed rest value, and plotted as a function of bed rest duration. Bottom panel Same as on top, except that the change in $\dot{V} \mathrm{O}_{2 \max }$ is expressed in logarithmic form. The lines are regression lines calculated for bed rests lasting less than 20 days and longer than 20 days, respectively. The slopes of the two lines indicate the velocity constant of the rapid $\left(0.083\right.$ day $\left.^{-1}\right)$ and the slow $\left(0.0098\right.$ day $\left.^{-1}\right)$ components of the $\dot{V} \mathrm{O}_{2 \max }$ decrease. The corresponding time constants are 8.4 and 70.7 days, respectively. From Ferretti and Capelli (2009)

to be complete within 15 days. Concerning $R_{\mathrm{p}}$, an analysis of muscle cross-sectional area from different sources in the literature indicates a time constant of decay similar to that of the slow component of the $\dot{V} \mathrm{O}_{2 \max }$ decrease (Capelli et al. 2006). This does not imply that the effects of muscle mass reduction do not intervene since the first days in bed, but since they are slow and relatively small, they are not visible in short-term bed rest, being overcome by the more rapid cardiovascular changes.

Most of the studies used for the construction of Fig. 11 concerned measurements carried out at least three days after the end of bed rest, at a time when recovery of cardiovascular function is already taking place (Spaak et al. 2005). This means that there might have been an underestimate of the amplitude of the rapid component of the $\dot{V} \mathrm{O}_{2 \max }$ decline, which might have had an impact especially in bed rests of short duration. The only exceptions, to my knowledge, were the studies by Bringard et al. (2010) and Lee et al. (2007, 2009), with measurements carried out on the day of reambulation. In Fig. 11, the points from these studies lie within those from other studies, but the bed rest duration was 35 and 30 days, respectively, with already significant impact of the slow component of the $\dot{V} \mathrm{O}_{2 \max }$ decline.

Similar results in upright posture were reported, upon return from a 17-day space flight, by Levine et al. (1996), who conversely found no changes in $\dot{V} \mathrm{O}_{2 \max }$ on the same subjects in space. They attributed the $\dot{V} \mathrm{O}_{2 \max }$ decline observed in upright posture upon return to the effects of sudden blood volume redistribution after gravity resumption, which are enhanced in Astronauts who underwent cardiovascular adaptation to microgravity. I would add that this is the case also after bed rest. The data of Levine et al. (1996), however, were obtained at the end of a space flight, the duration of which was barely too short to evidence the effects of the slow component of the $\dot{V} \mathrm{O}_{2 \max }$ decline, related to muscle hypotrophy. This component in fact was already visible, after the same time, in the study by Trappe et al. (2006) in space and in supine posture after bed rest.

Bringard et al. (2010) found a $44 \%$ reduction of stroke volume at maximal exercise in upright posture after 35-day bed rest as compared to the value before bed rest with no modification in maximal heart rate, which entailed a $45 \%$ decrease in maximal $\dot{Q}$. This, associated with a $13 \%$ increase in $C_{\mathrm{a}} \mathrm{O}_{2}$ due to higher haemoglobin concentration, resulted in a $38 \%$ decrease in $\dot{Q}_{\mathrm{a}} \mathrm{O}_{2 \max }$. On the contrary, no changes in maximal $\dot{Q}$ were observed in supine posture on the same subjects after bed rest, so that there was a slight, though nonsignificant, increase in $\dot{Q}_{\mathrm{a}} \mathrm{O}_{2 \max }$. As a consequence, after bed rest, $\dot{Q}_{\mathrm{a}} \mathrm{O}_{2 \max }$ was $56 \%$ lower, with $R_{\mathrm{Q}} 78 \%$ higher, upright than supine. Thus, an acute postural change from supine to upright would entail a $\dot{V} \mathrm{O}_{2 \max }$ decrease only due to changes in $R_{\mathrm{Q}}$. Nevertheless, we note that the $\dot{V} \mathrm{O}_{2 \max }$ supine was $17 \%$ lower after than before bed rest, similar to what was found in a previous study in the same posture after comparable bed rest duration (Greenleaf et al. 1989), a finding that can be attributed to the development of muscle hypotrophy, with associated increase in $R_{\mathrm{p}}$, and thus to the effects of the slow component of the after bed rest.

Figure 12 is a derivation of Fig. 4 specifically constructed for the case of prolonged bed rest, using the data of Bringard et al. (2010). The continuous line in Fig. 12 is the regression line from Fig. 4. The open dots lying on it refer to the acute manoeuvre of changing posture from supine to upright, before and after bed rest. The full dots lying above it refer to the overall effect of bed rest, in supine-lower left point—and upright—upper right point—posture. The upwards shift of open points with respect to the filled points in Fig. 12 is the same for both postures: the factor that caused the $\dot{V} \mathrm{O}_{2 \max }$ decrease supine after bed rest acted by the same extent upright and supine. This indicates that this factor is independent of the postural change, being related to a chronic adaptive change that took place during the bed 


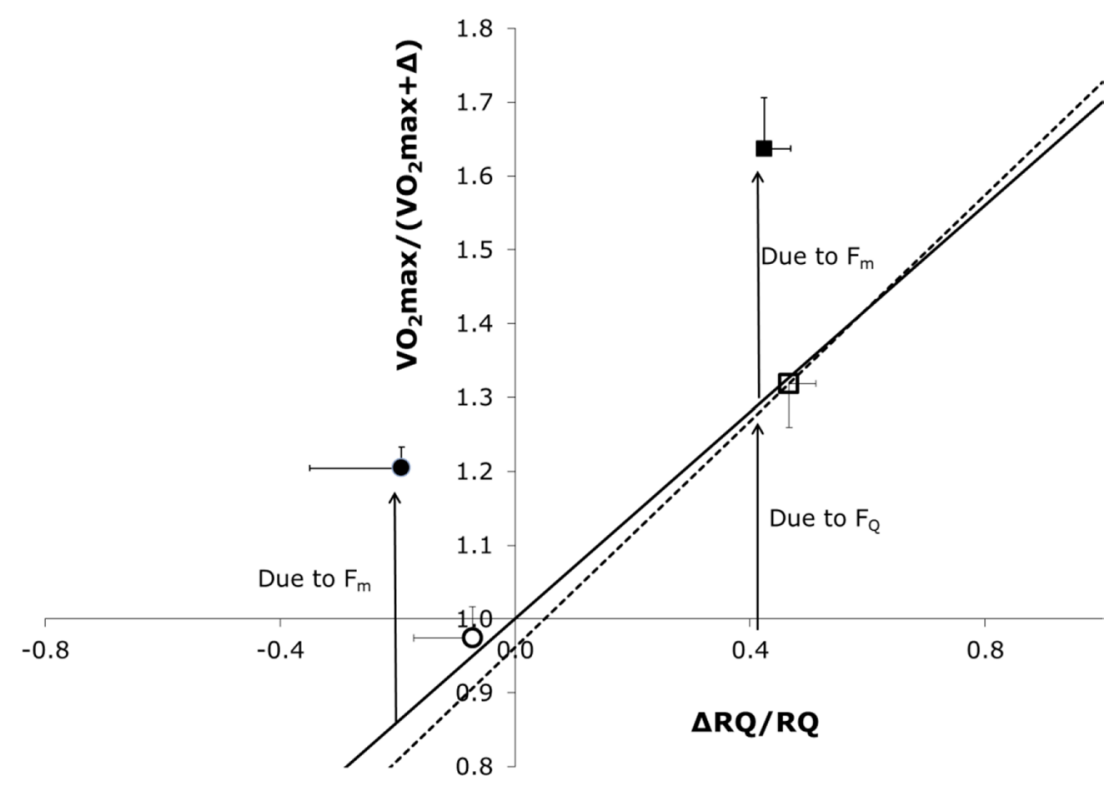

Fig. 12 The ratio between maximal oxygen consumption $\left(\dot{V} \mathrm{O}_{2 \max }\right)$ before and after a given manoeuvre $\left[\dot{V} \mathrm{O}_{2 \max } /\left(\dot{V} \mathrm{O}_{2 \max }+\Delta\right)\right]$ is reported as a function of the relative change in the cardiovascular resistance to oxygen flow $\left(\Delta \mathrm{R}_{\mathrm{Q}} / R_{\mathrm{Q}}\right.$, $\mathrm{x}$-axis). The continuous line, with a slope of 0.7, is theoretical and is taken from di Prampero and Ferretti (1990). The open symbols refer to the effects of postural changes (from supine to upright) before (open dot) and after (open square) bed rest. The dashed line is experimental and represents the regression equation calculated from the individual data of Bringard et al. (2010) after bed rest $(y=0.76 x+0.96)$. The slope of the experimental line was not significantly different from that of the theoretical line. The y-intercept of the experimental line was not significantly different from 1 . The filled symbols, located well above the experimental line, refer to the effects of bed rest in supine (filled dot) and upright (filled square). Error bars indicate standard error. The arrows evidence the effect on $\dot{V} \mathrm{O}_{2 \max }$ due to cardiovascular $\left(F_{\mathrm{Q}}\right)$ and peripheral $\left(F_{\mathrm{p}}\right) \dot{V} \mathrm{O}_{2 \max }$ limitation rest period. According to Bringard et al. (2010), the upwards shift of open points represents the effects of a change in $R_{\mathrm{p}}$ consequent to the development of muscle hypotrophy. In the context of Wagner's model, the increase in $R_{\mathrm{p}}$ due to muscle hypotrophy is represented by a decrease in the slope of the diffusion line, the cardiovascular effect is represented by the downwards shift of the $\dot{Q}_{\mathrm{a}} \mathrm{O}_{2}$ point, with consequent change in the slope of the convective curve (Fig. 13). The results of Figs. 12 and 13 reinforce the concept of the dual component of the $\dot{V} \mathrm{O}_{2 \max }$ decrease after bed rest. However, this does not necessarily imply that $F_{\mathrm{Q}}$ after bed rest be different from before bed rest, although I would tend to predict that, after the adaptation of the cardiovascular system has attained its steady state, $F_{\mathrm{Q}}$ would become lower and $F_{\mathrm{p}}$ higher, the longer would be the bed rest duration.

Training entails effects opposite to those of bed rest in Wagner's model. In fact, the observed $\dot{V} \mathrm{O}_{2 \max }$ increase with training is accompanied by an increase in $\dot{Q}_{\max }$ and $\dot{Q}_{\mathrm{a}} \mathrm{O}_{2 \max }$, as well as in muscle capillary density and muscle mitochondrial volume, as detailed in the section "Descriptive physiology of $\dot{V} \mathrm{O}_{2 \max }$ ". The former cardiovascular changes displace the $\dot{Q}_{\mathrm{a}} \mathrm{O}_{2}$ point of the convective curve upwards, so that its slope becomes steeper. The latter muscular changes increase $k_{\mathrm{w}}$. Thus, the effects of training would modify the curves of Wagner's plot in the opposite direction with respect to the changes induced by bed rest, by an amount that would depend on the characteristics of the training protocol. Unfortunately, as already pointed out, training protocols in physiological studies are not standardized: so many training protocols were proposed, differing in intensity, exercise type, modality of power administration, that transversal analyses as those carried out for bed rest are virtually impossible.

\section{Of the steady state assumption}

In quantitative analyses of $\dot{V} \mathrm{O}_{2 \max }$ limitation, a steady state at maximal exercise is generally assumed. This was the case for the development of the two models analysed in this paper. This assumption has clear computational advantages, for it allows utilization of simple, well-established equations, yet we must be aware that it is an oversimplification. When I state this, I do not think about the effects of the slow component of the $\dot{V} \mathrm{O}_{2}$ on- kinetics: the slow component appears below $\dot{w}_{\max }$, and the $\dot{V} \mathrm{O}_{2}$ increase stops as $\dot{V} \mathrm{O}_{2 \max }$ has been attained. The statement refers to oxygen flow discontinuities, heterogeneities and spontaneous variations, depending on the macroscopic and microscopic organization of the respiratory system. 


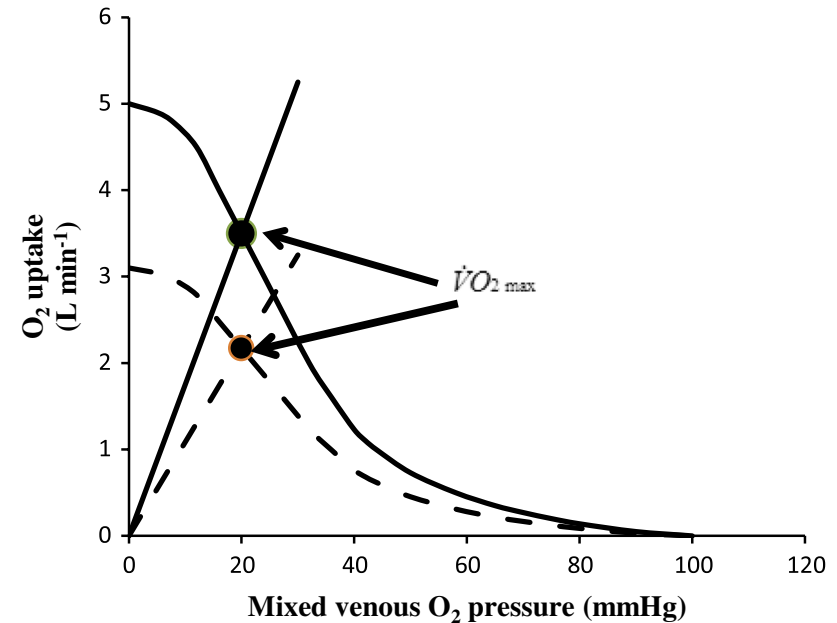

Fig. 13 The effects of bed rest are represented on Wagner's model. Oxygen uptake $\left(\dot{V} \mathrm{O}_{2}\right)$ is plotted as a function of mixed venous oxygen pressure $\left(P_{\overline{\mathrm{v}}} \mathrm{O}_{2}\right)$. Continuous lines represent the convective curve and the diffusion line, as from Fig. 8. Dashed lines refer to the convective curve and the diffusion line after bed rest in upright posture. Concerning the convective curves, the one after bed rest is flatter than the one before bed rest, because of the dramatic decrease in arterial oxygen flow after bed rest. The diffusion line after bed rest indicates the decrease of Wagner's constant $K_{\mathrm{w}}$, due to the development of muscle hypotrophy. The relative changes in cardiac output and muscle mitochondrial volume density reported by Ferretti et al. (1997a) after 42 days of head-down tilt bed rest without countermeasures have been used as reference for the modification of the convective curve and of the diffusion line. Arterial oxygen partial pressure was assumed unchanged and equal to $100 \mathrm{mmHg}$. The $P_{\overline{\mathrm{v}}} \mathrm{O}_{2}$ in the control condition was assumed equal to $20 \mathrm{mmHg}$

From the macroscopic viewpoint, one should not forget that ventilation occurs in a dead-end system, so that inhalation and exhalation occur necessarily in alternate manner. Moreover, the heart alternates systole and diastole, with alternate opening and closing of heart valves. Both mechanisms are sources of discontinuities, the former in air flow, the latter in blood flow, both in oxygen flow. Moreover, there is a spontaneous variability of respiratory and cardiac rhythms, related to mechanical and neural control mechanisms (Cottin et al. 2008; Perini and Veicsteinas 2003). In such conditions, the steady state oxygen flow cannot be considered as a continuous invariant flow, but as the integral mean of a highly variable, at several levels discontinuous, flow in time.

From the microscopic viewpoint, I remark that the blood flow at the lung capillary level is pulsatile, because of oscillations in capillary pressure related to the rhythmic activity of the heart and the lungs and the heterogeneous recruitment of lung capillaries (Baumgartner et al. 2003; Clark et al. 2011; Tanabe et al. 1998). This heterogeneity, however, may be reduced during exercise due to simultaneous recruitment of a larger number of lung capillaries. Similar heterogeneities, both in space and in time, have been demonstrated also in skeletal muscles, at rest and during contraction (Armstrong et al. 1987; Ellis et al. 1994; Heinonen et al. 2007; Kalliokoski et al. 2004; Marconi et al. 1988; Piiper et al. 1985). Heterogeneous muscle blood flow was found also in non-contracting muscles of exercising humans (Heinonen et al. 2012). Since contracting muscle fibres generate pressure, which compresses and closes muscle capillaries from outside, it is logical to speculate that contracting muscle fibres are unperfused and relaxing muscle fibres are perfused. If this is so, muscle fibre oxygenation occurs during relaxation, not during contraction, so that alternate recruitment of neighbouring motor units is a functional necessity, the inevitable consequence of which is heterogeneity of muscle blood flow distribution during muscular work. Wagner's constant $k_{\mathrm{w}}$ and peripheral resistance $R_{\mathrm{p}}$ at steady state are mean parameters applying to the whole active muscle mass, the local value of which at the muscle fibre level varies instantaneously and continuously in space and time.

\section{Conclusions}

This review is a critical analysis of the theoretical and experimental pathways that led to the conception and development of multifactorial models of $\dot{V} \mathrm{O}_{2 \text { max }}$ limitation. In the same theoretical context, two minds, grown inside different schools, afforded the problem from apparently different perspectives. This ended in the generation of two sets of equations, defining mechanistic models, both capable of explaining several aspects of $\dot{V} \mathrm{O}_{2 \max }$ limitation, often the same. These sets of equations competed for years, although they were pointing to the same direction. In fact, they were formulations of the same concepts in different terms. A statement like "cardiovascular oxygen transport provides $70 \%$ of the overall limitation to $\dot{V} \mathrm{O}_{2 \max }$ " implies that the crossing of the diffusion line with the convective curve of Fig. 6 necessarily occurs only at one precise point on a Cartesian plane, the point on the convective curve where the ratio between $\dot{V} \mathrm{O}_{2 \max }$ and $\dot{Q}_{\mathrm{a}} \mathrm{O}_{2 \max }$ is equal to 0.7 .

In hypoxia, where also the lungs become limiting, Wagner remained concentrated on the interactions between perfusion and diffusion downstream from the lungs, thus distal to arterial blood, whereas di Prampero tried to include $R_{\mathrm{V}}$ and $R_{\mathrm{L}}$ in the analysis. The consequence was a diminution of $F_{\mathrm{Q}}$ from 0.7 in normoxia to 0.2 at a $P_{\mathrm{I}} \mathrm{O}_{2}$ of $90 \mathrm{mmHg}$ (Ferretti and di Prampero 1995), so that $F_{\mathrm{Q}}$ became much lower than the $\dot{V} \mathrm{O}_{2 \max } \dot{Q}_{\mathrm{a}} \mathrm{O}_{2 \max }$ ratio. This may seem a holistic expansion of the model, but this is only partly true: the model remains the same, but Ferretti and di Prampero (1995) tried a speculative analysis which Wagner (1996a) refrained to do and perhaps wisely enough. In fact, there is an unresolved passage, that of the quantitative integration 
of the effects of $\dot{V}_{\mathrm{A}} / \dot{Q}$ heterogeneity on $R_{\mathrm{L}}$ and $F_{\mathrm{L}}$, at least in hypoxia. Ferretti and di Prampero (1995) circumvented the problem by creating a lumped conductance term for the alveolar-arterial step, which was assumed proportional to $D_{\mathrm{L}}$, although this is an oversimplification.

No other mechanistic models of $\dot{V} \mathrm{O}_{2 \max }$ limitation were created after the two models discussed in this review. Nevertheless, wide success had a kind of psychological model of the subject of $\dot{V} \mathrm{O}_{2 \max }$ limitation, generally known as the central governor hypothesis (Noakes 1998; Noakes et al. 2001). This hypothesis has the advantage of simplicity, as compared to the multifactorial models, and gained appeal by selling itself as an example of modernity, for its attempt at integrating the brain as a modulator of the entire system. In fact, its lack of quantitative analysis of mechanistic functional events undermines its epistemological value. In spite of this, the central governor hypothesis could be subjected to experimental testing (Brink-Elfegoun et al. 2007; Elliott et al. 2013) and confuted. These authors in fact demonstrated the possibility of increasing the work of the heart beyond the limits attained at maximal exercise, without any further increase in $\dot{V} \mathrm{O}_{2 \max }$, contrary to the central governor hypothesis, which predicts that $\dot{V} \mathrm{O}_{2 \max }$ would increase as long as the central governor (the brain) allows an increase in heart functional variables. It is noteworthy that Elliott et al. (2013) refused to admit refutation of this hypothesis, although they recognized the experimental evidence as a matter of fact. Indeed, the central governor hypothesis is still so deeply rooted in the debate within the exercise science community that I cannot refrain from at least mentioning it.

To sum up, I would say that the classical concept of cardiovascular $\dot{V} \mathrm{O}_{2 \max }$ limitation is reinforced by the multifactorial models, showing that cardiovascular oxygen transport-systemic or muscle oxygen delivery-provides most of the limitation to oxygen flow at maximal exercise, at least in normoxia. However, the same models show that the role of peripheral oxygen diffusion and utilization as limiting factors is such that it cannot be neglected. The role of peripheral factors is greater the smaller is the active muscle mass. In hypoxia, the progressive intervention of lung oxygen flow as a limiting factor restricts the role played by cardiovascular and muscular factors. Moreover, the balance between them is changed in favour of a greater role of peripheral factors. As a consequence, $F_{\mathrm{Q}}$ in hypoxia turns out drastically reduced.

Acknowledgments This work was supported by Swiss National Science Foundation Grant 32003B_143427, Switzerland, and by the Health\&Wealth@Unibs strategic plan, University of Brescia, Italy. I thank all the friends and colleagues with whom I had joyful and enriching discussions on the matters treated in this review, all the collaborators from Brescia and Geneva who had been involved in the 20 -year-long experimental work supporting this paper. My admiration goes to Pietro Enrico di Prampero and Peter Wagner, who demonstrated so vividly that research consists mainly of innovative thinking, and who traced the way along which I have been walking.

\section{References}

Adami A, Sivieri A, Moia C, Perini R, Ferretti G (2013) Effects of step duration in incremental ramp protocols on peak power and maximal oxygen consumption. Eur J Appl Physiol 113:2647-2653

Aghemo P, Piñera-Limas F, Sassi G (1971) Maximal aerobic power in primitive Indians. Int $Z$ angew Physiol 29:337-342

Amann M, Subudhi A, Foster C (2004) Influence of testing protocol on ventilatory thresholds and cycling performance. Med Sci Sports Exerc 36:613-622

Andersen P, Henriksson J (1977) Capillary supply of the quadriceps skeletal muscle of man: adaptive response to exercise. J Physiol 270:677-690

Andersen P, Saltin B (1985) Maximal perfusion of skeletal muscle in man. J Physiol 366:233-249

Andersen KL, Bolstad A, Loyning A, Irving L (1960) Physical fitness of arctic Indians. J Appl Physiol 15:645-648

Armstrong RB, Delp MD, Goljan MF, Laughlin MH (1987) Distribution of blood flow in muscles of miniature swine during exercise. J Appl Physiol 62:1285-1298

Aspenes ST, Nilsen TI, Skaug EA, Bertheussen GF, Ellingsen Ø, Vatten L, Wisløff U (2011) Peak oxygen uptake and cardiovascular risk factors in 4631 healthy women and men. Med Sci Sports Exerc 43:1465-1473

Astorino TA, Allen RP, Roberson DW, Jurancich M (2012) Effect of high-intensity interval training on cardiovascular function, $\dot{V} \mathrm{O}_{2 \max }$, and muscular force. J Strength Cond Res 26:398-407

Åstrand PO (1955) New records in human power. Nature 176:922-923

Åstrand PO (1956) Human physical fitness with special reference to sex and age. Physiol Rev 36:307-335

Åstrand I (1960) Aerobic work capacity in men and women with special reference to age. Acta Physiol Scand Suppl 169:1-92

Åstrand PO, Saltin B (1961) Maximal oxygen uptake and heart rate in various types of muscular activity. J Appl Physiol 16:977-981

Åstrand PO, Rodahl K, Dahl HA, Strømme SB (2003) Textbook of work physiology. Physiological bases of exercise, 4th ed., Human Kinetics, Champaign

Audran M, Gareau R, Matecki S, Durand F, Chenard C, Sicart M, Marion B, Bressolle F (1999) Effects of erythropoietin administration in training athletes and possible indirect detection in doping control. Med Sci Sports Exerc 31:639-645

Bailey SJ, Romer LM, Kelly J, Wilkerson DP, DiMenna FJ, Jones AM (2010) Inspiratory muscle training enhances pulmonary $\mathrm{O}_{2}$ uptake kinetics and high-intensity exercise tolerance in humans. J Appl Physiol 109:457-468

Bannister RG, Cunningham DJC (1954) The effects on the respiration and performance during exercise of adding oxygen to the inspired air. J Physiol 125:118-137

Baumgartner WA Jr, Jaryszak EM, Peterson AJ, Presson RG Jr, Wagner WW Jr (2003) Heterogeneous capillary recruitment among adjoining alveoli. J Appl Physiol 95:469-476

Benoit H, Busso T, Castells J, Denis C, Geyssant A (1995) Influence of hypoxic ventilatory response on arterial $\mathrm{O}_{2}$ saturation during maximal exercise in acute hypoxia. Eur J Appl Physiol 72:101-105

Berg HE, Dudley GA, Hather B, Tesch PA (1993) Work capacity and metabolic and morphologic characteristics of the human quadriceps muscle in response to unloading. Clin Physiol 13:337-347 
Bergh U, Ekblom B (1979) Physical performance and peak aerobic power at different body temperatures. J Appl Physiol $46: 885-889$

Bergh U, Kanstrup IL, Ekblom B (1976) Maximal oxygen uptake during exercise with various combinations of arm and leg work. $\mathrm{J}$ Appl Physiol 41:191-196

Berglund B, Ekblom B (1991) Effect of recombinant human erythropoietin treatment on blood pressure and some haematological parameters in healthy men. J Intern Med 229:125-130

Berglund B, Hemmingsson P (1987) Effect of reinfusion of autologous blood in cross-country skiers. Int J Sports Med 8:231-233

Billat V, Lepretre PM, Heugas AM, Laurence MH, Salim D, Koralsztein JP (2003) Training and bioenergetic characteristics in elite male and female Kenyan runners. Med Sci Sports Exerc 35:297-304

Blomqvist CG, Saltin B (1983) Cardiovascular adaptations to physical training. Annu Rev Physiol 45:169-189

Booth FW (1982) Effect of limb immobilization on skeletal muscle. J Appl Physiol 52:1113-1118

Booth FW, Roberts CK, Laye MJ (2012) Lack of exercise is a major cause of chronic diseases. Compr Physiol 2:1143-1211

Bosch AN, Goslin BR, Noakes TD, Dennis SC (1990) Physiological differences between black and white runners during a treadmill marathon. Eur J Appl Physiol 61:68-72

Bouchard C (2012) Genomic predictors of trainability. Exp Physiol 97:347-352

Bouchard C, An P, Rice T, Skinner JS, Wilmore JH, Gagnon J, Pérusse L, Leon AS, Rao DC (1999) Familial aggregation of $\dot{V} \mathrm{O}_{2 \max }$ response to exercise training: results from the HERITAGE Family Study. J Appl Physiol 87:1003-1008

Bouchard C, Rankinen T, Timmons JA (2011a) Genomics and genetics in the biology of adaptation to exercise. Compr Physiol 1:1603-1648

Bouchard C, Sarzynski MA, Rice TK, Kraus WE, Church TS, Sung YJ, Rao DC, Rankinen T (2011b) Genomic predictors of the maximal $\mathrm{O}_{2}$ uptake response to standardized exercise training programs. J Appl Physiol 110:1160-1170

Breil FA, Weber SN, Koller S, Hoppeler H, Vogt M (2010) Block training periodization in alpine skiing: effects of 11-day HIT on VO2max and performance. Eur J Appl Physiol 109:1077-1086

Bringard A, Pogliaghi S, Adami A, De Roia G, Lador F, Lucini D, Pizzinelli P, Capelli C, Ferretti G (2010) Cardiovascular determinants of maximal oxygen consumption in upright and supine posture at the end of prolonged bed rest in humans. Respir Physiol Neurobiol 172:53-62

Brink-Elfegoun T, Kaijser L, Gustafsson T, Ekblom B (2007) Maximal oxygen uptake is not limited by a central nervous system governor. J Appl Physiol 102:781-786

Brodal P, Ingjer F, Hermansen L (1977) Capillary supply of skeletal muscle fibers in untrained and endurance-trained men. Am $\mathrm{J}$ Physiol Heart Circ Physiol 232:H705-H712

Brooks GA (1985) Anaerobic threshold: review of the concept and directions for future research. Med Sci Sports Exerc 17:22-31

Buchfuhrer MJ, Hansen JE, Robinson TE, Sue DY, Wasserman K, Whipp BJ (1983) Optimizing the exercise protocol for cardiopulmonary assessment. J Appl Physiol 55:1558-1564

Buick FJ, Gledhill N, Froese AB, Spriet LL, Meyers EC (1980) Effect of induced erythrocythemia on aerobic work capacity. J Appl Physiol 48:636-642

Burnley M, Roberts C, Thatcher R, Doust JH (2006) Influence of blood donation on $\mathrm{O}_{2}$ uptake on-kinetics, peak $\mathrm{O}_{2}$ uptake and time to exhaustion during severe-intensity exercise. Exp Physiol 91:499-509

Burtscher M, Nachbauer W, Wilber R (2011) The upper limit of aerobic power in humans. Eur J Appl Physiol 111:2625-2628
Buskirk ER, Hodgson JL (1987) Age and aerobic power: the rate of change in men and women. Fed Proc 46:1824-1829

Calbet JAL, Jensen-Urstad M, Van Hall G, Holmberg HC, Rosdahl H, Saltin B (2004) Maximal muscular vascular conductances during whole body upright exercise in humans. J Physiol 558:319-331

Calbet JA, Gonzalez-Alonso J, Helge JW, Søndergaard H, MunchAndersen T, Boushel R, Saltin B (2007) Cardiac output and leg and arm blood flow during incremental exercise to exhaustion on the cycle ergometer. J Appl Physiol 103:969-978

Calbet JAL, Rådegran G, Boushel R, Saltin (2009) On the mechanisms that limit oxygen uptake during exercise in acute and chronic hypoxia: role of muscle mass. J Physiol 587:477-490

Camus G, Atchou G, Bruckner JC, Giezendanner D, di Prampero PE (1988) Slow upward drift of $\dot{V} \mathrm{O}_{2}$ during constant-load cycling in untrained subjects. Eur J Appl Physiol 58:197-202

Capelli C, di Prampero PE (1995) Effects of altitude on top speeds during $1 \mathrm{~h}$ unaccompanied cycling. Eur J Appl Physiol 71:469-471

Capelli C, Schena F, Zamparo P, Dal Monte A, Faina M, di Prampero PE (1998) Energetics of best performances in track cycling. Med Sci Sports Exerc 30:614-624

Capelli C, Antonutto G, Azabji-Kenfack M, Cautero M, Lador F, Moia C, Tam E, Ferretti G (2006) Factors determining the time course of $\dot{V} \mathrm{O}_{2 \max }$ decay during bedrest: implications for $\dot{V} \mathrm{O}_{2 \max }$ limitation. Eur J Appl Physiol 98:152-160

Cardus J, Marrades RM, Roca J, Barbera JA, Diaz O, Mascians JR, Rodriguez-Roisin R, Wagner PD (1998) Effect of $\mathrm{FIO}_{2}$ on leg $\dot{V} \mathrm{O}_{2}$ during cycle ergometry in sedentary subjects. Med Sci Sports Exerc 30:697-703

Ceaser TG, Fitzhugh EC, Thompson DL, Bassett DR Jr (2013) Association of physical activity, fitness, and race: NHANES 19992004. Med Sci Sports Exerc 45:286-293

Celsing F, Svedenhag J, Pihlstedt P, Ekblom B (1987) Effects of anaemia and stepwise-induced polycythaemia on maximal aerobic power in individuals with high and low haemoglobin concentrations. Acta Physiol Scand 129:47-54

Cerretelli P (1976) Limiting factors to oxygen transport on Mount Everest. J Appl Physiol 40:658-667

Cerretelli P (1980) Gas exchange at high altitude. In: West JB (ed) Pulmonary gas exchange, vol II. Academic Press, New York, pp 97-147

Cerretelli P, di Prampero PE (1987) Gas exchange in exercise. In: Farhi LE, Tenney SM (eds) Handbook of physiology. The respiratory system III, vol 4: gas exchange. The American Physiological Society, Bethesda, pp 297-339

Cerretelli P, Hoppeler H (1996) Morphologic and metabolic response to chronic hypoxia. In: Fregly MJ, Blatteis CM (eds) Handbook of physiology. Environmental physiology, sect. 4, vol II. Oxford University Press, New York, pp 1155-1181

Cerretelli P, Margaria R (1961) Maximum oxygen consumption at altitude. Int Z Angew Physiol 18:460-464

Cerretelli P, Pendergast DR, Paganelli WC, Rennie DW (1979) Effects of specific muscle training on $\dot{V} \mathrm{O}_{2}$-on response and early blood lactate. J Appl Physiol 47:761-769

Chan OL, Duncan MT, Sundsten JW, Thinakaran T, Noh MN, Klissouras V (1976) The maximum aerobic power of the Temiars. Med Sci Sports 8:235-238

Chatterjee S, Saha SK, Saha D, Nag SK (1991) Maximal aerobic capacity of Bengali girl athletes of different sports activities. Jpn J Physiol 41:397-411

Chidnok W, Dimenna FJ, Bailey SJ, Burnley M, Wilkerson DP, Vanhatalo A, Jones AM (2013) $\dot{V} \mathrm{O}_{2 \max }$ is not altered by self-pacing during incremental exercise. Eur J Appl Physiol 113:529-539

Clark AR, Tawhai MH, Hoffman EA, Burrowes KS (2011) The interdependent contributions of gravitational and structural features 
to perfusion distribution in a multiscale model of the pulmonary circulation. J Appl Physiol 110:943-955

Clausen JP (1977) Effect of physical training on cardiovascular adjustments to exercise in man. Physiol Rev 57:779-815

Clausen JP, Klausen K, Rasmussen B, Trap-Jensen J (1973) Central and peripheral circulation changes after training of arms and legs. Am J Physiol 225:675-682

Convertino VA (1996) Exercise and adaptation to microgravity environments. In: Fregly MJ, Blatteis CM (eds) Handbook of physiology. Environmental physiology, sect. 4, vol I. Oxford University Press, New York, pp 815-843

Convertino VA, Hung J, Goldwater DJ, Debusk RF (1982) Cardiovascular responses to exercise in middle age men after 10 days of bed-rest. Circulation 65:134-140

Convertino VA, Goldwater DJ, Sandler H (1986) Bed rest induced peak $\dot{V} \mathrm{O}_{2}$ reduction associated with age, gender and aerobic capacity. Aviat Space Environ Med 57:17-22

Costill DL, Daniels J, Evans W, Fink W, Krahenbuhl G, Saltin B (1976) Skeletal muscle enzymes and fiber composition in male and female track athletes. J Appl Physiol 40(149-154):67

Cottin F, Médigue C, Papelier Y (2008) Effect of heavy exercise on spectral baroreflex sensitivity, heart rate, and blood pressure variability in well-trained humans. Am J Physiol Heart Circ Physiol 295:H1150-H1155

Cymerman A, Reeves JT, Sutton JR, Rock PB, Groves BM, Malconian MK, Young PM, Wagner PD, Houston CM (1989) Operation Everest II: maximal oxygen uptake at extreme altitude. J Appl Physiol 66:2446-2453

Daussin FN, Ponsot E, Dufour SP, Lonsdorfer-Wolf E, Doutreleau S, Geny B, Piquard F, Richard R (2007) Improvement of $\dot{V} \mathrm{O}_{2 \max }$ by cardiac output and oxygen extraction adaptation during intermittent versus continuous endurance training. Eur J Appl Physiol 101:377-383

Davies CTM, Sargeant AJ (1974) Effects of training on the physiological responses of one- and two-leg work. J Appl Physiol 38:377-381

Davies CTM, Barnes C, Fox RH, Osikuto RO, Samueloff AS (1972) Ethnic differences in physical working capacity. J Appl Physiol 33:726-732

Dekerle J, Mucci P, Carter H (2012) Influence of moderate hypoxia on tolerance to high-intensity exercise. Eur J Appl Physiol 112:327-335

Dempsey JA, Wagner PD (1999) Exercise-induced arterial hypoxemia. J Appl Physiol 87:1997-2006

Dempsey JA, Hanson PG, Henderson KS (1984) Exercise-induced arterial hypoxaemia in healthy human subjects at sea level. J Physiol 355:161-175

Dempsey JA, McKenzie DC, Haverkamp HC, Eldridge MW (2008) Update in the understanding of respiratory limitations to exercise performance in fit, active adults. Chest 134:613-622

di Prampero PE (1981) Energetics of muscular exercise. Rev Physiol Biochem Pharmacol 89:143-222

di Prampero PE (1985) Metabolic and circulatory limitations to $\dot{V} \mathrm{O}_{2 \max }$ at the whole animal level. J Exp Biol 115:319-331

di Prampero PE (1986) The energy cost of human locomotion on land and in water. Int J Sports Med 7:55-72

di Prampero PE (2000) Cycling on Earth, in space, on the Moon. Eur J Appl Physiol 82:345-360

di Prampero PE (2003) Factors limiting maximal performance in humans. Eur J Appl Physiol 90:420-429

di Prampero PE, Cerretelli P (1969) Maximal muscular power (aerobic and anaerobic) in African natives. Ergonomics 12:51-59

di Prampero PE, Ferretti G (1990) Factors limiting maximal oxygen consumption in humans. Respir Physiol 80:113-128

di Prampero PE, Ferretti G (1999) The energetics of anaerobic muscle metabolism: a reappraisal of older and recent concepts. Respir Physiol Neurobiol 118:103-115 di Prampero PE, Piñera-Limas F, Sassi G (1970) Maximal muscular power, aerobic and anaerobic, in 116 athletes performing at the XIXth Olympic Games in Mexico. Ergonomics 13:665-674

di Prampero PE, Cortili G, Mognoni P, Saibene F (1979) Equation of motion of a cyclist. J Appl Physiol 47:201-206

Dill DB, Adams WC (1971) Maximal oxygen uptake at sea level and at 3,090 m altitude in high school champion runners. J Appl Physiol 30(854-859):80

Dill DB, Myhre LG, Phillips EE, Brown DK (1966) Work capacity in acute exposures to altitude. J Appl Physiol 21:1168-1176

Downey AE, Chenoweth LM, Townsend DK, Ranum JD, Ferguson CS, Harms CA (2007) Effects of inspiratory muscle training on exercise responses in normoxia and hypoxia. Respir Physiol Neurobiol 156:137-146

Duncan MT, Horvath SM (1988) Physiological adaptations to thermal stress in tropical Asians. Eur J Appl Physiol 57:540-544

Duncan GE, Howley ET, Johnson BN (1997) Applicability of $\dot{V} \mathrm{O}_{2 \max }$ criteria: discontinuous versus continuous protocols. Med Sci Sports Exerc 29:273-278

Duncan GE, Li SM, Zhou XH (2005) Cardiovascular fitness among U.S. adults: NHANES 1999-2000 and 2001-2002. Med Sci Sports Exerc 37:1324-1328

Dunham C, Harms CA (2012) Effects of high-intensity interval training on pulmonary function. Eur J Appl Physiol 112:3061-3068

Edwards AM, Cooke CB (2004) Oxygen uptake kinetics and maximal aerobic power are unaffected by inspiratory muscle training in healthy subjects where time to exhaustion is extended. Eur J Appl Physiol 93:139-144

Ekblom B (1969) The effect of physical training on oxygen transport system in man. Acta Physiol Scand Suppl 328:1-45

Ekblom B (1986) Factors determining maximal aerobic power. Acta Physiol Scand Suppl 556:15-19

Ekblom B, Hermansen L (1968) Cardiac output in athletes. J Appl Physiol 25:619-625

Ekblom B, Huot R (1972) Response to submaximal and maximal exercise at different levels of carboxyhemoglobin. Acta Physiol Scand 86:474-482

Ekblom B, Åstrand PO, Saltin B, Stenberg J, Wallström B (1968) Effect of training on circulatory response to exercise. J Appl Physiol 24:518-528

Ekblom B, Huot R, Stein EM, Thorstensson AT (1975) Effect of changes in arterial oxygen content on circulation and physical performance. J Appl Physiol 39:71-75

Ekblom B, Wilson G, Åstrand PO (1976) Central circulation during exercise after venesection and reinfusion of red blood cells. $\mathrm{J}$ Appl Physiol 40:379-383

Eliakim A, Nemet D (2010) Exercise training, physical fitness and the growth hormone-insulin-like growth factor-1 axis and cytokine balance. Med Sport Sci 55:128-140

Elliott AD, Skowno J, Prabhu M, Noakes TD, Ansley L (2013). Evidence of cardiac functional reserve upon exhaustion during incremental exercise to determine $\dot{V} \mathrm{O}_{2 \max }$. Br J Sports Med. doi:10.1136/bjsports-2012-091752

Ellis CG, Wrigley SM, Groom AC (1994) Heterogeneity of red blood cell perfusion in capillary networks supplied by a single arteriole in resting skeletal muscle. Circ Res 75:357-368

Esposito F, Ferretti G (1997) The effects of breathing $\mathrm{He}-\mathrm{O}_{2}$ mixtures on maximal oxygen consumption in normoxic and hypoxic men. J Physiol 503:215-221

Esposito F, Limonta E, Alberti G, Veicsteinas A, Ferretti G (2010) Effect of respiratory muscle training on maximum aerobic power in normoxia and hypoxia. Respir Physiol Neurobiol 170:268-272

Fagraeus L, Karlsson J, Linnarsson D, Saltin B (1973) Oxygen uptake during maximal work at lowered and raised ambient air pressure. Acta Physiol Scand 87:411-421 
Fairshter RD, Walters J, Salness K, Fox M, Minh VD, Wilson AF (1983) A comparison of incremental exercise tests during cycle and treadmill ergometry. Med Sci Sports Exerc 15:549-554

Faoro V, Huez S, Vanderpool RR, Groepenhoff H, de Bisschop C, Martinot JB, Lamotte M, Pavelescu A, Guénard H, Naeije R (2014) Pulmonary circulation and gas exchange at exercise in Sherpas at altitude. J Appl Physiol 116:919-926

Favier R, Spielvogel H, Desplanches D, Ferretti G, Kayser B, Grünenfelder A, Leuenberger M, Tüscher L, Caceres E, Hoppeler $H$ (1995) Training in hypoxia vs training in normoxia in high altitude natives. J Appl Physiol 78:2286-2293

Ferretti G (1990) On maximal oxygen consumption in hypoxic humans. Experientia 46:1188-1194

Ferretti G (2003) Limiting factors to oxygen transport on Mount Everest 30 years after: a critique of Paolo Cerretelli's contribution to the study of altitude physiology. Eur J Appl Physiol 90:344-350

Ferretti G, Capelli C (2009) Maximal $\mathrm{O}_{2}$ consumption: effects of gravity withdrawal and resumption. Respir Physiol Neurobiol 169:S50-S54

Ferretti G, di Prampero PE (1995) Factors limiting maximal $\mathrm{O}_{2}$ consumption: effects of acute changes in ventilation. Respir Physiol 99:259-271

Ferretti G, Atchou G, Grassi B, Marconi C, Cerretelli P (1991) Energetics of locomotion in African pygmies. Eur J Appl Physiol 62:7-10

Ferretti G, Antonutto G, Denis C, Hoppeler H, Minetti AE, Narici MV, Desplanches D (1997a) The interplay of central and peripheral factors in limiting maximal $\mathrm{O}_{2}$ consumption in man after prolonged bed rest. J Physiol 501:677-686

Ferretti G, Moia C, Thomet J, Kayser B (1997b) The decrease of maximal oxygen consumption during hypoxia in man: a mirror image of the oxygen equilibrium curve. J Physiol 498:231-237

Ferretti G, Bringard A, Perini R (2011) An analysis of performance in human locomotion. Eur J Appl Physiol 111:391-401

Fleg JL, Lakatta EG (1989) Role of muscle loss in the age-associated reduction of $\dot{V} \mathrm{O}_{2 \max }$. J Appl Physiol 65:1147-1151

Fleg JL, Morrell CH, Bos AG, Brant LJ, Talbot LA, Wright JG, Lakatta EG (2005) Accelerated longitudinal decline of aerobic capacity in healthy older adults. Circulation 112:674-682

Flück M (2010) Myocellular limitations of human performance and their modification through genome-dependent responses at altitude. Exp Physiol 95:451-462

Friman G (1979) Effect of clinical bed rest for seven days on physical performance. Acta Med Scand 205(389-393): 103

Fulco CS, Rock PB, Trad L, Forte V, Cymerman A (1988) Maximal cardiorespiratory responses to one- and two-legged cycling during acute and long-term exposure to 4,300 meters altitude. Eur J Appl Physiol 57:761-766

Gaesser GA, Poole DC (1996) The slow component of oxygen uptake kinetics in humans. Exerc Sport Sci Rev 24:35-71

Gaesser GA, Wilson LA (1988) Effects of continuous and interval training on the parameters of the power-endurance time relationship for high-intensity exercise. Int J Sports Med 9:417-421

Gaskill SE, Serfass RC, Bacharach DW, Kelly JM (1999) Responses to training in cross-country skiers. Med Sci Sports Exerc 31:1211-1217

Gavin TP, Derchak PA, Stager JM (1998) Ventilation's role in the decline in $\dot{\mathrm{V}} \mathrm{O}_{2 \max }$ and $\mathrm{SaO}_{2}$ in acute hypoxic exercise. Med Sci Sport Exerc 30:195-199

Gayeski TE, Honig CR (1986) $\mathrm{O}_{2}$ gradients from sarcolemma to cell interior in red muscle at maximal $\dot{V} \mathrm{O}_{2}$. Am J Physiol Heart Circ Physiol 251:H789-H799

Geiser J, Vogt M, Billeter R, Zuleger C, Belforti F, Hoppeler H (2001) Training high - living low: changes of aerobic performance and muscle structure with training at simulated altitude. Int J Sports Med 22:579-585
Gibala MJ, Little JP, Macdonald MJ, Hawley JA (2012) Physiological adaptations to low-volume, high-intensity interval training in health and disease. J Physiol 590:1077-1084

Giesbrecht GG, Puddy A, Ahmed M, Younes M, Anthonisen NR (1991) Exercise endurance and arterial desaturation in normobaric hypoxia with increased chemosensitivity. J Appl Physiol 70:1770-1774

Gledhill N, Warburton D, Jamnik V (1999) Haemoglobin, blood volume, cardiac function, and aerobic power. Can J Appl Physiol 24:54-65

Glick Z, Schwartz E (1974) Physical working capacity of young men of different ethnic groups in Israel. J Appl Physiol 37:22-26

Gollnick PD, Armstrong RB, Saubert CW IV, Piehl K, Saltin B (1972) Enzyme activity and fiber composition in skeletal muscle of trained and untrained men. J Appl Physiol 33:312-319

Gollnick PD, Armstrong RB, Saltin B, Saubert CW IV, Sembrowich L, Shephard RE (1973) Effect of training on enzyme activity and fiber composition of human skeletal muscle. J Appl Physiol 34:107-111

Gordon D, Mehter M, Gernigon M, Caddy O, Keiller D, Barnes R (2012) The effects of exercise modality on the incidence of plateau at $\dot{V} \mathrm{O}_{2 \max }$. Clin Physiol Funct Imaging 32:394-399

Gordon D, Wood M, Porter A, Vetrivel V, Gernigon M, Caddy O, Merzbach V, Keiller D, Baker J, Barnes R (2014) Influence of blood donation on the incidence of plateau at $\dot{V} \mathrm{O}_{2 \max }$. Eur $\mathrm{J}$ Appl Physiol 114:21-27

Gormley SE, Swain DP, High R, Spina RJ, Dowling EA, Kotipalli US, Gandrakota R (2008) Effect of intensity of aerobic training on VO2max. Med Sci Sports Exerc 40:1336-1343

Greenleaf JE, Bernauer EM, Ertl AC, Trowbridge TS, Wade CE (1989) Work capacity during 30 days of bed rest with isometric and isotonic exercise. J Appl Physiol 67:1820-1826

Greksa LP, Haas JD, Leatherman TL, Thomas RB, Spielvogel H (1984) Work performance of high-altitude Aymara males. Ann Hum Biol 11:227-233

Grimsmo J, Arnesen H, Maehlum S (2010) Changes in cardiorespiratory function in different groups of former and still active male cross-country skiers: a 28-30-year follow-up study. Scand J Med Sci Sports 20:151-161

Hagberg JM (1987) Effect of training on the decline of $\dot{V} \mathrm{O}_{2 \max }$ with aging. Fed Proc 46:1830-1833

Hagberg JM, Coyle EF (1984) Physiological comparison of competitive race walking and running. Int J Sports Med 5:74-77

Hahn AG, Gore CJ, Martin DT, Ashenden MJ, Roberts AD, Logan PA (2001) An evaluation of the concept of living at moderate altitude and training at sea level. Comp Biochem Physiol A 128:777-789

Hawkins SA, Marcell TJ, Victoria Jaque S, Wiswell RA (2001) A longitudinal assessment of change in $\dot{V} \mathrm{O}_{2 \max }$ and maximal heart rate in master athletes. Med Sci Sports Exerc 33:1744-1750

Hawkins MN, Raven PB, Snell PG, Stray-Gundersen J, Levine BD (2007) Maximal oxygen uptake as a parametric measure of cardiorespiratory capacity. Med Sci Sports Exerc 39:103-107

Heath GW, Hagberg JM, Ehsani AA, Holloszy JO (1981) A physiological comparison of young and older endurance athletes. J Appl Physiol 51:634-640

Heinonen I, Nesterov SV, Kemppainen J, Nuutila P, Knuuti J, Laitio R, Kjaer M, Boushel R, Kalliokoski KK (2007) Role of adenosine in regulating the heterogeneity of skeletal muscle blood flow during exercise in humans. J Appl Physiol 103:2042-2048

Heinonen I, Duncker DJ, Knuuti J, Kalliokoski KK (2012) The effect of acute exercise with increasing workloads on inactive muscle blood flow and its heterogeneity in humans. Eur J Appl Physiol 112:3503-3509

Helgerud J (1994) Maximal oxygen uptake, anaerobic threshold and running economy in women and men with similar performances level in marathons. Eur J Appl Physiol 68:155-161 
Helgerud J, Høydal K, Wang E, Karlsen T, Berg P, Bjerkaas M, Simonsen T, Helgesen C, Hjorth N, Bach R, Hoff J (2007) Aerobic high-intensity intervals improve $\dot{V} \mathrm{O}_{2 \max }$ more than moderate training. Med Sci Sports Exerc 39:665-671

Henriksson J (1977) Training induced adaptation of skeletal muscle and metabolism during submaximal exercise. J Physiol 270:661-675

Henriksson J, Reitmann JS (1977) Time course of changes in human skeletal muscle succinate dehydrogenase and cytochrome oxidase activities and maximal oxygen uptake with physical activity and inactivity. Acta Physiol Scand 99:91-97

Henson LC, Poole DC, Whipp BJ (1989) Fitness as a determinant of oxygen uptake response to constant-load exercise. Eur J Appl Physiol 59:21-28

Herbst R (1928) Der Gasstoffwechsel als Mass der körperlichen Leistungsfähigkeit. I. Mitteilung : die Bestimmung des Sauerstoffaufnahmevermögens bein Gesunden. Deut Arch Klin Med 162:33-50

Hermansen L, Saltin B (1969) Oxygen uptake during maximal treadmill and bicycle exercise. J Appl Physiol 26:31-37

Hermansen L, Wachtlova M (1971) Capillary density of skeletal muscle in well-trained and untrained men. J Appl Physiol 30:860-863

Heubert R, Bocquet V, Koralsztein JP, Billat VL (2003) Effets de 4 semaines d'entraînement sur le temps limite à $\dot{V} \mathrm{O}_{2 \max }$. Can $\mathrm{J}$ Appl Physiol 28:717-736

Heubert RAP, Billat VL, Chasseaing P, Bocquet V, Morton RH, Koralsztein JP, di Prampero PE (2005) Effects of a previous sprint on the parameters of the work-time to exhaustion relationship in high intensity cycling. Int J Sport Med 26:583-592

Hickson RC, Hagberg JM, Ehsani AA, Holloszy JO (1981) Time course of the adaptive responses of aerobic power and heart rate to training. Med Sci Sports Exerc 13:17-20

Hickson RC, Foster C, Pollock ML, Galassi TM, Rich S (1985) Reduced training intensities and loss of aerobic power, endurance, and cardiac growth. J Appl Physiol 58:492-499

Hickson RC, Bomze HA, Holloszy JO (1997) Linear increase in aerobic power induced by a strenuous program of endurance exercise. J Appl Physiol 42:372-376

Hikida RS, Gollnick PD, Dudley GA, Convertino VA, Buchanan P (1989) Structural and metabolic characteristics of human skeletal muscle following 30 days of simulated microgravity. Aviat Space Environ Med 60:664-670

Hildebrandt AL, Pilegaard H, Neufer PD (2003) Differential transcriptional activation of select metabolic genes in response to variations in exercise intensity and duration. Am J Physiol Endocrinol Metab 285:E1021-E1027

Hill DW (1993) The critical power concept. Sports Med 16:237-254

Hill AV, Lupton H (1923) Muscular exercise, lactic acid, and the supply and utilization of oxygen. Q J Med 16:135-171

Hogan MC, Bebout DE, Wagner PD (1991a) Effect of hemoglobin concentration on maximal $\mathrm{O}_{2}$ uptake in canine gastrocnemius muscle in situ. J Appl Physiol 70:1105-1112

Hogan MC, Bebout DE, Wagner PD (1991b) Effect of increased Hb$\mathrm{O} 2$ affinity on $\dot{V} \mathrm{O}_{2 \max }$ at constant $\mathrm{O}_{2}$ delivery in dog muscle in situ. J Appl Physiol 70:2656-2662

Holloszy JO, Coyle EF (1984) Adaptations of skeletal muscle to endurance exercise and their metabolic consequences. J Appl Physiol 56:831-838

Honig CR, Gayeski TE (1993) Resistance to $\mathrm{O}_{2}$ diffusion in anemic red muscle: roles of flux density and cell $\mathrm{PO}_{2}$. Am J Physiol Heart Circ Physiol 265:H868-H875

Hoppeler H (1986) Exercise-induced ultrastructural changes in skeletal muscle. Int J Sports Med 7:187-204

Hoppeler H (1990) The different relationship of $\dot{V} \mathrm{O}_{2 \max }$ to muscle mitochondria in humans and quadrupedal animals. Respir Physiol 80:137-146
Hoppeler H, Flück M (2003) Plasticity of skeletal muscle mitochondria: structure and function. Med Sci Sports Exerc 35:95-104

Hoppeler H, Weibel ER (2000) Structural and functional limits for oxygen supply to muscle. Acta Physiol Scand 168:445-456

Hoppeler H, Howald H, Conley K, Lindstedt SL, Claassen H, Vock P, Weibel ER (1985) Endurance training in humans: aerobic capacity and structure of skeletal muscle. J Appl Physiol 59:320-327

Hoppeler H, Kleinert E, Schlegel C, Claassen H, Howald H, Kayar SR, Cerretelli P (1990) Morphological adaptations of human skeletal muscle to chronic hypoxia. Int J Sports Med 11(Suppl 1):S3-S9

Hoppeler H, Klossner S, Vogt M (2008) Training in hypoxia and its effects on skeletal muscle tissue. Scand J Med Sci Sports 18(Suppl 1):38-49

Horvath SM, Bedi JF, Wagner JA, Agnew J (1988) Maximal aerobic capacity at several ambient concentrations of $\mathrm{CO}$ at several altitudes. J Appl Physiol 65:2696-2708

Howald H (1982) Training-induced morphological and functional changes in skeletal muscle. Int J Sports Med 3:1-12

Howald H, Hoppeler H, Claassen H, Mathieu O, Straub R (1985) Influences of endurance training on the ultrastructural composition of the different muscle fibre types in humans. Pflügers Arch 403:369-376

Howley ET, Bassett DR Jr, Welch HG (1995) Criteria for maximal oxygen uptake: review and commentary. Med Sci Sports Exerc 27:1292-1301

Hunter GR, Weinsier RL, McCarthy JP, Enette Larson-Meyer D, Newcomer BR (2001) Hemoglobin, muscle oxidative capacity, and $\dot{V} \mathrm{O}_{2 \max }$ in African-American and Caucasian women. Med Sci Sports Exerc 33:1739-1743

Ingjer F (1979) Effects of endurance training on muscle fiber ATP-ase activity, capillary supply and mitochondrial content in man. $\mathrm{J}$ Physiol 294:419-432

Jenkins DG, Quigley BM (1992) Endurance training enhances critical power. Med Sci Sports Exerc 24:1283-1289

Johnson BD, Saupe KW, Dempsey JA (1992) Mechanical constraints on exercise hyperpnea in endurance athletes. J Appl Physiol 73:874-886

Jones AM, Vanhatalo A, Burnley M, Morton RH, Poole DC (2010) Critical power: implications for the determination of $\dot{V} \mathrm{O}_{2 \max }$ and exercise tolerance. Med Sci Sports Exerc 42:1876-1890

Kaijser L (1970) Limiting factors for aerobic muscle performance. Acta Physiol Scand Suppl 346:1-96

Kaiser P, Tesch PA, Frisk-Holmberg M, Juhlin-Dannfeldt A, Kaijser L (1986) Effect of beta-1-selective and non-selective beta blockade on work capacity and muscle metabolism. Clin Physiol 6:197-207

Kalliokoski KK, Knuuti J, Nuutila P (2004) Blood transit time heterogeneity is associated to oxygen extraction in exercising human skeletal muscle. Microvasc Res 67:125-132

Kashihara H, Haruna Y, Suzuki Y, Kawakubo K, Takenaka K, BondePetersen F, Gunji A (1994) Effects of mild supine exercise during 20 days bed rest on maximal oxygen uptake rate in young humans. Acta Physiol Scand Suppl 616:19-26

Kayser B, Hoppeler H, Claassen H, Cerretelli P (1991) Muscle structure and performance capacity of Himalayan Sherpas. J Appl Physiol 70:1938-1942

Kayser B, Marconi C, Amatya T, Basnyat B, Colombini A, Broers B, Cerretelli P (1994) The metabolic and ventilatory response to exercise in Tibetans born at low altitude. Respir Physiol 98:15-26

Knight DR, Schaffartzik W, Poole DC, Hogan MC, Bebout DE, Wagner PD (1993) Effects of hyperoxia on maximal leg $\mathrm{O}_{2}$ supply and utilization in humans. J Appl Physiol 75:2586-2594

Koistinen P, Takala T, Martikkala V, Leppaluoto J (1995) Aerobic fitness influences the response of maximal oxygen uptake and 
lactate threshold in acute hypobaric hypoxia. Int J Sports Med 16:78-81

Krip B, Gledhill N, Jamnik V, Warburton D (1997) Effect of alterations in blood volume on cardiac function during maximal exercise. Med Sci Sports Exerc 29:1469-1476

Kruk B, Pekkarinen H, Manninen K, Hänninen O (1991) Comparison in men of physiological responses to exercise of increasing intensity at low and moderate ambient temperatures. Eur J Appl Physiol 62:353-357

Krustrup P, Jones AM, Wilkerson DP, Calbet JA, Bangsbo J (2009) Muscular and pulmonary $\mathrm{O}_{2}$ uptake kinetics during moderate and high-intensity sub-maximal knee-extensor exercise in humans. J Physiol 587:1843-1856

Lawler J, Powers SK, Thompson D (1988) Linear relationship between $\dot{V} \mathrm{O}_{2 \max }$ and $\dot{V} \mathrm{O}_{2 \max }$ decrement during exposure to acute hypoxia. J Appl Physiol 64:1486-1992

Lee SM, Schneider SM, Boda WL, Watenpaugh DE, Macias BR, Meyer RS, Hargens AR (2007) Supine LBNP exercise maintains exercise capacity in male twins during $30-\mathrm{d}$ bed rest. Med Sci Sports Exerc 39:1315-1326

Lee SM, Schneider SM, Boda WL, Watenpaugh DE, Macias BR, Meyer RS, Hargens AR (2009) LBNP exercise protects aerobic capacity and sprint speed of female twins during 30 days of bed rest. J Appl Physiol 106:919-928

Levine BD (2008) $\dot{V} \mathrm{O}_{2 \max }$ : what do we know, and what do we still need to know? J Physiol 586:25-34

Levine BD, Stray-Gundersen J (1997) 'Living high-training low': effect of moderate-altitude acclimatization with low-altitude training on performance. J Appl Physiol 83:102-112

Levine BD, Lane LD, Buckey JC, Friedman DB, Blomqvist CG (1991) Left ventricular pressure-volume and Frank-Starling relations in endurance athletes. Implications for orthostatic tolerance and exercise performance. Circulation 84:1016-1023

Levine BD, Lane LD, Watenpaugh DE, Gaffney FA, Buckey JC, Blomqvist CG (1996) Maximal exercise performance after adaptation to microgravity. J Appl Physiol 81:686-694

Lindstedt SL, Wells DJ, Jones JR, Hoppeler H, Thronson HA (1988) Limitations to aerobic performance in mammals: interaction of structure and demand. Int J Sports Med 9:210-217

Losnegard T, Myklebust H, Spencer M, Hallén J (2013) Seasonal variations in $\dot{V} \mathrm{O}_{2 \max }, \mathrm{O}_{2}$-cost, $\mathrm{O}_{2}$-deficit, and performance in elite cross-country skiers. J Strength Cond Res 27:1780-1790

Lucia A, Hoyos J, Chicharro JL (2000) Physiological response to professional road cycling: climbers vs. time trialists. Int J Sports Med 21:505-512

Maksud MG, Coutts KD (1971) Comparison of a continuous and discontinuous graded treadmill test for maximal oxygen uptake. Med Sci Sports 3:63-65

Marconi C, Heisler N, Meyer M, Weitz H, Pendergast DR, Cerretelli P, Piiper J (1988) Blood flow distribution and its temporal variability in stimulated dog gastrocnemius muscle. Respir Physiol 74:1-13

Marconi C, Marzorati M, Grassi B, Basnyat B, Colombini A, Kayser B, Cerretelli P (2004) Second generation Tibetan lowlanders acclimatize to high altitude more quickly than Caucasians. J Physiol 556:661-671

Margaria R, Cerretelli P, Marchi S, Rossi L (1961) Maximum exercise in oxygen. Int $Z$ angew Physiol 18:465-467

Margaria R, Camporesi E, Aghemo P, Sassi G (1972) The effect of $\mathrm{O}_{2}$ breathing on maximal aerobic power. Pflügers Arch 336:225-235

Markov G, Spengler CM, Knopfli-Lenzin C, Stuessi C, Boutellier U (2001) Respiratory muscle training increases cycling endurance without affecting cardiovascular responses to exercise. Eur $\mathbf{J}$ Appl Physiol 85:233-239

Masuda K, Okazaki K, Kuno S, Asano K, Shimojo H, Katsuta S (2001) Endurance training under 2500-m hypoxia does not increase myoglobin content in human skeletal muscle. Eur J Appl Physiol 85:486-490

McArdle WD, Katch FI, Pechar GS (1973) Comparison of continuous and discontinuous treadmill and bicycle tests for $\max \dot{V} \mathrm{O}_{2}$. Med Sci Sports 5:156-160

McArdle WD, Magel JR, Lesmes GR, Pechar GS (1976) Metabolic and cardiovascular adjustment to work in air and water at 18, 25 and $33^{\circ} \mathrm{C}$. J Appl Physiol 40:85-90

McGuire DK, Levine BD, Williamson JW, Snell PG, Blomqvist CG, Saltin B, Mitchell JH (2001) A 30-year follow-up of the Dallas Bedrest and Training Study: I. Effect of age on the cardiovascular response to exercise. Circulation 104:1350-1357

Mekjavic IB, Golja P, Tipton MJ, Eiken O (2005) Human thermoregulatory function during exercise and immersion after 35 days of horizontal bed-rest and recovery. Eur J Appl Physiol 95:163-171

Mitchell JH, Blomqvist CG (1971) Maximal oxygen uptake. New Engl J Med 284:1018-1022

Miura A, Sato H, Sato H, Whipp BJ, Fukuba Y (2000) The effect of glycogen depletion on the curvature constant parameter of the power-duration curve for cycle ergometry. Ergonomics 43:133-141

Mollard P, Woorons X, Letournel M, Lamberto C, Favret F, Pichon A, Beaudry M, Richalet JP (2007) Determinants of maximal oxygen uptake in moderate acute hypoxia in endurance athletes. Eur J Appl Physiol 100:663-673

Monod H, Scherrer J (1965) The work capacity of a synergic muscular group. Ergonomics 8:329-338

Mooren FC, Viereck J, Krüger K, Thum T (2014) Circulating microRNAs as potential biomarkers of aerobic exercise capacity. Am J Physiol Heart Circ Physiol 306:H557-H563

Moritani T, Nagata A, deVries HA, Muro M (1981) Critical power as a measure of physical work capacity and anaerobic threshold. Ergonomics 24:339-350

Morton RH (1994) Critical power test for ramp exercise. Eur J Appl Physiol 69:435-438

Morton RH (1996) A 3-parameter critical power model. Ergonomics 39:611-619

Morton RH (2011) Why peak power is higher at the end of steeper ramps: an explanation based on the "critical power" concept. J Sport Sci 29:307-309

Morton RH, Billat LV (2004) The critical power model for intermittent exercise. Eur J Appl Physiol 91:303-307

Morton RH, Green S, Bishop D, Jenkins DG (1997) Ramp and constant power trials produce equivalent critical power estimates. Med Sci Sports Exerc 29:833-836

Noakes TD (1998) Maximal oxygen uptake: 'classical' versus 'contemporary' viewpoints: a rebuttal. Med Sci Sports Exerc 30:1381-1398

Noakes TD, Peltonen JE, Rusko HK (2001) Evidence that a central governor regulates exercise performance during acute hypoxia and hyperoxia. J Exp Biol 204:3225-3234

Oelz O, Howald H, di Prampero PE, Hoppeler H, Claassen H, Jenni R, Bühlmann A, Ferretti G, Brückner JC, Veicsteinas A, Gussoni M, Cerretelli P (1986) Physiological profile of world class high altitude climbers. J Appl Physiol 60:1734-1742

Ogawa T, Spina RJ, Martin WH 3rd, Kohrt WM, Schechtman KB, Holloszy JO, Ehsani AA (1992) Effects of aging, sex, and physical training on cardiovascular responses to exercise. Circulation 86:494-503

Ogawa T, Hayashi K, Ichinose M, Nishiyasu T (2007) Relationship between rest ventilatory chemosensitivity and maximal oxygen uptake in moderate hypobaric hypoxia. J Appl Physiol 103:1221-1226

Ogawa T, Calbet JAL, Honda Y, Fuji N, Nishiyasu T (2010) The effects of breathing a helium-oxygen gas mixture on maximal 
pulmonary ventilation and maximal oxygen consumption during exercise in acute moderate hypobaric hypoxia. Eur J Appl Physiol 110:853-861

Ogita F, Hara M, Tabata I (1996) Anaerobic capacity and maximal oxygen uptake during arm stroke, leg kicking and whole body swimming. Acta Physiol Scand 157:435-441

Otis AB (1987) An overview of gas exchange. In: Farhi LE, Tenney SM (eds) Handbook of physiology. The respiratory system, Sect. 3, vol IV. American Physiological Society, Bethesda, pp $1-11$

Padilla S, Bourdin M, Barthélémy JC, Lacour JR (1992) Physiological correlates of middle-distance running performance. A comparative study between men and women. Eur J Appl Physiol 65:561-566

Padilla S, Mujika I, Cuesta G, Goiriena JJ (1999) Level ground and uphill cycling ability in professional road cycling. Med Sci Sports Exerc 31:878-885

Perini R, Veicsteinas A (2003) Heart rate variability and autonomic activity at rest and during exercise in various physiological conditions. Eur J Appl Physiol 90:317-325

Perry CG, Talanian JL, Heigenhauser GJ, Spriet LL (2007) The effects of training in hyperoxia vs. normoxia on skeletal muscle enzyme activities and exercise performance. J Appl Physiol 102:1022-1027

Perry CGR, Heigenhauser GJF, Bonen A, Spriet LL (2008) Highintensity aerobic interval training increases fat and carbohydrate metabolic capacities in human skeletal muscle. Appl Physiol Nutr Metab 33:1112-1123

Piiper J, Scheid P (1981) Model for capillary-alveolar equilibration with special reference to $\mathrm{O}_{2}$ uptake in hypoxia. Respir Physiol 46:193-208

Piiper J, Dejours P, Haab P, Rahn H (1971) Concepts and basic quantities in gas exchange physiology. Respir Physiol 13:292-304

Piiper J, Meyer M, Scheid P (1984) Dual role of diffusion in tissue gas exchange: blood-tissue equilibration and diffusion shunt. Respir Physiol 56:131-144

Piiper J, Pendergast DR, Marconi C, Meyer M, Heisler N, Cerretelli P (1985) Blood flow distribution in dog gastrocnemius muscle at rest and during stimulation. J Appl Physiol 58:2068-2074

Pirnay F, Dujardin J, Deroanne R, Petit JM (1971) Muscular exercise during intoxication by carbon monoxide. J Appl Physiol 31:573-575

Pirnay F, Deroanne R, Petit JM (1977) Influence of water temperature on thermal, circulatory and respiratory responses to muscular work. Eur J Appl Physiol 37:129-136

Plowman SA, Drinkwater BL, Horvath SM (1979) Age and aerobic power in women: a longitudinal study. J Gerontol 34:512-520

Poole DC, Ward SA, Gardner GW, Whipp BJ (1988) Metabolic and respiratory profile of the upper limit for prolonged exercise in man. Ergonomics 31:1265-1279

Poole DC, Ward SA, Whipp BJ (1990) The effects of training on the metabolic and respiratory profile of high-intensity cycle ergometer exercise. Eur J Appl Physiol 59:421-429

Poole DC, Schaffartzik W, Knight DR, Derion T, Kennedy B, Guy HJ, Prediletto R, Wagner PD (1991) Contribution of exercising legs to the slow component of oxygen uptake kinetics in humans. $\mathrm{J}$ Appl Physiol 71:1245-1260

Poole DC, Barstow TJ, Gaesser GA, Willis WT, Whipp BJ (1994) $\dot{V} \mathrm{O}_{2}$ slow component: physiological and functional significance. Med Sci Sports Exerc 26:1354-1358

Powers SK, Lawler J, Dempsey JA, Dodd S, Landry G (1989) Effects of incomplete pulmonary gas exchange on $\mathrm{VO}_{2} \max$. J Appl Physiol 66:2491-2495

Pringle JSM, Jones AM (2002) Maximal lactate steady state, critical power and EMG during cycling. Eur J Appl Physiol 88:214-226
Prior SJ, Hagberg JM, Phares DA, Brown MD, Fairfull L, Ferrell RE, Roth SM (2003) Sequence variation in hypoxia-inducible factor 1alpha (HIF1A): association with maximal oxygen consumption. Physiol Genomics 15:20-26

Prior SJ, Hagberg JM, Paton CM, Douglass LW, Brown MD, McLenithan JC, Roth SM (2006) DNA sequence variation in the promoter region of the VEGF gene impacts VEGF gene expression and maximal oxygen consumption. Am J Physiol Heart Circ Physiol 290:H1848-H1855

Proctor DN, Joyner MJ (1997) Skeletal muscle mass and the reduction of $\dot{V} \mathrm{O}_{2 \max }$ in trained older subjects. J Appl Physiol 82:1411-1415

Pugh LGCE (1967) Athletes at altitude. J Physiol 192:619-646

Pugh LGCE, Gill MB, Lahiri S, Milledge JS, Ward MP, West JB (1964) Maximal exercise at great altitudes. J Appl Physiol 19:431-440

Rådegran G, Blomstrand E, Saltin B (1999) Peak muscle perfusion and oxygen uptake in humans: importance of precise estimates of muscle mass. J Appl Physiol 87:2375-2380

Rahn H, Fenn WO (1955) A graphical analysis of the respiratory gas exchange. The $\mathrm{O}_{2}-\mathrm{CO}_{2}$ diagram. American Physiological Society, Washington

Rice TK, Sarzynski MA, Sung YJ, Argyropoulos G, Stütz AM, TeranGarcia M, Rao DC, Bouchard C, Rankinen T (2012) Fine mapping of a QTL on chromosome 13 for submaximal exercise capacity training response: the HERITAGE Family Study. Eur J Appl Physiol 112:2969-2978

Richardson RS, Kennedy B, Knight DR, Wagner PD (1995a) High muscle blood flows are not attenuated by recruitment of additional muscle mass. Am J Physiol Heart Circ Physiol 269:H1545-H1552

Richardson RS, Knight DR, Poole DC, Kurdak SS, Hogan MC, Grassi B, Wagner PD (1995b) Determinants of maximal exercise $\dot{V} \mathrm{O}_{2}$ during single leg knee-extensor exercise in humans. Am J Physiol Heart Circ Physiol 268:H1453-H1461

Richardson RS, Noyszewski EA, Kendrick KF, Leigh JS, Wagner PD (1995c) Myoglobin $\mathrm{O}_{2}$ desaturation during exercise. Evidence of limited $\mathrm{O}_{2}$ transport. J Clin Invest 96:1916-1926

Richardson RS, Grassi B, Gavin TP, Haseler LJ, Tagore K, Roca J, Wagner PD (1999) Evidence of $\mathrm{O}_{2}$ supply-dependent $\dot{V} \mathrm{O}_{2 \max }$ in the exercise-trained human quadriceps. J Appl Physiol 86:1048-1053

Richardson RS, Newcomer SC, Noyszewski EA (2001) Skeletal muscle intracellular $\mathrm{PO}_{2}$ assessed by myoglobin desaturation: response to graded exercise. J Appl Physiol 91:2679-2685

Roach RC, Koskolou MD, Calbet JA, Saltin B (1999) Arterial O con- $^{2}$ tent and tension in regulation of cardiac output and leg blood flow during exercise in humans. Am J Physiol Heart Circ Physiol 276:H438-H445

Robertson EY, Saunders PU, Pyne DB, Gore CJ, Anson JM (2010) Effectiveness of intermittent training in hypoxia combined with live high/train low. Eur J Appl Physiol 110:379-387

Robinson S (1938) Experimental studies of physical fitness in relation to age. Arbeitphysiol 10:251-323

Robinson S, Edwards HT, Dill DB (1937) New records in human power. Science 85:409-410

Robinson S, Dill DB, Tzankoff SP, Wagner JA, Robinson RD (1975) Longitudinal studies of aging in 37 men. J Appl Physiol 38:263-267

Robinson S, Dill DB, Robinson RD, Tzankoff SP, Wagner JA (1976) Physiological aging of champion runners. J Appl Physiol 41:46-51

Roca J, Hogan MC, Story D, Bebout DE, Haab P, Gonzalez R, Ueno O, Wagner PD (1989) Evidence for tissue diffusion limitation of $\dot{V} \mathrm{O}_{2 \max }$ in normal humans. J Appl Physiol 67:291-299 
Roca J, Agusti AG, Alonso A, Poole DC, Viegas C, Barbera JA, Rodriguez-Roisin R, Ferrer A, Wagner PD (1992) Effects of training on muscle $\mathrm{O}_{2}$ transport at $\dot{V} \mathrm{O}_{2 \max }$. J Appl Physiol 73:1067-1076

Rode A, Shephard RJ (1971) Cardio-respiratory fitness of an artic community. J Appl Physiol 31:519-526

Rode A, Shephard RJ (1984) Ten years of "civilization" fitness of Canadian Inuit. J Appl Physiol 56:1472-1477

Rodríguez FA, Truijens MJ, Townsend NE, Stray-Gundersen J, Gore CJ, Levine BD (2007) Performance of runners and swimmers after four weeks of intermittent hypobaric hypoxic exposure plus sea level training. J Appl Physiol 103:1523-1535

Roels B, Bentley DJ, Coste O, Mercier J, Millet GP (2007) Effects of intermittent hypoxic training on cycling performance in welltrained athletes. Eur J Appl Physiol 101:359-368

Rogers MA, Hagberg JM, Martin WH 3rd, Ehsani AA, Holloszy JO (1990) Decline in $\dot{V} \mathrm{O}_{2 \max }$ with aging in master athletes and sedentary men. J Appl Physiol 68:2195-2199

Roi GS, Giacometti M, von Duvillard SP (1999) Marathons in altitude. Med Sci Sports Exerc 31:723-728

Rossiter HB, Ward SA, Kowalchuk JM, Howe FA, Griffiths JR, Whipp BJ (2001) Effects of prior exercise on oxygen uptake and phosphocreatine kinetics during high-intensity knee-extension exercise in humans. J Physiol 537:291-303

Rowell LB (1974) Human cardiovascular adjustments to exercise and thermal stress. Physiol Rev 54:75-159

Rowell LB, Saltin B, Kiens B, Christensen NJ (1986) Is peak quadriceps blood flow in humans even higher during exercise with hypoxemia? Am J Physiol Heart Circ Physiol 251:H1038-H1044

Rusko HK (1992) Development of aerobic power in relation to age and training in cross-country skiers. Med Sci Sports Exerc 24:1040-1047

Russell G, Gore CJ, Ashenden MJ, Parisotto R, Hahn AG (2002) Effects of prolonged low doses of recombinant human erythropoietin during submaximal and maximal exercise. Eur J Appl Physiol 86:442-449

Saltin B (1977) The interplay between peripheral and central factors in the adaptive response to exercise and training. Ann N Y Acad Sci 301:224-231

Saltin B, Åstrand PO (1967) Maximal oxygen uptake in athletes. J Appl Physiol 23:353-358

Saltin B, Rowell LB (1980) Functional adaptations to physical activity and inactivity. Fed Proc 39:1506-1513

Saltin B, Strange S (1992) Maximal oxygen uptake: "old" and "new" arguments for a cardiovascular limitation. Med Sci Sports Exerc 24:30-37

Saltin B, Blomqvist CG, Mitchell RC, Johnson RL, Wildenthal K, Chapman CB (1968) Response to exercise after bed rest and after training. Circulation 38(Suppl 7):1-78

Saltin B, Nazar K, Costill DL, Stein E, Jansson E, Essén B, Gollnick PD (1976) The nature of the training response: peripheral and central adaptations to one-legged exercise. Acta Physiol Scand 96:289-305

Saltin B, Larsen H, Terrados N, Bangsbo J, Bak T, Kim CK, Svedenhag J, Rolf CJ (1995) Aerobic exercise capacity at sea level and at altitude in Kenyan boys, junior and senior runners compared with Scandinavian runners. Scand J Med Sci Sports 5:209-221

Sanada K, Kuchiki T, Miyachi M, McGrath K, Higuchi M, Ebashi H (2007) Effects of age on ventilatory threshold and peak oxygen uptake normalised for regional skeletal muscle mass in Japanese men and women aged 20-80 years. Eur J Appl Physiol 99:475-483

Sawka MN, Young AJ, Muza SR, Gonzalet RR, Pandolf KB (1987) Erythrocyte reinfusion and maximal aerobic power. J Am Med Ass 257:1496-1499
Schaffartzik W, Barton ED, Poole DC, Tsukimoto K, Hogan MC, Bebout DE, Wagner PD (1993) Effect of reduced hemoglobin concentration on leg oxygen uptake during maximal exercise in humans. J Appl Physiol 75:491-498

Scheuer J, Tipton CM (1977) Cardiovascular adaptations to physical training. Annu Rev Physiol 39:221-251

Secher N, Ruberg-Larsen H, Binkhorst RA, Bonde-Petersen F (1974) Maximal oxygen uptake during arm cranking and combined arm plus leg exercise. J Appl Physiol 36:515-518

Seene T, Kaasik P, Alev K (2011) Muscle protein turnover in endurance training: a review. Int J Sports Med 32:905-911

Shephard RJ (1969) A non-linear solution of the oxygen conductance equation: applications to performance at sea level and at an altitude of 7,350 ft. Int Z Angew Physiol 27:212-225

Sloth M, Sloth D, Overgaard K, Dalgas U (2013) Effects of sprint interval training on $\dot{V} \mathrm{O}_{2 \max }$ and aerobic exercise performance: a systematic review and meta-analysis. Scand J Med Sci Sports 23:341-352

Smorawinski J, Nazar K, Kaciuba-Uscilko H, Kaminska E, Cybulski G, Kodrzycka A, Bicz B, Greenleaf JE (2001) Effects of 3-day bed rest on physiological responses to graded exercise in athletes and sedentary men. J Appl Physiol 91:249-257

Sonetti DA, Wetter TJ, Pegelow DF, Dempsey JA (2001) Effects of respiratory muscle training versus placebo on endurance exercise performance. Respir Physiol Neurobiol 127:185-199

Spaak J, Montmerle S, Sundblad P, Linnarsson D (2005) Long-term bed rest-induced reductions in stroke volume during rest and exercise: cardiac dysfunction vs. volume depletion. J Appl Physiol 98:648-654

Spriet LL, Gledhill N, Froese AB, Wilkes DL (1986) Effect of graded erythrocythemia on cardiovascular and metabolic responses to exercise. J Appl Physiol 61:1942-1948

Steinacker JM, Liu Y, Böning D, Halder A, Maassen N, Thomas A, Stauch M (1996) Lung diffusion capacity, oxygen uptake, cardiac output and oxygen transport during exercise before and after an Himalayan expedition. Eur J Appl Physiol 74:187-193

Stray-Gundersen J, Levine BD (2008) Live high, train low at natural altitude. Scand J Med Sci Sports 18(Suppl 1):21-28

Stray-Gundersen J, Chapman RF, Levine BD (2001) "Living hightraining low" altitude training improves sea level performance in male and female elite runners. J Appl Physiol 91:1113-1120

Stremel RW, Convertino VA, Bernauer EM, Greenleaf JE (1976) Cardiorespiratory deconditioning with static and dynamic leg exercise during bed rest. J Appl Physiol 41:905-909

Strømme FB, Ingjer F, Meen HD (1977) Assessment of maximal aerobic power in specifically trained athletes. J Appl Physiol 42:833-837

Talbot LA, Metter EJ, Fleg JL (2000) Leisure-time physical activities and their relationship to cardiorespiratory fitness in healthy men and women 18-95 years old. Med Sci Sports Exerc 32:417-425

Tam E, Rossi H, Moia C, Berardelli C, Rosa G, Capelli C, Ferretti $G$ (2012) Energetics of running in top-level marathon runners from Kenya. Eur J Appl Physiol 112:3797-3806

Tanabe N, Todoran TM, Zenk GM, Bunton BR, Wagner WW Jr, Presson RG Jr (1998) Perfusion heterogeneity in the pulmonary acinus. J Appl Physiol 84:933-938

Taunton JE, Banister EW, Patrick TR, Ofordsag P, Duncan WR (1970) Physical work capacity in hyperbaric environments and conditions of hyperoxia. J Appl Physiol 28:421-427

Taylor CR (1987) Structural and functional limits to oxidative metabolism: insights from scaling. Annu Rev Physiol 49:135-146

Taylor CR, Weibel ER (1981) Design of the mammalian respiratory system. I. Problem and strategy. Respir Physiol 44:1-10

Taylor HL, Buskirk E, Henschel A (1955) Maximal oxygen uptake as an objective measure of cardiorespiratory performance. J Appl Physiol 8:73-80 
Tesch PA, Karlsson J (1985) Muscle fiber types and size in trained and untrained muscles of elite athletes. J Appl Physiol 59:1716-1720

Thomsen JJ, Rentsch RL, Robach P, Calbet JAL, Boushel R, Rasmussen P, Juel C, Lundby C (2007) Prolonged administration of recombinant human erythropoietin increases submaximal performance more than maximal aerobic power. Eur J Appl Physiol 101:481-486

Thomson JM, Stone JA, Ginsburg AD, Hamilton P (1982) Oxygen transport during exercise following blood reinfusion. J Appl Physiol 53:1213-1219

Trappe T, Trappe S, Lee G, Widrick J, Fitts R, Costill D (2006) Cardiorespiratory responses to physical work during and following 17 days of bed rest and spaceflight. J Appl Physiol 100:951-957

Turner DL, Hoppeler H, Noti C, Gurtner HP, Gerber H, Schena F, Kayser B, Ferretti G (1993) Limitations to $\mathrm{VO}_{2} \max$ in humans after blood retransfusion. Respir Physiol 92:329-341

Valli G, Cogo A, Passino C, Bonardi D, Morici G, Fasano V, Agnesi M, Bernardi L, Ferrazza AM, Ward SA, Palange P (2011) Exercise intolerance at high altitude $(5050 \mathrm{~m})$ : critical power and W'. Respir Physiol Neurobiol 177:333-341

Vanderburgh PM, Katch FI (1996) Ratio scaling of $\dot{V} \mathrm{O}_{2 \max }$ penalizes women with larger percent body fat, not lean body mass. Med Sci Sports Exerc 28:1204-1208

Vanhatalo A, Jones AM (2009) Influence of prior sprint exercise on the parameters of the all-out critical power test in men. Exp Physiol 94:255-263

Veicsteinas A, Samaja M, Gussoni M, Cerretelli P (1984) Blood $\mathrm{O}_{2}$ affinity and maximal $\mathrm{O}_{2}$ consumption in elite bicycle racers. $\mathrm{J}$ Appl Physiol 57:52-58

Ventura N, Hoppeler H, Seiler R, Binggeli A, Mullis P, Vogt M (2003) The response of trained athletes to six weeks of endurance training in hypoxia or normoxia. Int J Sports Med 24:166-172

Vogel JA, Gleser MA (1972) Effect of carbon monoxide on oxygen transport during exercise. J Appl Physiol 32(234-239):287

Vogel JA, Hansen JE, Harris CW (1967) Cardiovascular responses in man during exhaustive work at sea level and high altitude. $\mathrm{J}$ Appl Physiol 23:531-539

Vogiatzis I, Zakynthinos S, Boushel R, Athanasopoulos D, Guenette JA, Wagner H, Roussos C, Wagner PD (2008) The contribution of intrapulmonary shunts to the alveolar-to-arterial oxygen difference during exercise is very small. J Physiol 586:2381-2391

Wagner PD (1992) Gas exchange and peripheral diffusion limitation. Med Sci Sports Exerc 24:54-58

Wagner PD (1993) Algebraic analysis of the determinants of $\dot{V} \mathrm{O}_{2 \max }$. Respir Physiol 93:221-237

Wagner PD (1995) Muscle $\mathrm{O}_{2}$ transport and $\mathrm{O}_{2}$ dependent control of metabolism. Med Sci Sports Exerc 27:47-53

Wagner PD (1996a) Determinants of maximal oxygen transport and utilization. Annu Rev Physiol 58:21-50

Wagner PD (1996b) A theoretical analysis of factors determining $\dot{V} \mathrm{O}_{2 \max }$ at sea level and altitude. Respir Physiol 106:329-343

Wagner PD (2010) The physiological basis of reduced $\dot{V} \mathrm{O}_{2 \max }$ in operation everest II. High Alt Med Biol 11:209-215

Wagner PD (2012) Muscle intracellular oxygenation during exercise: optimization for oxygen transport, metabolism, and adaptive change. Eur J Appl Physiol 112:1-8
Wagner PD, Gillespie JR, Landgren GL, Fedde MR, Jones BW, DeBowes RM, Pieschl RL, Erickson HH (1989) Mechanism of exercise-induced hypoxemia in horses. J Appl Physiol 66:1227-1233

Wagner PD, Erickson BK, Seaman J, Kubo K, Hiraga A, Kai M, Yamaya Y (1996) Effects of altered $F I O_{2}$ on maximum $\dot{V} \mathrm{O}_{2}$ in the horse. Respir Physiol 105:123-134

Wehrlin JP, Hallén J (2006) Linear decrease in $\dot{V} \mathrm{O}_{2 \max }$ and performance with increasing altitude in endurance athletes. Eur $\mathrm{J}$ Appl Physiol 96:404-412

Weibel E (1984) The pathway for oxygen. Harvard University Press, Boston

Weibel ER (1987) Scaling of structural and functional variables in the respiratory system. Annu Rev Physiol 49:147-159

Welch HG, Pedersen PK (1981) Measurement of metabolic rate in hyperoxia. J Appl Physiol 51:725-731

West JB (1983) Climbing Mt. Everest without oxygen: an analysis of maximal exercise during extreme hypoxia. Respir Physiol 52:265-279

West JB, Boyer SJ, Graber DJ, Hackett PH, Maret KH, Milledge JS, Peters RM, Pizzo CJ, Samaja M, Sarnquist FH, Schoene RB, Winslow RM (1983) Maximal exercise at extreme altitude on Mount Everest. J Appl Physiol 55:688-698

Weston AR, Mbambo Z, Myburgh KH (2000) Running economy of African and Caucasians distance runners. Med Sci Sports Exerc 32:1130-1134

Whipp BJ (1994) The bioenergetic and gas exchange basis of exercise testing. Clin Chest Med 15:173-192

Wilhite DP, Mickleborough TD, Laymon AS, Chapman RF (2013) Increases in $\dot{V} \mathrm{O}_{2 \max }$ with "live high-train low" altitude training: role of ventilatory acclimatization. Eur J Appl Physiol 113:419-426

Wilmore JH, Stanforth PR, Gagnon J, Rice T, Mandel S, Leon AS, Rao DC, Skinner JS, Bouchard C (2001) Cardiac output and stroke volume changes with endurance training: the HERITAGE Family Study. Med Sci Sports Exerc 33:99-106

Woodson RD, Wills RE, Lenfant C (1978) Effect of acute and established anemia on $\mathrm{O}_{2}$ transport at rest, submaximal and maximal work. J Appl Physiol 44:36-43

Woorons X, Mollard P, Lamberto C, Letournel M, Richalet JP (2005) Effect of acute hypoxia on maximal exercise in trained and sedentary women. Med Sci Sports Exerc 37:147-154

Wyndham CH, Strydom NB, Morrison JF, Peter J, Williams CG, Bredell GAG, Joffe A (1963) Differences between ethnic groups in physical working capacity. J Appl Physiol 18:361-366

Zhang YY, Johnson MC 2nd, Chow N, Wasserman K (1991) Effect of exercise testing protocol on parameters of aerobic function. Med Sci Sports Exerc 23:625-630

Zoladz JA, Rademaker ACHJ, Sargeant AJ (1995) Non-linear relationship between $\mathrm{O}_{2}$ uptake and power output at high intensities of exercise in humans. J Physiol 488:211-217

Zumstein A, Mathieu O, Howald H, Hoppeler H (1983) Morphometric analysis of the capillary supply in skeletal muscles of trained and untrained subjects. Its limitations in muscle biopsies. Pflügers Arch 397:277-283 